CHAPITRE 3

\title{
MESSAGERS CHIMIQUES PARTICULIERS : SIGNAUX MITOGÉNIQUES, KININES, NO, PAF, ENDOTHÉLINE, ECDYSONE
}

\section{MÉCANISMES DE RÉCEPTION ET DE TRANSMISSION DES SIGNAUX MITOGÉNIQUES}

Le développement harmonieux d'un organisme pluricellulaire nécessite une coordination rigoureuse, dans l'espace et dans le temps, de deux processus caractéristiques de la vie, la prolifération et la différenciation cellulaires. Chez un organisme adulte, certaines cellules différenciées ne se divisent plus, comme les neurones ou les cellules musculaires striées ; d'autres, au contraire, continuent à se diviser et / ou à se différencier pendant toute la vie, comme les cellules souches des spermatozoïdes et des cellules du sang; d'autres enfin ne se divisent que pour réparer une lésion ou compenser la mort d'autres cellules.

C'est au début du XX' $\mathrm{XX}^{\mathrm{e}}$ siècle que l'établissement de communications intercellulaires fut impliqué dans la balance entre prolifération et différenciation cellulaires. Dès lors, l'enjeu fut de trouver des conditions adéquates pour la culture in vitro de tissus ou de cellules, puis de définir la nature des substances nécessaires à la croissance. Ces recherches ont conduit à l'identification, à côté des vitamines et autres nutriments, du premier facteur soluble défini comme un facteur de croissance cellulaire, le facteur de croissance épidermique (epidermal growth factor ou EGF) (Cohen, 1962). Cette découverte capitale a été à l'origine de la caractérisation de très nombreux facteurs de croissance. Ces facteurs représentent des molécules "signal", clés du réseau de communication entre les cellules d'un organisme.

Les facteurs de croissance sont des polypeptides ayant des caractéristiques particulières qui les distinguent des hormones: d'une part les facteurs de croissance sont synthétisés par des types cellulaires nombreux et variés, alors que les hormones sont synthétisées par des glandes spécialisées, d'autre part ils agissent localement sur leur lieu de synthèse, alors que les hormones sont excrétées et véhiculées par le sang jusqu'au tissu cible. 
De cette "endocrinologie locale" exercée par les facteurs de croissance, sont nés les concepts de paracrinie et d'autocrinie (voir chap. 2 , § 1). Contrairement à l'endocrinie qui suggère que la cellule sécrétant l'hormone soit distincte et à distance de la cellule cible, la paracrinie implique que la cellule sécrétant le facteur de croissance et les cellules cibles soient dans un environnement immédiat, et l'autocrinie implique que la cellule sécrétrice soit sa propre cible.

\subsection{RECONNAISSANCE ET TRANSMISSION DES SIGNAUX MITOGÉNIQUES}

Afin d'adapter son comportement à son environnement immédiat, la cellule doit être capable de reconnaître un stimulus externe spécifique et de transmettre l'information qu'il porte à l'intérieur de la cellule. Pour cela, les facteurs de croissance se lient à des récepteurs protéiques spécifiques situés au niveau de la membrane plasmique (Van der Geer et coll., 1994).

\subsubsection{Fixation du facteur de croissance et activation du récepteur}

Les récepteurs des facteurs de croissance sont des protéines constituées d'un domaine extracellulaire porteur d'un site de liaison spécifique pour le ligand, d'un domaine transmembranaire et d'un domaine cytoplasmique possédant une activité protéine tyrosine kinase intrinsèque chargée du relais avec la machinerie intracellulaire.

Enfin, une région carboxy-terminale de longueur variable et possédant plusieurs résidus tyrosine prolonge le domaine catalytique. Les récepteurs existent normalement sous la forme de monomères diffusibles dans le plan de la membrane plasmique (fig. 3.1).

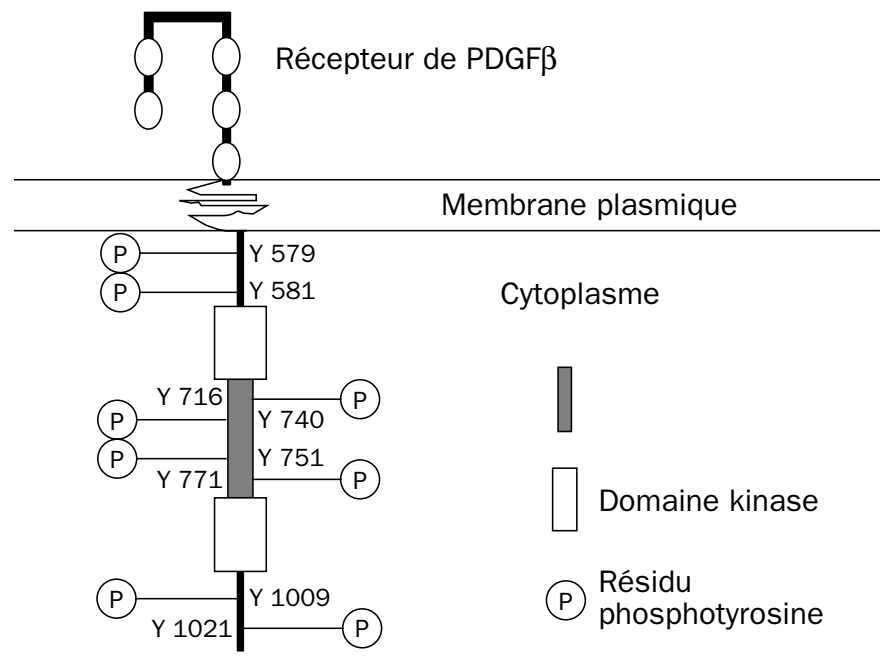

Figure 3.1 - Schéma représentant les résidus phosphotyrosine impliqués dans la liaison du récepteur humain de PDGF $\beta$ aux protéines de signalisation PDGF : platelet derived growth factor. 
La fixation du facteur de croissance à son récepteur provoque la dimérisation des domaines extracellulaires qui s'accompagne d'un changement de conformation du récepteur. Cette dimérisation induit une juxtaposition des domaines cytoplasmiques qui permet une transphosphorylation de plusieurs résidus tyrosine présents dans ce domaine. Bien que resté mystérieux pendant de nombreuses années, le rôle de cette transphosphorylation est double : elle permet non seulement l'activation maximale du récepteur dimérique, mais elle représente aussi un mécanisme essentiel pour le recrutement des substrats qui seront des cibles de l'activité tyrosine kinase du récepteur.

Les récepteurs pour les différents facteurs de croissance montrent des homologies de structure qui permettent de les regrouper en familles. La topologie moléculaire de quelques sous-familles de récepteurs est illustrée dans la figure 3.2.

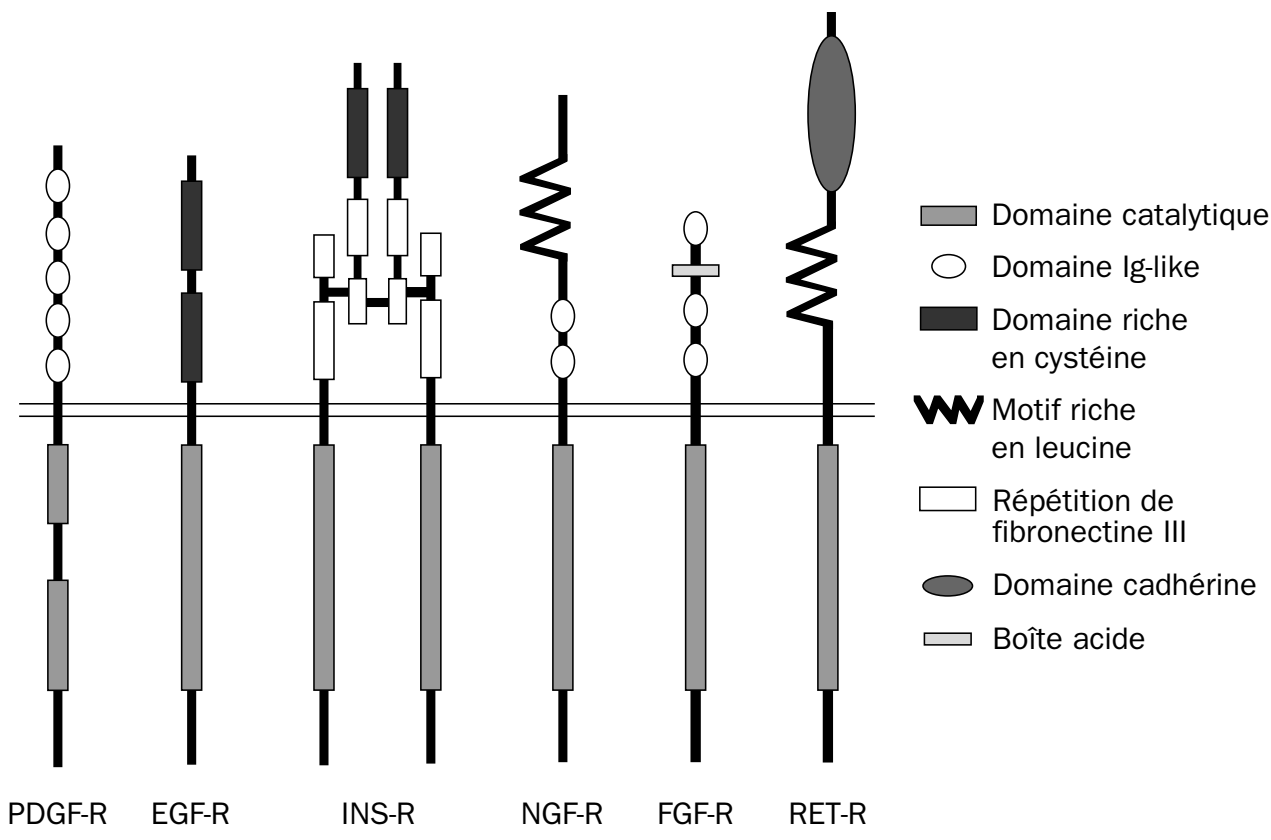

Figure 3.2 - Structure schématique

de quelques récepteurs protéine tyrosine kinases

EGF : epidermal growth factor ; FGF : fibroblast growth factors ; Ins : insuline ; NGF : necrosing growth factor ; PDGF : platelet derived growth factor ; $R$ : récepteur.

\subsubsection{Fonctions des récepteurs de facteurs de croissance}

Dès leur découverte, il est apparu clairement que les récepteurs pour les facteurs de croissance sont des récepteurs enzymes et qu'une de leurs fonctions majeures est de phosphoryler des protéines intracellulaires sur des résidus tyrosine. Une découverte plus récente a montré que, bien que les protéines cibles des récepteurs tyrosine kinases aient des activités biochimiques et des fonctions biologiques différentes, elles ont en commun des domaines qui fonctionnent de façon autonome (Pawson, 1995). 
Comme nous allons le voir, une des fonctions de ces modules est de permettre l'assemblage de complexes moléculaires dans le proche voisinage du récepteur activé.

\subsubsection{Rôle des domaines $\mathrm{SH} 2, \mathrm{SH}, \mathrm{PtB}$ et $\mathrm{PH}$ dans les réseaux de signalisation cellulaire}

La figure 3.3.a illustre quelques protéines porteuses de modules de signalisation. Les protéines qui possèdent des domaines $\mathrm{SH} 2$ (SRC-homology 2 domain) ou PtB (phosphotyrosin binding domain) se fixent avec une forte affinité $\left(K_{D}=1 \mathrm{nM}\right)$ sur les sites d'autophosphorylation des récepteurs activés. Les domaines $\mathrm{SH} 2$ représentent des modules protéiques d'une centaine d'acides aminés qui reconnaissent avec affinité et spécificité les phosphotyrosines et les 3 à $5 \mathrm{AA}$ adjacents. La liaison de protéines cibles via leur domaine $\mathrm{SH} 2$ ou PtB aux récepteurs activés peut avoir trois types d'effets :

1. cette liaison peut faciliter la phosphorylation de la protéine cible complexée au récepteur. Phosphorylation qui peut soit activer, soit inhiber la protéine cible ;

2. la liaison de la protéine au récepteur peut se traduire par une activation allostérique ;

3. enfin, cette liaison peut représenter un mécanisme de localisation de la protéine à proximité de son substrat, notamment au niveau de la surface interne de la membrane plasmique.

Un autre type de domaine permettant des interactions protéine-protéine est le domaine SH3 (SRC-homology 3 domain). Ce type de domaine est retrouvé dans de nombreuses protéines de signalisation mais également dans des composants du cytosquelette (fig. 3.3.a).

Les domaines PH (plectrin homology) sont des domaines globulaires de 120 AA dont les ligands sont moins bien définis. Toutefois, ils semblent capables de se lier à certains lipides du type phosphoinositides tels que l'inositol $(1,4,5)$ triphosphate (IP3) et le phosphatidylinositol $(4,5)$ biphosphate (PIP2).

Ainsi, lors de l'activation d'un récepteur par un facteur de croissance, les sites d'autophosphorylation permettent un assemblage moléculaire, au niveau de la membrane cellulaire, d'un réseau de protéines qui préexistent dans le cytoplasme sous des formes inactives. Différentes combinaisons des domaines SH2, SH3 et PH sont fréquemment retrouvées dans les mêmes protéines, domaines qui peuvent ainsi collaborer entre eux pour former des complexes de signalisation en aval des récepteurs actifs (fig. 3.3.b).

\subsubsection{Cas des récepteurs à plusieurs sous-unités}

Sur les lymphocytes, les récepteurs pour les antigènes utilisent des mécanismes d'activation et de signalisation identiques à ceux que nous venons de décrire. Toutefois, le site de liaison du ligand, l'activité tyrosine kinase et les protéines à SH2 résident sur des entités protéiques différentes. 


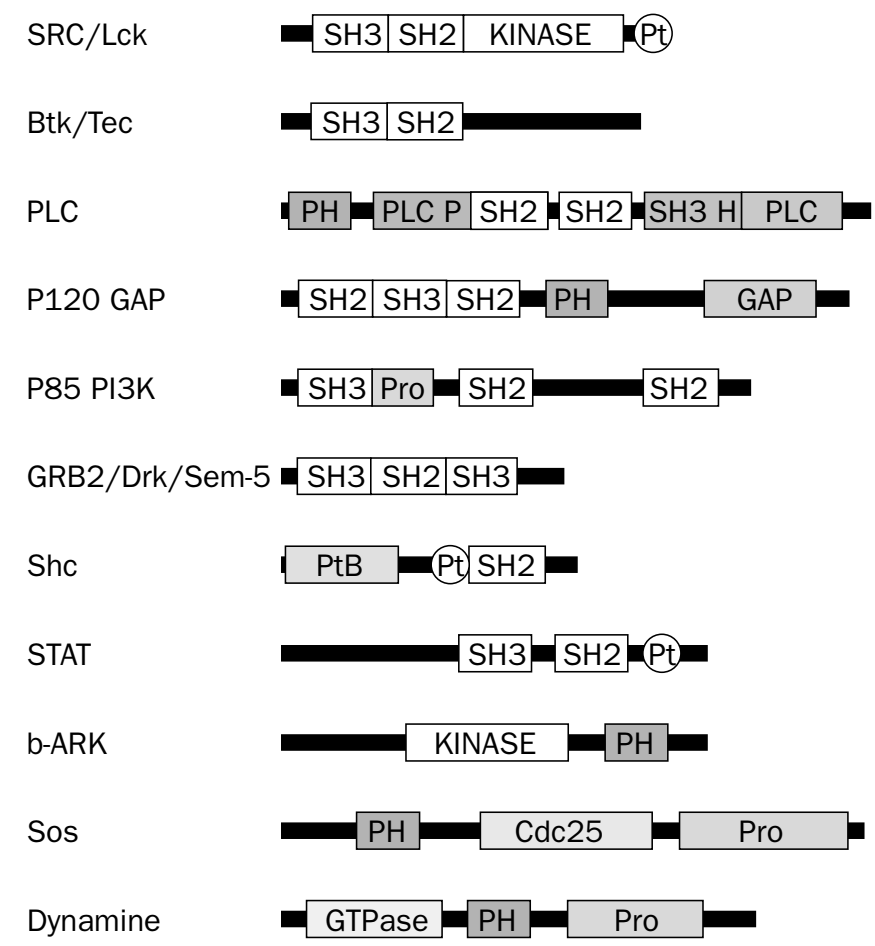

Figure 3.3.a - Quelques protéines contenant des domaines SH2, PtB, SH3 et PH Cdc25 : domaine d'échange du nucléotide guanine de Ras ; Pt : phosphotyrosine ; Pro : domaine riche en proline.

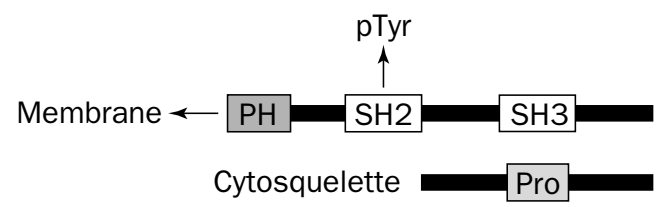

Figure 3.3.b - Les domaines SH2, SH3 et PH peuvent former un réseau de protéines.

De même, les récepteurs pour les cytokines et les interférons sont dépourvus d'activité enzymatique. Après fixation du ligand, ces récepteurs s'associent avec une tyrosine kinase cytoplasmique appelée Janus activated kinase (JAK), qui va phosphoryler le récepteur sur des résidus tyrosine et ainsi créer des sites d'interaction pour des protéines à domaine $\mathrm{SH} 2$.

\subsection{PROPAGATION DES SIGNAUX DE LA MEMBRANE PLASMIQUE AU NOYAU CELLULAIRE : UN RÉSEAU À MULTIPLES RELAIS}

L'un des plus fascinants développements récents de la biologie cellulaire a été la dissection étape par étape de plusieurs réseaux de signalisation qui permettent la transmission de signaux extracellulaires de la membrane au noyau cellulaire. 
Parmi les cinq réseaux de signalisation distincts identifiés à ce jour, ceux qui s'activent en réponse à des facteurs de croissance présentent un intérêt particulier car leur dérèglement conduit souvent à la transformation cellulaire.

Un réseau de signalisation mitogénique peut schématiquement se décomposer en une phase membranaire et une phase cytoplasmique. La première de ces phases se déroule à proximité du récepteur activé et conduit à la fixation d'une protéine adaptatrice GRB2 sur une des tyrosines phosphorylées du récepteur. Cette fixation entraîne en réalité la translocation sous la membrane plasmique du complexe GRB2-Sos à proximité de la protéine de liaison du GTP (Ras) qui, elle, est ancrée dans la membrane. Sos est une protéine d'échange de nucléotide dont la caractéristique essentielle est de convertir la forme inactive de Ras (Ras-GDP) en une forme active (Ras-GTP). L'activation de Ras est l'étape déterminante pour déclencher la phase cytoplasmique de la propagation du signal qui est constituée par l'activation séquentielle de plusieurs protéine kinases appelées collectivement la cascade de signalisation des MAP kinases (mitogen activated protein kinase ou MAPK).

Par souci de clarté, la description de cette voie sera ici simplifiée (le lecteur pourra se référer à l'excellente revue de R. Seger et E. Krebs, 1995). La propriété essentielle de cette voie de signalisation est qu'elle met en jeu plusieurs protéines qui vont dialoguer principalement par des interactions moléculaires faisant intervenir des domaines $\mathrm{SH} 2$, $\mathrm{SH} 3, \mathrm{PtB}$ et $\mathrm{PH}$, ainsi que des réactions de phosphorylation. Le premier étage de la cascade de protéine kinases est occupé par Raf, une sérine thréonine protéine kinase qui s'associe via son domaine régulateur avec Ras activé. Cette association permet de délocaliser Raf du cytoplasme vers la membrane où la kinase est activée par un mécanisme impliquant une phosphorylation. Parmi les candidats pour cette phosphorylation, citons la protéine kinase $\mathrm{C}$ et la protéine tyrosine kinase c-SRC. Raf, une fois activée, est une kinase qui phosphoryle et active sélectivement la protéine kinase MEK. MEK appartient à une famille de protéine kinases particulières, MAP kinaseskinases, capables de phosphoryler aussi bien des résidus thréonine que tyrosine (kinases à double spécificité). MEK activée va, à son tour, phosphoryler sur des résidus thréonine et tyrosine et ainsi activer ERK1 et ERK2 qui représentent deux isoformes des MAP kinases. A la différence de Raf et de MEK, les MAP kinases possèdent un large éventail de substrats protéiques qui sont localisés soit dans le cytoplasme, soit dans le noyau (fig. 3.4). Plusieurs des cibles des MAP kinases sont des facteurs de transcription nucléaires tels que Elk-1, c-Fos, c-Myc, p53 et l'ARN polymérase II, suggérant que ces kinases sont des régulateurs importants d'activités transcriptionnelles. Cette vision est renforcée par l'observation que les formes activées des MAP kinases subissent une translocation du cytoplasme vers le noyau. Il est donc clair que la cascade de signalisation des MAP kinases est nécessaire et suffisante pour propager et amplifier un signal extracellulaire dans le cytoplasme, et finalement le convertir en événements transcriptionnels au niveau du noyau. In fine, cette stimulation va permettre d'activer de nombreux gènes précoces qui jouent un rôle clé dans la prolifération cellulaire. 


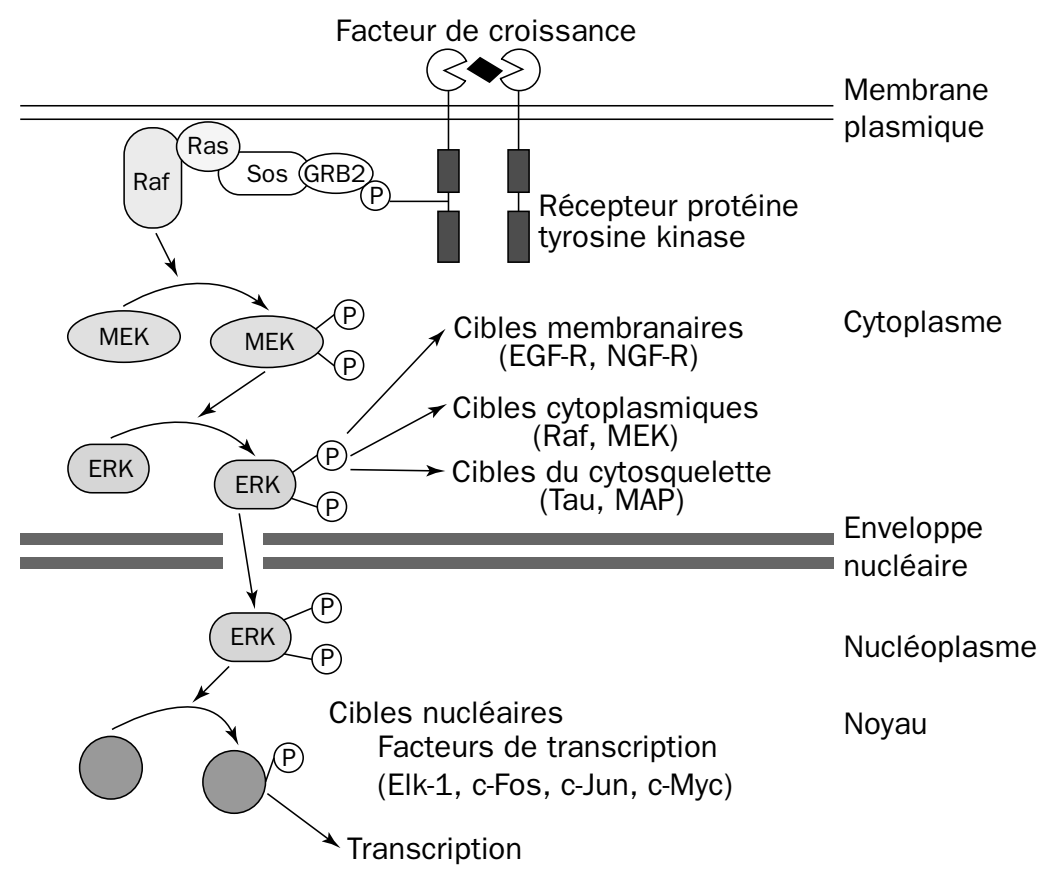

Figure 3.4 - La cascade de signalisation des MAP kinases

\subsubsection{Signalisation mitogénique et oncogenèse}

Un intérêt considérable s'est développé autour de ce type de voie de signalisation lorsqu'on a réalisé que, parmi la cinquantaine d'oncogènes connus actuellement, la plupart sont des acteurs de la cascade d'événements déclenchée par les facteurs de croissance lors de la division cellulaire normale. A titre d'exemple, des oncogènes peuvent représenter des protéines homologues de facteurs de croissance, des récepteurs pour des facteurs de croissance, des effecteurs des voies de signalisation ou des facteurs de transcription activés lors de la prolifération cellulaire.

\subsubsection{La voie des MAP kinases: une voie de signalisation mitogénique universelle?}

Il a été observé depuis longtemps que de nombreux agonistes tels que la thrombine, l'acide lysophosphatidique, dont les récepteurs à sept domaines transmembranaires sont couplés à des protéines $\mathrm{G}$ trimériques, sont des mitogènes puissants. La question d'un couplage des voies de signalisation utilisées par ce type de mitogènes avec la voie des MAP kinases devait être posée.

De fait, il a été clairement montré que l'activation cellulaire par la thrombine ou l'acide lysophosphatidique permet la dissociation de la protéine $\mathrm{G}$ trimérique et que les sous-unités $\beta$ et $\gamma$ du complexe peuvent stimuler Ras et par conséquent la voie des MAP kinases. Toutefois, les récepteurs couplés aux protéines $\mathrm{G}$ trimériques peuvent également stimuler la voie MAP kinase en l'absence d'activation détectable de Raf. 
Ceci suggère une voie de signalisation mettant en jeu une MEK kinase différente de Raf (fig. 3.5).

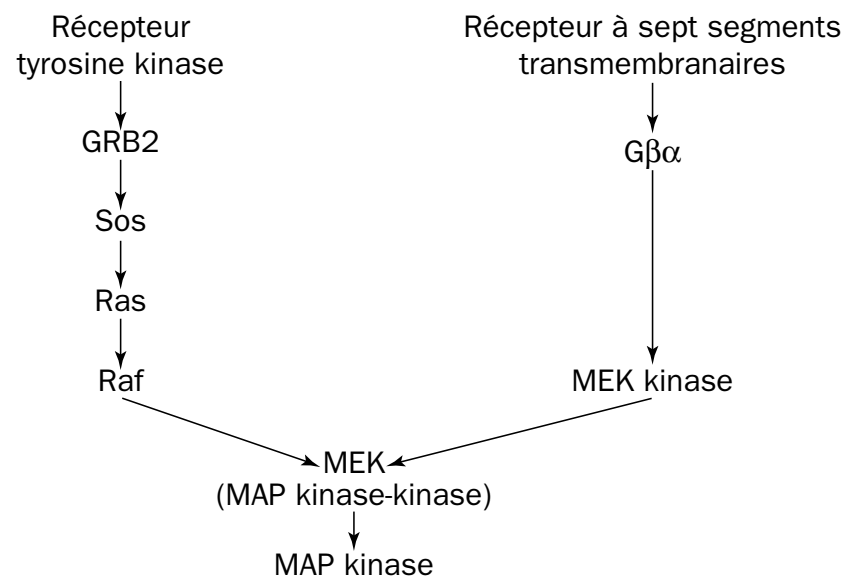

Figure 3.5 - Schéma représentant les deux voies conduisant à l'activation de MEK

Les interférons, ainsi que des cytokines telles que les interleukines, activent de nombreux gènes en réponse à la liaison de facteurs de transcription appelés protéines STAT. Ces protéines s'assemblent dans le cytoplasme sous la forme d'un complexe actif qui migre dans le noyau, où il se fixe à des séquences d'ADN spécifiques localisées dans les régions promotrices de plusieurs gènes.

Il a été observé que l'activation du complexe STAT nécessite une phosphorylation sur un résidu tyrosine. Cette phosphorylation est assurée par une protéine tyrosine kinase cytoplasmique appelée JAK qui se lie aux récepteurs membranaires des interférons ou des cytokines. Il s'agit là d'une voie de signalisation étonnamment simple. Cependant, il est à présent établi que les interférons et les cytokines stimulent également la voie des MAP kinases. Inversement, les facteurs de croissance sont capables d'activer le complexe STAT et de provoquer sa translocation nucléaire (fig. 3.6). Il existe donc une coordination entre les voies d'activation de STAT et des MAP kinases, ce qui se traduira par un accroissement de la transcription des gènes en réponse à différents signaux.

\subsubsection{Spécificité et plasticité des réseaux de signalisation cellulaire}

Les axes de signalisation décrits précédemment font partie de systèmes dynamiques dont les composants dialoguent principalement par des interactions moléculaires et des réactions de phosphorylation.

\section{Vers une circuiterie semi-solide}

Les interactions protéine-protéine mises en jeu font appel soit à des modules reconnaissant spécifiquement des résidus tyrosine phosphorylés dans un contexte particulier (cas des domaines $\mathrm{SH} 2$ et $\mathrm{PtB}$ ), soit à des séquences riches en protéine (domaine $\mathrm{SH} 3$ ) ou à des lipides (domaine $\mathrm{PH}$ ou plectrin homology). 


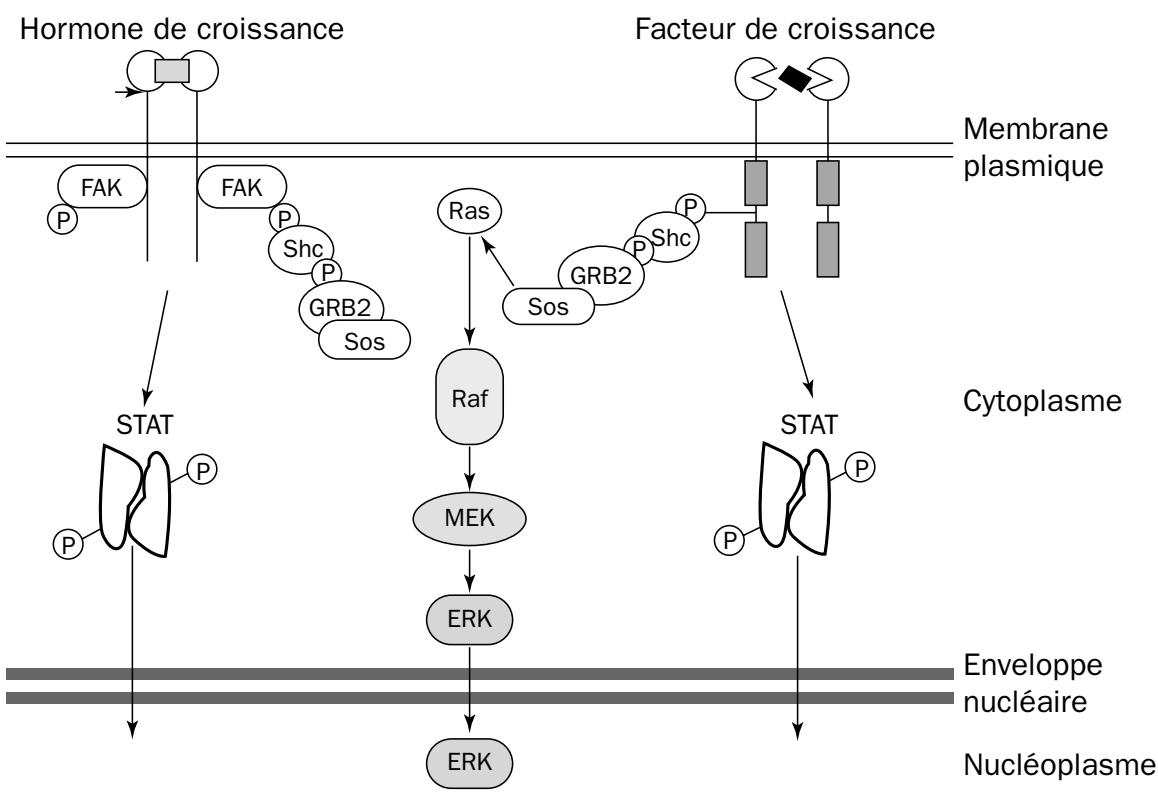

Figure 3.6 - Activation des STAT via JAK2 et de ERK / MAPK par les hormones et / ou les facteurs de croissance

Ces assemblages moléculaires, tel un "lego", permettent d'établir une circuiterie où la notion de proximité entre les protéines semble représenter un principe aussi important que la diffusion passive de messagers secondaires.

\section{Spécificité cellulaire}

Un des problèmes pour ce type de signalisation est de comprendre comment des centaines de récepteurs membranaires différents peuvent engendrer des réponses cellulaires spécifiques, alors qu'il existe un nombre relativement restreint de voies de signalisation de la membrane au noyau. Une solution à ce problème réside dans le fait que les différents réseaux de signalisation sont utilisés de façon combinatoire, chaque récepteur utilisant une combinaison spécifique "d'intégrateurs". Une autre possibilité implique que la réponse cellulaire à un récepteur donné soit dictée par la disponibilité, au niveau de la membrane dans le proche environnement du récepteur, des composants des différentes voies de signalisation. Dans cette hypothèse, il est nécessaire d'envisager l'existence entre la membrane et le noyau de microdomaines dans lesquels le trafic des protéines est restreint.

Comme il a déjà été mentionné, les composants trouvés aux mêmes "étages" des différentes voies de signalisation présentent à la fois des homologies structurelles mais aussi fonctionnelles très importantes. Malgré cela, on observe que chaque voie est spécifique d'un stimulus donné (ainsi l'activation de la voie spécifique du stress cellulaire ne fera jamais proliférer la cellule). 


\section{Combinaisons multiples pour réponses spécifiques}

Au-delà de cette signalisation linéaire de la membrane au noyau, il est clair que la plupart des circuits sont dotés d'une extraordinaire plasticité. Cette propriété leur permet de coopérer de façon spatio-temporelle (voie MAP kinase, voie JAK), et ainsi d'activer de multiples facteurs de transcription dont la présence simultanée est nécessaire à l'activité de nombreux promoteurs.

\section{Intensité des signaux : notion de seuil}

Des observations troublantes ont montré qu'en fonction du type cellulaire, les mêmes facteurs de croissance pouvaient induire soit une prolifération, soit une différenciation. Ainsi, le FGF (fibroblast growth factor) qui est un mitogène puissant pour de nombreux types cellulaires induit une différenciation d'une lignée cellulaire (cellules PC12). Un autre facteur de croissance EGF (epidermal growth factor) stimule la prolifération de ces mêmes cellules. Globalement, les deux facteurs de croissance empruntent les mêmes voies de signalisation. Cependant, une analyse détaillée a permis de montrer que la différence observée en réponse au FGF est corrélée à une activation persistante de Ras-GTP et des MAP kinases qui se délocalisent dans le noyau pendant plusieurs heures. Au contraire, la prolifération des cellules PC12 en réponse à l'EGF est corrélée à une activation transitoire de Ras-GTP et de la MAP kinase qui demeure localisée dans le cytoplasme.

Ainsi, la modulation de l'intensité et/ou de la durée d'activation provoquée par les deux facteurs de croissance semble représenter une composante importante de la réponse cellulaire finale.

Ce concept rejoint les effets de seuil bien connus en biologie du développement, où des variations graduelles de la concentration d'un ligand ou de celle d'un facteur nucléaire provoquent des différences fondamentales de l'expression génique.

\section{Vers une multitude de réseaux de signalisation}

Les techniques de biologie moléculaire ont récemment révélé l'existence de nouvelles protéines homologues des protéine kinases de la cascade des MAP kinases. Ces résultats ont permis l'élucidation de plusieurs voies parallèles de transduction de signaux qui, en activant de façon séquentielle des protéine kinases, fonctionnent de manière analogue à la voie classique mitogénique.

Ce type de modules de signalisation a été mis en place très tôt dans les processus d'évolution puisqu'ils existent dans la levure. Il est à noter que la voie des MAP kinases est activée par la plupart des facteurs de croissance et joue un rôle dans la prolifération cellulaire et l'activation des autres voies. Elle est observée en réponse à des facteurs qui "agressent" la cellule, tels les rayons ultraviolets, les chocs thermiques, les changements d'osmolarité ou l'exposition à des inhibiteurs de synthèse protéique. 


\subsection{RÉGULATION DU CYCLE CELLULAIRE}

La division des cellules au sein d'un organisme repose sur le déroulement correct des phases successives du cycle cellulaire (fig. 3.7). Sous l'effet des facteurs de croissance, une cellule sort de son état quiescient (phase G0) pour accomplir la phase G1 qui prépare la cellule à dupliquer son $\mathrm{ADN}$. La division de l'ADN se fait lors de la phase S suivie d'une courte phase G2 qui prépare la mitose proprement dite (phase M).

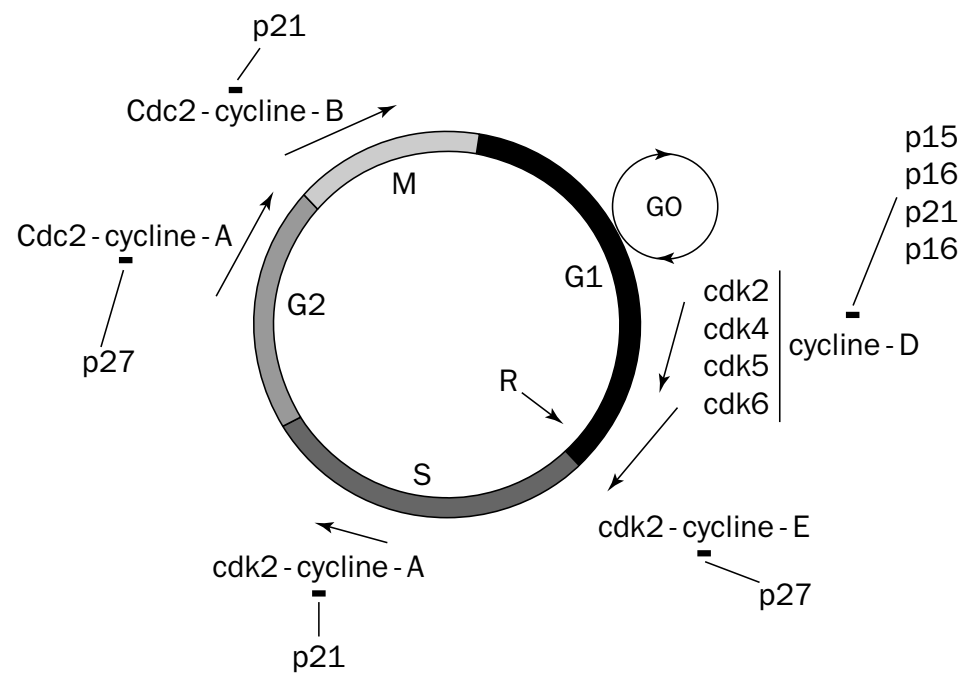

Figure 3.7 - Les acteurs principaux du cycle cellulaire

La division cellulaire correcte, qui repose donc sur le déroulement chronologique strict de ces différentes phases, est assurée par une famille de protéine kinases appelées kinases dépendantes des cyclines (cyclin dependent kinases ou cdk). Pour être actives, les cdk doivent s'associer à une sous-unité régulatrice nommée cycline, dont l'expression cyclique conditionne la chronologie de l'activation des cdk (Wolowiec et French, 1996). Les cyclines sont divisées en deux groupes : les cyclines mitotiques, regroupant les cyclines A et B, et les cyclines de la phase G1H. Les cyclines de la phase $\mathrm{G} 1$, cyclines $\mathrm{D}$ et $\mathrm{E}$, sont présentes dans les cellules dès la phase G1 et activent les cdk engagées dans les étapes précoces du cycle cellulaire.

\subsubsection{Régulation des cdk-cyclines par phosphorylation-déphosphorylation}

L'activité des cdk dépend non seulement de leur association avec les cyclines, mais également de modifications post-traductionnelles par réactions de phosphorylationdéphosphorylation. Deux sites de phosphorylation des cdk ont des effets inhibiteurs et doivent être impérativement déphosphorylés lors de l'activation de la kinase. Un site de phosphorylation des cdk est activateur, la phosphorylation de ce site est essentielle pour une activité maximale du complexe cdk-cycline. 
Les cdk activées participent à la régulation du cycle cellulaire par la phosphorylation de la protéine Rb qui contrôle l'activité de plusieurs facteurs de transcription.

\subsubsection{Protéines inhibitrices des cdk-cyclines}

L'horloge du cycle cellulaire fait également appel à une série de petites protéines (protéines 16, 21 et 27) capables de se lier aux complexes cdk-cyclines et d'inhiber leur activité kinase (voir fig. 3.7). Ces protéines inhibitrices participent à la régulation du cycle cellulaire en retardant l'activation des divers complexes cdk-cyclines spécifiques des phases $\mathrm{G} 1$ et $\mathrm{S}$ jusqu'au temps adéquat, assurant ainsi leur mise en œuvre ordonnée. La perte ou le disfonctionnement de ces inhibiteurs pourrait entraîner une prolifération cellulaire incontrôlée telle qu'on l'observe dans les cellules cancéreuses.

\section{LES KININES}

C'est au début du siècle qu'il est fait référence, pour la première fois, à une substance (l'urohypotensine) extraite de l'urine humaine, substance qui, injectée chez le chien, produit une forte hypotension. Toutefois, ce n'est qu'à la suite des travaux du groupe de Werle (Frey et coll., 1932-1950) que ce facteur hypotensif que l'on pensait alors produit par le pancréas (killikreas en grec) est appelé kallicréine.

L'action des kallicréines, protéases à sérine (plasmatique ou cellulaire) sur leur substrat - les kininogènes (de haut et de bas poids moléculaire) -, conduit à la production de peptides bioactifs : les kinines. Le plus connu de ces peptides est un nonapeptide vaso-actif, la bradykinine (fig. 3.8). Les kinines sont rapidement métabolisées par des peptidases - les kininases - présentes dans la circulation et les tissus. Une de ces kininases (KII-ACE) n'est autre que l'enzyme de conversion de l'angiotensine (ACE) (voir chap. 6, § 2.4.3).

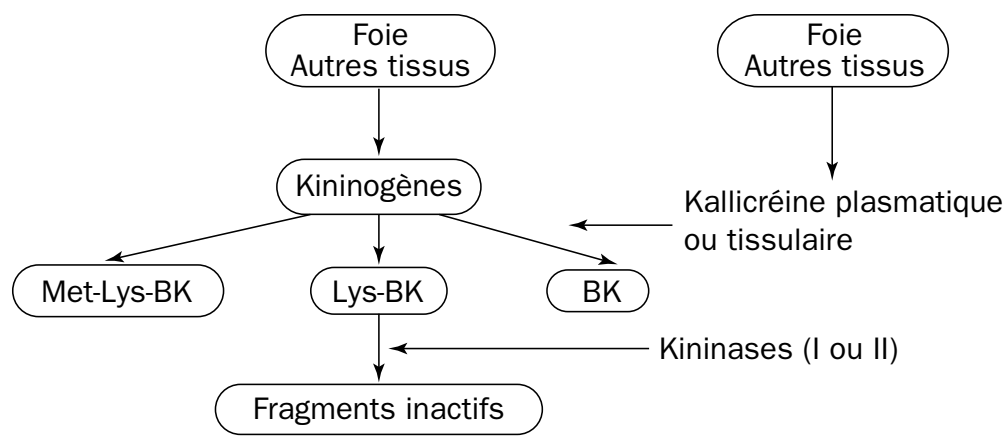

Figure 3.8 - Représentation schématique du métabolisme des kininogènes

BK : bradykinine ; Lys-BK : lysyl-bradykinine (kallidine); Met-Lys-BK : méthyl-lysyl-bradykinine. 


\subsection{LES KALLICRÉINES}

Les kallicréines appartiennent à la famille des protéases à sérine. Ces protéases présentent des structures voisines et ont tendance à cliver leurs substrats au niveau des résidus arginine. Les kallicréines plasmatique ou cellulaire induisent la production de kinines à partir des kininogènes.

\subsubsection{La kallicréine plasmatique}

\section{Structure chimique et métabolisme}

La kallicréine plasmatique $(60 \mathrm{kDa})$ est produite au niveau des hépatocytes sous la forme d'un hétérodimère inactif : la pro-kallicréine. La pro-kallicréine circulante est complexée au kininogène de haut poids moléculaire. Elle est clivée en kallicréine plasmatique active par le facteur XII activé. Le facteur XII, qui par ailleurs est impliqué dans la régulation des processus conduisant à la coagulation, est rétroactivé positivement par la kallicréine elle-même (fig. 3.9).

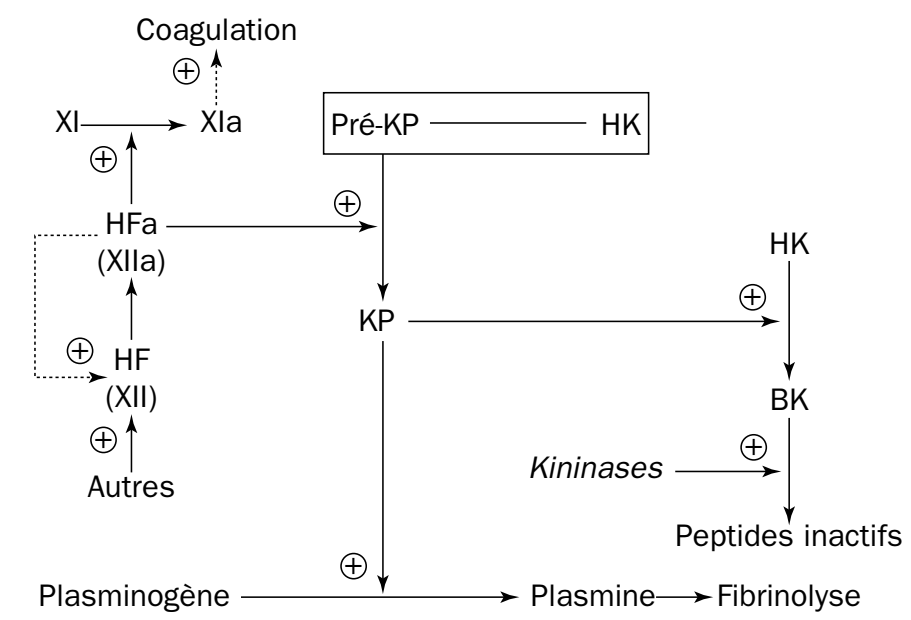

Figure 3.9 - Représentation schématique de l'activation de la pré-kallicréine (d'après Bhoola et coll., 1992)

BK : bradykinine ; HF : Hageman factor ou facteur XII ; HK : kininogène de haut poids moléculaire ; Pré-KP : pré-kallicréine plasmatique ; KP : kallicréine plasmatique.

\section{Propriétés - Rôles physiologiques}

La kallicréine plasmatique entraîne, à partir du kininogène de haut poids moléculaire, la production d'un nonapeptide, la bradykinine.

\subsubsection{Les kallicréines tissulaires}

\section{Structure chimique et métabolisme}

Les kallicréines tissulaires (24-45 kDa) ont été mises en évidence au niveau du pancréas, des glandes salivaires, du rein, du cerveau. Elles sont codées par plusieurs 
gènes portés, chez l'homme, par le chromosome 19. Dans la majorité des espèces, les kallicréines tissulaires induisent la production d'un décapeptide : la lysyl-bradykinine ou kallidine. En revanche, chez les rongeurs, l'action de la kallicréine conduit à la production de bradykinine (BK).

Ces kallicréines sont des glycoprotéines produites à partir de l'action de la trypsine et de la chémotrypsine sur un précurseur, la pro-kallicréine. Les kallicréines sont stockées dans des granules intracellulaires dont la localisation varie en fonction des types cellulaires et du rôle joué par l'enzyme. Il faut noter que les neutrophiles qui possèdent une kallicréine tissulaire présentent, en outre, sur leur membrane externe, des sites de fixation pour les kininogènes de haut et de bas poids moléculaires, ainsi que pour la kallicréine plasmatique.

\section{Propriétés - Rôles physiologiques}

La localisation tissulaire des kallicréines conduit à penser qu'elles exercent, à côté de leur propriété de kininogénase, des actions spécifiques. Ainsi, il a été montré que les kallicréines sont impliquées dans le "processing" (apprêtage) de facteurs de croissance, de certaines hormones (pro-insuline, pro-rénine), du peptide intestinal vasoactif (VIP), ainsi que dans le clivage de grosses molécules (angiotensinogène, procollagène). Les kallicréines tissulaires participent, par la synthèse de kinines actives, à la régulation des débits sanguins locaux. De plus, il est maintenant admis que les kallicréines tissulaires peuvent se retrouver dans la circulation où elles joueraient un rôle similaire à celui de la kallicréine plasmatique. La source principale de ces kallicréines tissulaires circulantes semble être le rein. Toutefois, leur libération en fin de cycle cellulaire, lors de la lyse des neutrophiles, pourrait être une source nonnégligeable d'enzyme. Enfin, il a été montré que les cellules musculaires lisses vasculaires possèdent les éléments de l'ensemble de ce système (kallicréine, kininogènes, kinines, kininases), ce qui laisse supposer, via une action autocrine, un rôle possible dans la régulation du tonus vasculaire.

\subsection{LES KININOĠ̀NES}

\subsubsection{Structure chimique et métabolisme}

Si la source majeure des kininogènes est le foie, la présence de kininogènes et celle des ARNm correspondants ont été montrées au niveau du rein, des cellules endothéliales humaines et des plaquettes. Les kininogènes sont synthétisées par les hépatocytes sous la forme de glycoprotéines. Outre un kininogène spécifique (le T-kininogène), présent uniquement chez le rat, il existe deux types de kininogènes : l'un de haut poids moléculaire (110000), l'autre de bas poids moléculaire (68 000). De plus, ces kininogènes diffèrent par leur structure spatiale (le kininogène de haut poids moléculaire est constitué de six domaines ; le kininogène de bas poids moléculaire est, lui, constitué de quatre domaines), ainsi que par leur sensibilité aux kallicréines (voir plus haut) ; enfin, le T-kininogène est clivé non par une kallicréine, 
mais par la trypsine. Comme l'indique la figure 3.10, les deux kininogènes sont constitués de trois chaînes, une chaîne de haut poids moléculaire et une de bas poids moléculaire séparées par la bradykinine.

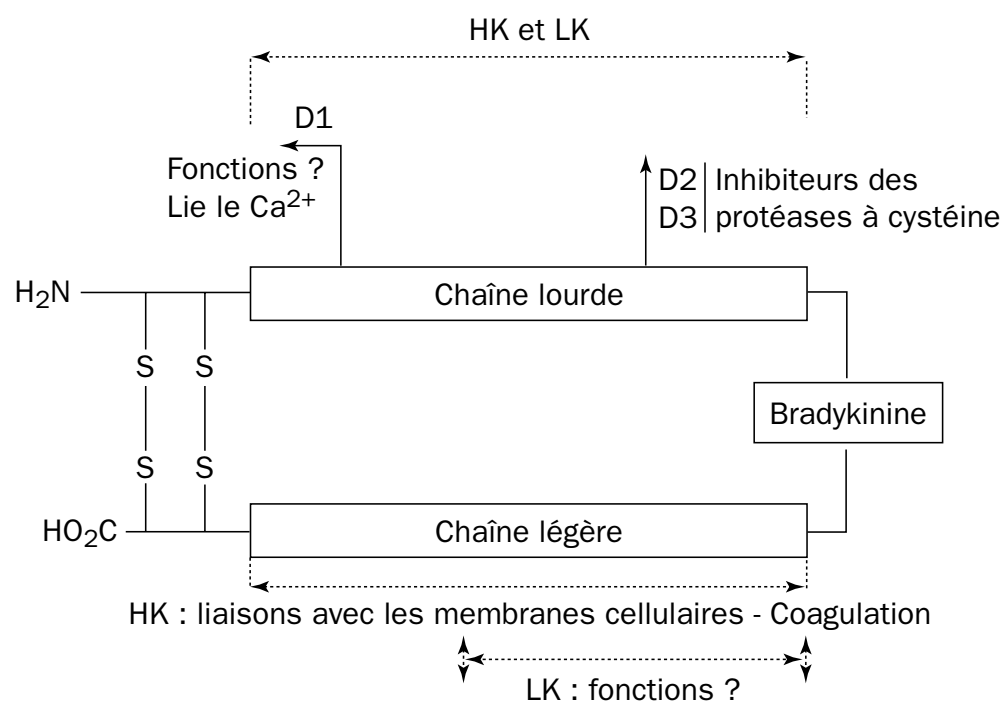

Figure 3.10 - Représentation schématique des molécules de kininogènes (d'après Carbini et coll., 1993)

La chaîne lourde constituée de trois domaines (D1, D2, D3) est identique pour les kininogènes de haut poids moléculaire (HK) et de bas poids moléculaire (LK). En revanche, la différence entre ces deux kininogènes porte sur la structure de la chaîne légère, constituée de deux domaines dans le cas du HK et d'un seul dans celui du LK. Plusieurs ponts disulfures lient les chaînes entre elles.

\subsubsection{Rôles physiologiques}

Les kininogènes, en tant que précurseurs des kinines, jouent un rôle fondamental dans la régulation du tonus vasculaire. Cependant, ils exercent d'autres rôles physiologiques importants. Ainsi, en association avec les facteurs XII et XI et la prékallicréine plasmatique, la molécule de kininogène de haut poids moléculaire est un co-facteur de la coagulation (voir fig. 3.9).

Différents types de récepteurs spécifiques pour les molécules entières ou clivées des différents kininogènes ont été mis en évidence sur différents types cellulaires (cellules endothéliales, plaquettes...). L'existence de plusieurs types de récepteurs, ainsi que le rôle des différents domaines des deux molécules de kininogènes dans l'internalisation (en particulier au niveau des cellules endothéliales) des molécules entières ou fragmentées de kininogènes (et des kinines) sont discutés.

Comme le montre la figure 3.10, la structure de la chaîne lourde des deux types de kininogène est identique. Cette chaîne est constituée de trois domaines. Les domaines D2 et D3 sont des inhibiteurs des protéases à cystéine. Bien qu'il ait été montré que le 
domaine D1 peut lier le calcium, son rôle est inconnu. Les kininogènes diffèrent par leur chaîne légère : le rôle de la chaîne légère de kininogène de faible poids moléculaire (LK) est inconnu. En revanche, la chaîne légère du kininogène de haut poids moléculaire (HK) est impliquée dans la fixation membranaire du HK, ainsi que dans le rôle joué par le HK dans les processus conduisant à la coagulation.

\subsection{LES KININASES}

Les kinines sont rapidement inactivées (quelques dizaines de secondes) par des kinases appelées kininases. Deux familles de kininases (KI et KII) clivent la bradykinine. Les kininases KI (KI-CPN et KI-CPM) clivent la bradykinine au niveau de l'arginine terminale pour donner un résidu actif sur les récepteurs BK1. Les kininases KII (KII-ACE et KII-NEP) sont des peptidases qui clivent la bradykinine au niveau du $8^{e}$ AA de la terminaison carboxylique. A côté de ces deux types de kininases, on connait deux kininases tissulaires (A et B), une aminopeptidase clivant la méthyl-lysyl-bradykinine au niveau du résidu méthionine, une autre clivant la lysbradykinine au niveau du résidu lysine et une troisième clivant le résidu arginine initial de la bradykinine (tab. 3.1).

\subsection{LES KININES}

\subsubsection{Structure chimique et métabolisme}

Les kinines sont des peptides actifs produits par l'action des kinigénases sur les kininogènes. Il est généralement admis que la kallidine est produite par l'action de la kallicréine tissulaire sur le kininogène de faible poids moléculaire, alors que la bradykinine est produite par l'action de la kallicréine plasmatique sur le kininogène de haut poids moléculaire. Différentes aminopeptidases peuvent convertir la kallidine ou Lys-BK en BK. Un analogue endogène de la bradykinine, la Met-Lys-BK, est formé par l'action de la pepsine et de l'uropepsine sur les kininogènes. L'existence d'autres kinines présentes chez les Mammifères a été rapportée (T-kinine, Met-Tkinine). De plus, il a été montré que les kinines des Mammifères possèdent beaucoup d'homologies avec les kinines présentes dans les venins d'insectes et de reptiles, la peau des amphibiens, ainsi qu'avec les kinines des oiseaux.

Le taux de bradykinine circulante est estimé entre 3,8 et $50 \mu \mathrm{g} / \mathrm{ml}$ (dispersion des mesures liée aux techniques de dosage). L'action très efficace des kininases fait que les actions biologiques de la bradykinine circulante et de la kallidine sont de courte durée (demi-vie de 15 à $30 \mathrm{~s}$ ).

Les deux kinines des Mammifères (kallidine et bradykinine) sont impliquées dans les mécanismes de l'inflammation, la régulation de la pression artérielle et des débits sanguins locaux, le métabolisme du glucose et des électrolytes, ainsi que dans la différenciation et la prolifération cellulaires. 


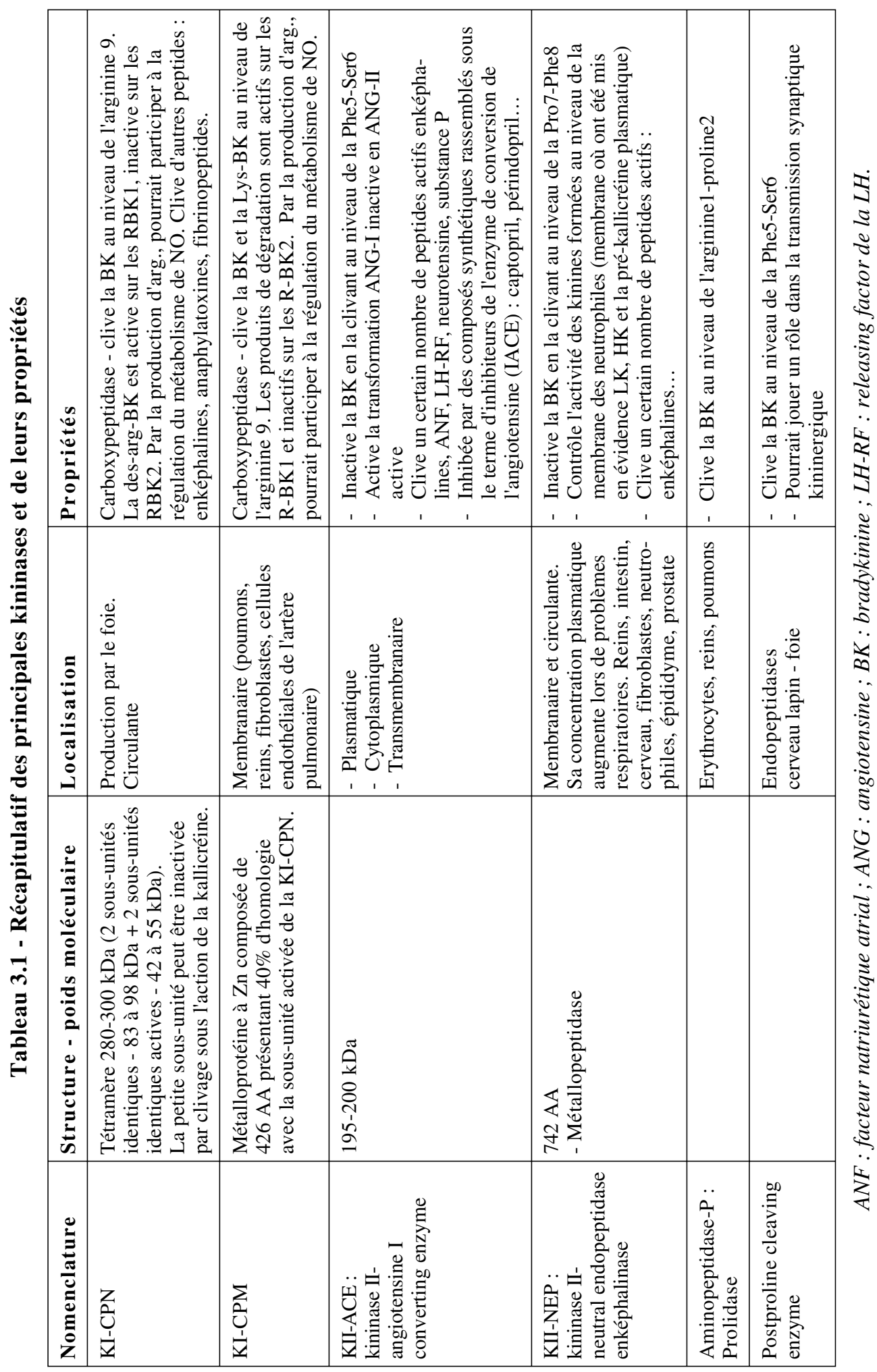


Ces actions résultent soit d'un effet direct mettant en jeu des récepteurs membranaires spécifiques, soit de la libération d'autres messagers (platelet activating factor [PAF], métabolites de l'acide arachidonique, neuromédiateurs...).

\subsubsection{Les récepteurs des kinines}

A la suite de nombreux travaux utilisant différents types de préparation (aorte, veine mésentérique, jugulaire, duodénum), ainsi que le clivage de la molécule de BK et/ou la substitution de divers acides aminés, il a été distingué pour les kinines deux types de récepteurs à sept domaines transmembranaires : les récepteurs BK1 (R-BK1) et BK2 (R-BK2).

Les récepteurs BK1 semblent, dans les conditions non-pathologiques, être peu présents, voire absents. Cependant, leur densité augmente (en particulier sur les fibroblastes et les cellules musculaires lisses) dans les situations d'agression telles que celles conduisant à la réponse inflammatoire.

C'est par l'activation des récepteurs BK2 que les effets intracellulaires de la bradykinine et de la kallidine s'expriment. Il a été suggéré l'existence, en particulier au niveau de l'épithélium pulmonaire, de récepteurs BK3, de même que celle de soustypes de récepteurs K2 (R-K2-A ; R-K2-B) au niveau du cerveau, des fibroblastes et de l'épithélium intestinal.

Les récepteurs BK1 et BK2 sont couplés via des protéines G (dont la nature n'a pas été, dans tous les cas, clairement explicitée) à des phospholipases $\mathrm{A} 2$ et $\mathrm{C}$ (fig. 3.11). La grande variété de seconds messagers qui peuvent être ainsi synthétisés, ainsi que l'action autocrine de certains d'entre eux (en particulier des dérivés de l'acide arachidonique), alliées à l'augmentation de calcium libre intracellulaire, peuvent conduire à des effets variables selon le type cellulaire et la densité relative des couplages avec l'une ou l'autre des phospholipases (fig. 3.11 et tab. 3.2).

Dans certains types cellulaires (comme les cellules endothéliales vasculaires) possédant une NO synthase constitutive (activable par le calcium), la stimulation de récepteurs couplés à une PLC et la production d'arginine via le métabolisme des kinines (voir plus haut) peuvent conduire à la stimulation de la synthèse de NO (fig. 3.11).

C'est principalement par son action sur le métabolisme calcique des cellules endothéliales (voir plus loin), que s'exerce l'effet vaso-dilatateur de la BK. Celle-ci pourrait stimuler la libération du facteur hyperpolarisant dérivé de l'endothélium (EDHF). Ce facteur, de nature inconnue (probablement du potassium), provoque la fermeture des canaux calciques sensibles au voltage, induisant ainsi la relaxation des cellules musculaires lisses. 
Tableau 3.2 - Récepteurs membranaires des kinines, cellules impliquées, rôles et voies de traduction (d'après Caroline Lagneux, 1999, com. pers.)

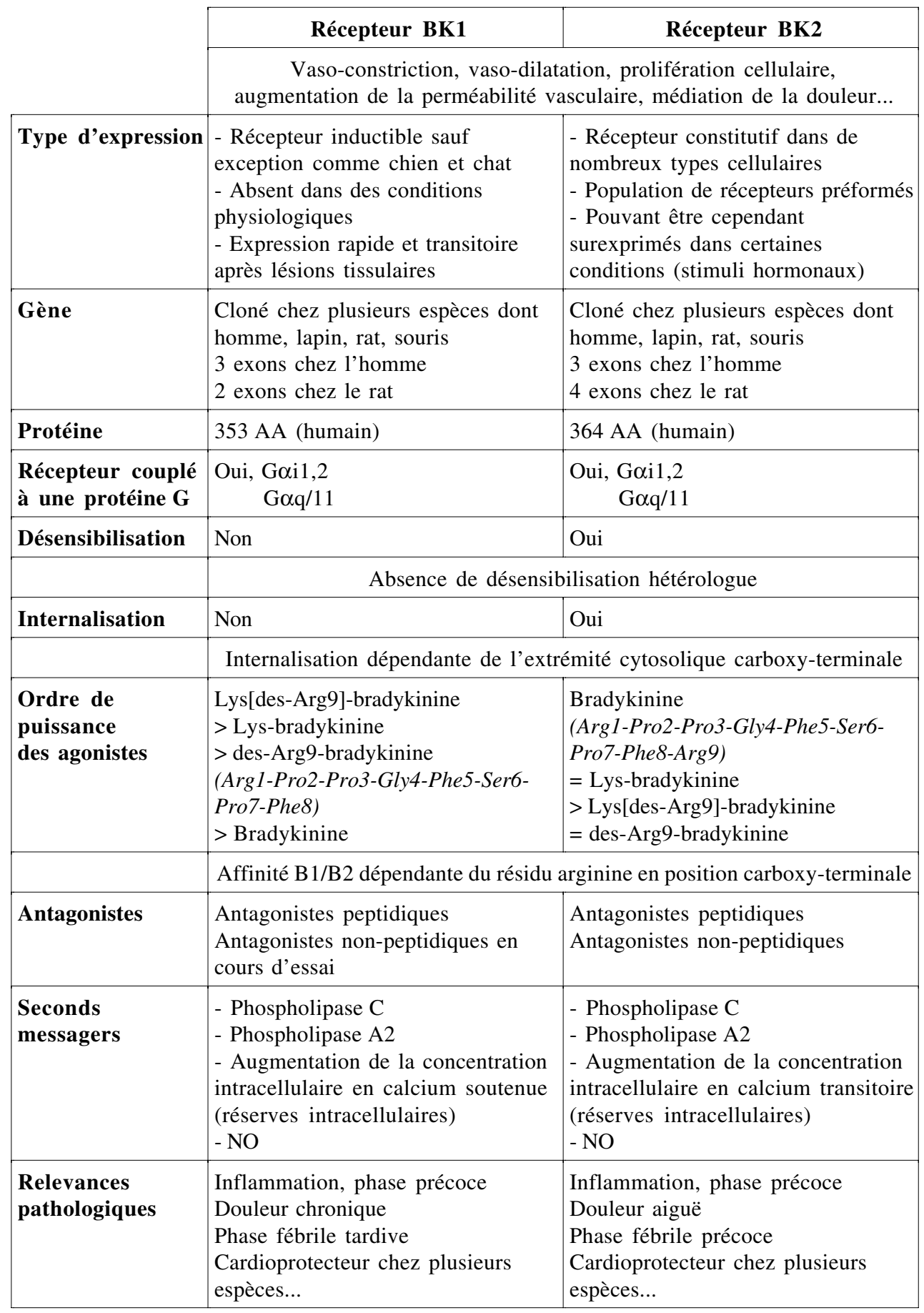




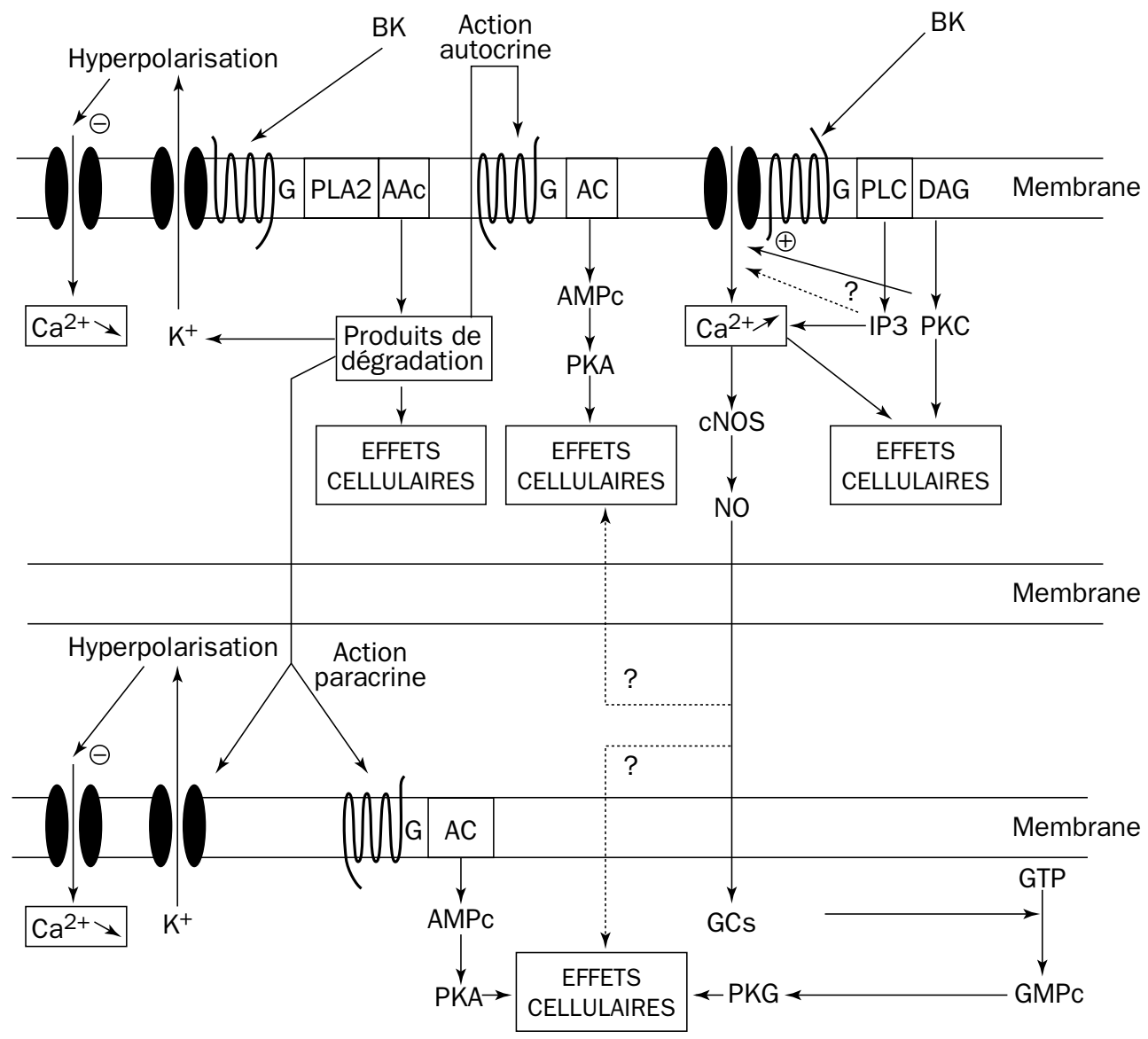

Figure 3.11 - Représentation schématique des effets de l'activation des récepteurs BK2 $A A c$ : acide arachidonique; $A C$ : adénylate cyclase ; $A M P c$ : adénosine monophosphate cyclique; DAG : diacylglycérol; GCs : guanylate cyclase soluble; GMPc: guanosine monophosphate cyclique ; IP3 : inositol $(1,4,5)$ triphosphate ; PKA : protéine kinase $A$; PKC : protéine kinase $C$; PLA2 : phospholipase A2; PLC: phospholipase $C$; VOC: voltage operated channel.

Le type de couplage (type de protéines G) du récepteur BK2 avec ses effecteurs cellulaires (PLC-PLA) varie suivant le type cellulaire. II en résulte une proportion différente de la nature et/ou de la quantité des seconds messagers synthétisés et, par là, des effets cellulaires différents. En outre, suivant la voie de dégradation mise en jeu, les dérivés de l'acide arachidonique peuvent être, eux aussi, de nature et de quantité variables, et vont conduire à des effets cellulaires divers (voir chap. 2, § 2.2.7). De plus, ces dérivés peuvent agir de façon autocrine et/ou paracrine. Dans le cas d'une action autocrine, suivant le dérivé synthétisé, le récepteur mis en jeu peut moduler l'activité cellulaire via la stimulation (ou l'inhibition) de la synthèse de seconds messagers tels que I'AMPC. Dans le cas de cellule possédant une NO synthase constitutive, cNOS (voir $\S$ 3.2.1), l'augmentation de la teneur en calcium libre intracellulaire peut conduire à la stimulation de la synthèse de NO. Cette production de NO peut conduire à son tour (action paracrine) à la synthèse de GMPc via l'activation d'une GCs (guanylate cyclase soluble), GMPc qui, dans le cas des cellules musculaires vasculaires, provoquera une relaxation (voir chap. $2, \S 2.2 .2$ ). 


\subsubsection{Rôles physiologiques}

\section{Actions sur le système cardio-vasculaire}

La bradykinine est connue essentiellement par son action sur le système cardio-vasculaire. Elle agit au niveau des vaisseaux et du myocarde.

\section{Action sur les vaisseaux}

La bradykinine exerce un effet vaso-dilatateur puissant qui, in vivo, provoque une forte hypotension. Cet effet résulte de la libération par l'endothélium du NO, du facteur hyperpolarisant (EDHF), de diverses prostaglandines et du PAF. Cet effet vaso-dilatateur s'observe in vivo et in vitro sur les coronaires, d'où l'intérêt des inhibiteurs de l'enzyme de conversion de l'angiotensine (IACE) qui limitent la dégradation de la bradykinine. D'une façon analogue à ce qui est rapporté pour d'autres messagers dont l'action vaso-dilatatrice dépend de l'endothélium, la bradykinine exerce, en l'absence d'endothélium, un effet constricteur direct sur les cellules musculaires lisses. Cet effet résulte principalement de la libération, sous l'action de l'IP3, du calcium du réticulum. En outre, l'activation de la PKC, l'éventuelle synthèse d'AMPc résultant de la production de prostaglandines et l'activation de la PKA qui en résulte, conduisent à des modifications profondes de la physiologie des cellulaires musculaires vasculaires. Ces modifications, comme le montre la figure 3.12 peuvent entraîner un remodelage vasculaire pathologique. Il faut noter que les cellules endothéliales, ainsi que les cellules musculaires lisses vasculaires, possèdent une partie et/ou la totalité de l'équipement enzymatique nécessaire au métabolisme des kinines et des kininogènes. La part prise par cet équipement enzymatique dans le métabolisme de la BK (de même que dans celui de l'angiotensine) est mal connue. De ce fait, il semble admis que les effets hypotenseurs des inhibiteurs de l'enzyme de conversion de l'angiotensine (ACE), qui inhibent la transformation de BK active en BK inactive, passent, en majorité, par l'inhibition de l'ACE portée par l'endothélium, et non par celle de l'ACE plasmatique.

\section{Action sur le cour}

Les cellules myocardiques possèdent l'équipement enzymatique nécessaire à la production de kinines. Toutefois, nous ne disposons pas de données précises quant à la part respective de ces cellules, des endothéliums vasculaire et cardiaque et des cellules neutrophiles (en particulier lors d'ischémie ou d'infarctus du myocarde) dans la production locale de bradykinine. L'action directe de la bradykinine sur les myocytes cardiaques en culture ou isolés conduit à une forte augmentation de la teneur en calcium libre intracellulaire. Sur le cœur isolé et perfusé, les kinines stimulent le rythme et la force des contractions, ainsi que le débit cardiaque. Les inhibiteurs de l'ACE ou l'infusion de bradykinine exercent un effet protecteur contre les altérations cardiaques induites par l'ischémie. En particulier, le statut énergétique est préservé et, lors de la reperfusion post-ischémique, le débit cardiaque est augmenté alors que la fréquence d'apparition des arythmies est diminuée. 


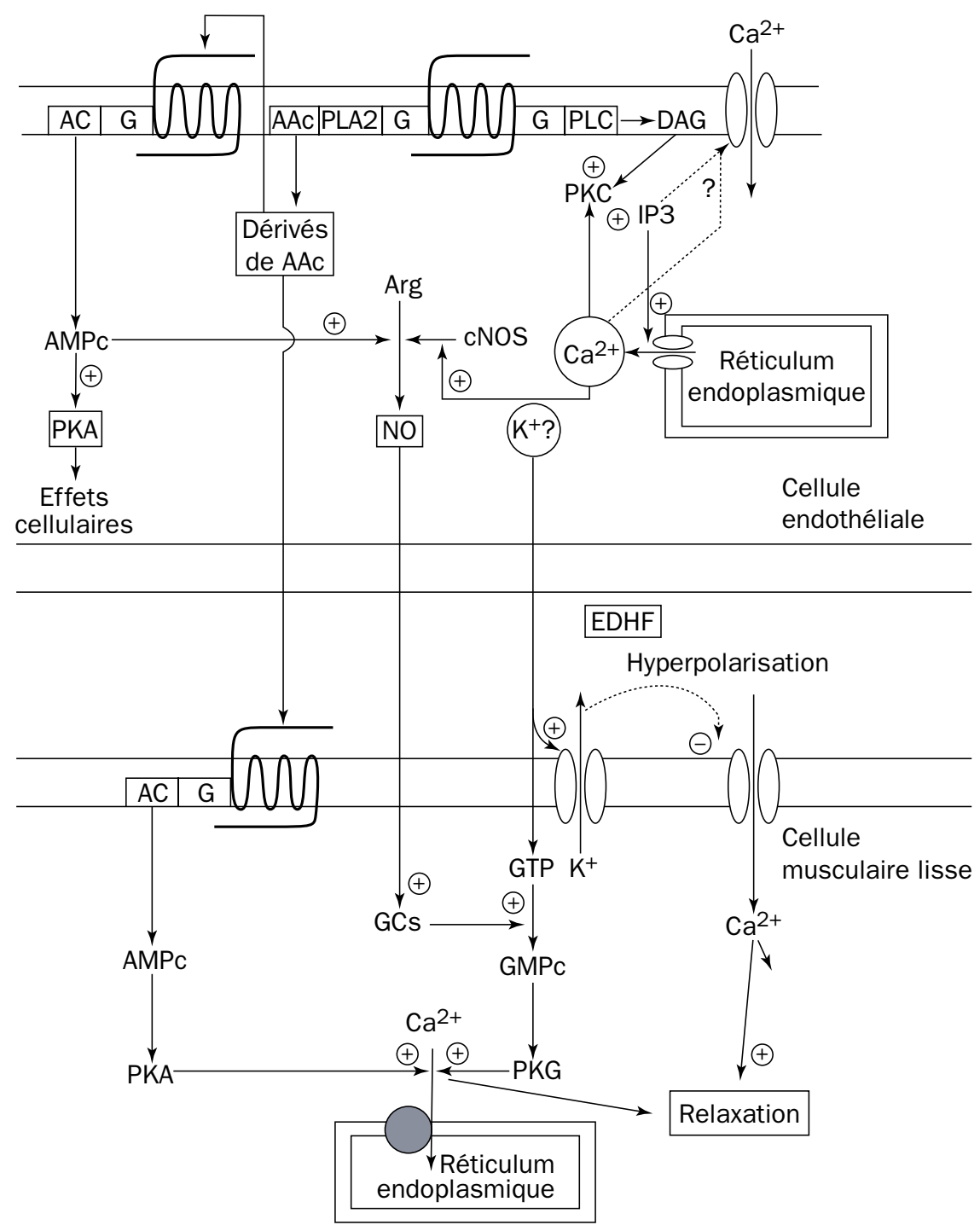

Figure 3.12.a - Représentation schématique des effets de la bradykinine sur les cellules endothéliales vasculaires

$A A c$ : acide arachidonique ; $A C$ : adénylate cyclase ; $A M P C$ : adénosine monophosphate cyclique ; Ang II : angiotensine II ; BK : bradykinine ; DAG : diacylglycérol ; Et1 : endothéline 1 ; G : protéine G ; GMPc : guanosine monophosphate cyclique ; GTP : guanosine triphosphate ; IP3 : inositol $(1,4,5)$ triphosphate ; MAPK : mitogen activated protein (MAP) kinase; MEK : MAP kinase-kinase ; PLA : phospholipase A ; PLC : phospholipase $C$

En présence d'endothélium, la bradykinine induit une vaso-dilatation médiée par NO, des dérivés de l'acide arachidonique, et peut-être le facteur hyperpolarisant (potassium ?). Lorsque la stimulation est intense, la contraction des cellules endothéliales des capillaires, provoquée par une augmentation massive de la teneur en calcium libre intracellulaire, alliée à la libération des dérivés de l'acide arachidonique, peut conduire à un état de choc (hypotension - extravasion). 


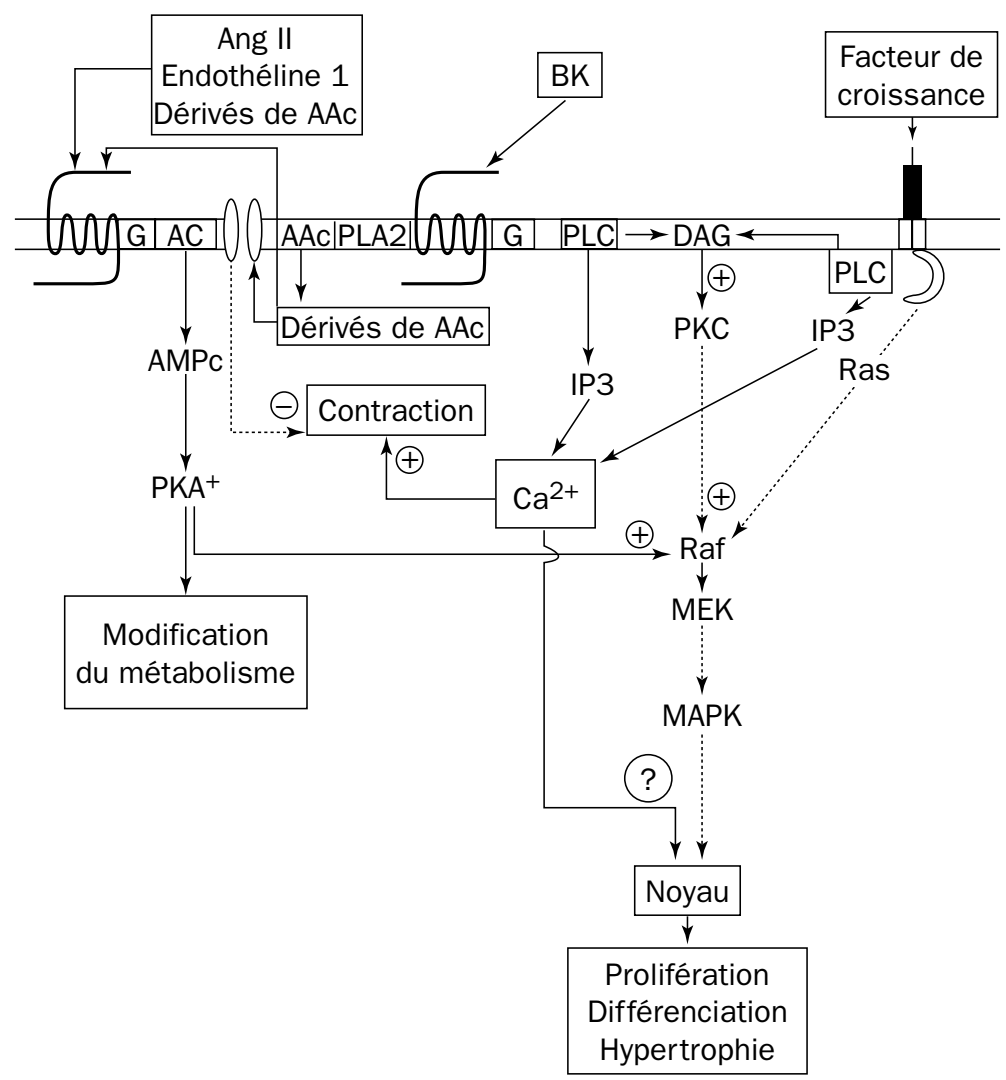

Figure 3.12.b - Représentation schématique des effets de la bradykinine sur les cellules musculaires lisses vasculaires

En l'absence d'endothélium, la bradykinine, comme d'autres messagers tels que la thrombine, l'angiotensine, l'endothéline, provoque la contraction des cellules musculaires lisses et exerce une action co-mitogène conduisant à leur prolifération et à leur différenciation. Le remodelage vasculaire qui en résulte peut conduire à des pathologies (hypertension - thrombose).

Ces observations sont à mettre en parallèle avec le fait que, lors de ligatures expérimentales de l'artère coronaire, ou chez des patients présentant un infarctus du myocarde, le taux plasmatique de kinines augmente alors que celui du kininogène diminue.

Enfin, chez un grand nombre d'espèces, l'application épicardiale de bradykinine entraine une activation des terminaisons végétatives. Elle peut provoquer une tachycardie et l'augmentation de la pression sanguine conduisant, dans certains cas, par voie réflexe, à une bradycardie génératrice d'une importante diminution de la pression sanguine.

\section{Action au niveau rénal}

La présence de kallicréine tissulaire, de kininogène et de kinines (bradykinine, lysylbradykinine, méthyl-lysyl-bradykinine) a été mise en évidence dans l'urine humaine. 
L'étude chez l'animal a permis de montrer que plus de $90 \%$ de la kallicréine est produite par certaines cellules du cortex rénal. La kallicréine rénale peut agir sur le kininogène produit par les cellules du tubule et/ou le kininogène circulant au niveau des capillaires, et ainsi conduire à la production de kinines qui seront retrouvées dans les urines et dans la circulation, et vont agir localement. Les kinines ainsi produites vont agir, d'une part, sur le système circulatoire rénal (vaso-dilatation médullaire et glomérulaire) et, d'autre part, sur le métabolisme hydrominéral en diminuant la réabsorption d'eau et de $\mathrm{Na}^{+}$. Par ailleurs, la kallicréine rénale peut agir sur la prorénine pour produire la rénine (fig. 3.13).

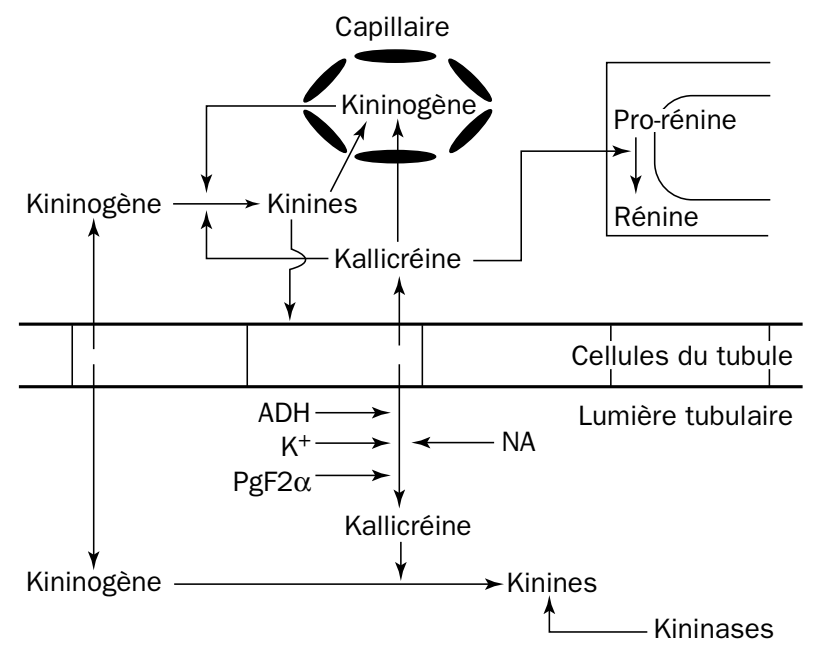

Figure 3.13 - Le système rénal kallicréine-kinine

L'action des kinines produites au niveau rénal conduit, via l'activation de récepteurs BK1 et BK2, à une vaso-dilatation locale, ainsi qu'à une augmentation de la natriurèse et de la diurèse.

\section{Autres effets biologiques des kinines}

Outre leurs actions au niveau des reins et du système cardio-vasculaire, les kinines exercent de nombreux autres effets biologiques.

\section{Action des kinines sur le système nerveux}

La présence de récepteurs à la BK2 a été mise en évidence au niveau des différentes régions du cerveau, en particulier au niveau des centres régulateurs de l'activité cardio-vasculaire. Cette action passerait par la régulation de la libération d'amines (noradrénaline, sérotonine). De plus, la BK est directement impliquée, au niveau central, dans la conduction d'informations nociceptives (fibres A et C). Par ailleurs, l'injection intraventriculaire de bradykinine entraîne une vaso-dilatation des vaisseaux cérébraux, ce qui induit une augmentation de la pression artérielle et une réduction de la production d'hormone antidiurétique. Le rôle éventuel de la bradykinine dans le développement des œdèmes cérébraux et la maladie d'Alzheimer reste à démontrer. 


\section{Action des kinines sur les leucocytes}

Les leucocytes humains possèdent deux kallicréines, l'une capable d'agir sur un kininogène spécifique, le leucokininogène, et une seconde, proche de la kallicréine plasmatique, active sur les kininogènes plasmatiques. La production de kinines, ainsi que l'induction par ces substances de la libération d'interleukine 1 par les monocytes, conduit à penser que les kinines sont impliquées lors de la réponse inflammatoire dans l'adhérence, la diapédèse et la migration des monocytes.

Action des kinines sur les muscles lisses (autres que vasculaires) et les épithéliums

Les kinines provoquent la contraction de l'utérus, du colon, de l'iléon et des bronches. Au niveau des épithéliums, les kinines stimulent la sécrétion de $\mathrm{Cl}^{-}$et de mucus. Ces mécanismes mettent en jeu les deux types de récepteurs des kinines.

Par ailleurs, les kinines stimulent la production de bicarbonate par la vésicule biliaire et modulent le contenu en eau et sodium de la sueur.

\section{Les kinines et la reproduction}

L'activation des récepteurs de type BK2 stimule la mobilité des spermatozoïdes, induit la contraction de l'utérus et est impliquée dans la rupture du follicule ovarien. En outre, il a été mis en évidence, au niveau de l'hypophyse antérieure et intermédiaire, une enzyme analogue à la kallicréine tissulaire. Cette enzyme, ainsi que les kinines (de même que l'angiotensine II), pourraient intervenir dans la modulation de la sécrétion de prolactine.

\subsection{CONCLUSION ET PERSPECTIVES}

Un certain nombre de pathologies (allergie, asthme, arthrite, œdème) semblent être corrélées avec une hyperproduction de kinines et/ou l'expression d'un nombre anormalement élevé de récepteurs. En particulier des récepteurs BK1 dont l'expression est stimulée par les cytokines. En revanche, il n'a pas été démontré de relation nette entre certains types d'hypertension et une hypoproduction de bradykinine ou du nombre (et/ou de l'efficacité) des récepteurs. Néanmoins, l'action bénéfique exercée par les inhibiteurs de l'enzyme de conversion de l'angiotensine (qui sont aussi des inhibiteurs des kinases) sur certains types d'hypertension, sur l'athérosclérose, ainsi que sur les altérations liées à la reperfusion post-ischémique, suggère un rôle possible de la bradykinine.

L'ensemble des données actuelles ne permet pas de déterminer avec précision le rôle respectif des récepteurs BK1, BK2 (et éventuellement des autres types ou sous-types de récepteurs) dans ces situations. De l'ensemble des données cliniques et expérimentales, découlent des interrogations quant au rôle bénéfique et/ou délétère des kinines. Il se peut que la réponse ne soit pas univoque et que, comme dans le cas de $\mathrm{NO}$, la bradykinine soit un médiateur à deux visages. 


\section{LE MONOXYDE D’AZOTE : NO}

Le monoxyde d'azote est - probablement avec $\mathrm{CO}$ - la plus petite biomolécule présentant des propriétés de messager chimique. Il est synthétisé par une grande variété de types cellulaires des Invertébrés aux Mammifères. Depuis la mise en évidence, par Furchgott et Zawadski, en 1980, que la vaso-dilatation induite par l'acétylcholine nécessite la mise en jeu d'un facteur relaxant libéré par l'endothélium (l'endothelium derived relaxing factor ou EDRF) et l'identification de ce facteur à NO (Moncada et coll., 1987), il a été montré que le monoxyde d'azote est impliqué dans un grand nombre de processus physiologiques ou physiopathologiques. Processus aussi complexes que les mécanismes de vaso-dilatation, de neurotransmission, de transcription génétique ou de réaction inflammatoire et immunitaire.

\subsection{PROPRIÉTÉS PHYSICO-CHIMIQUES}

A température et pression ambiantes, le monoxyde d'azote est un gaz coloré, sa solution dans l'eau est de l'ordre de celle de l'oxygène $\left(2-3 \mathrm{mM}, 20^{\circ} \mathrm{C}, 1 \mathrm{~atm}\right)$. C'est une molécule non-polaire qui peut facilement franchir les membranes biologiques car il est aussi soluble dans les lipides. Du fait de sa forte réactivité, sa durée de vie dans les milieux biologiques est courte (quelques secondes) et sa capacité de diffusion estimée à quelques fractions de millimètre.

NO comporte un nombre impair d'électrons, ce qui lui confère la nature d'un radical libre $\left[\mathrm{NO}^{\circ}\right]$ présentant des propriétés paramagnétiques. La structure électronique de NO (fig. 3.14) lui permet d'être considéré soit comme une base, soit comme un acide de Lewis. De plus, suivant l'environnement rédox, il sera oxydant ou réducteur.

$$
\ddot{*} \cdot \ddot{\cdot} \cdot \ddot{0} \rightarrow \ddot{N}:: \ddot{0}:
$$

Figure 3.14 - NO : structure de Lewis

$\mathrm{NO}$ peut réagir avec $\mathrm{O}_{2}$ pour former le dioxyde d'azote $\mathrm{NO}_{2}$. Si, dans l'air, le produit terminal est bien le gaz $\mathrm{NO}_{2}$, en solution aqueuse, $\mathrm{NO}_{2}$ se décompose en nitrite $\mathrm{NO}_{2}{ }^{-}$et nitrate $\mathrm{NO}_{3}{ }^{-}$(fig. 3.15). En présence du radical $\left[\mathrm{O}_{2}{ }^{-}\right]$, $\mathrm{NO}$ réagit pour former un intermédiaire instable, l'anion peroxynitrite $\mathrm{ONOO}^{-}$. L'anion peroxynitrite est un générateur de radical $\left[\mathrm{OH}^{*}\right]$ et un puissant oxydant qui pourrait être, en partie, le vecteur de la toxicité de NO.

Dans des conditions de température et de $\mathrm{pH}$ physiologiques, $\mathrm{NO}$ est capable de réagir avec les groupements thiols pour donner des thionitrites ou S-nitroso-thiols (S-NO). Les S-nitroso-thiols peuvent être formés, en particulier, au niveau de protéines portant des groupes thiols (fig. 3.15) (sérum albumine, cathepsine B, glutathion, hémoglobine...). Ces S-nitroso protéines sont particulièrement stables et, pour certaines, sont considérées comme des donneurs de NO. En particulier, il a été 
démontré récemment que la S-nitro-hémoglobine formée au niveau des poumons peut libérer $\mathrm{NO}$ au niveau des vaisseaux et pourrait ainsi participer à la régulation de la pression artérielle.

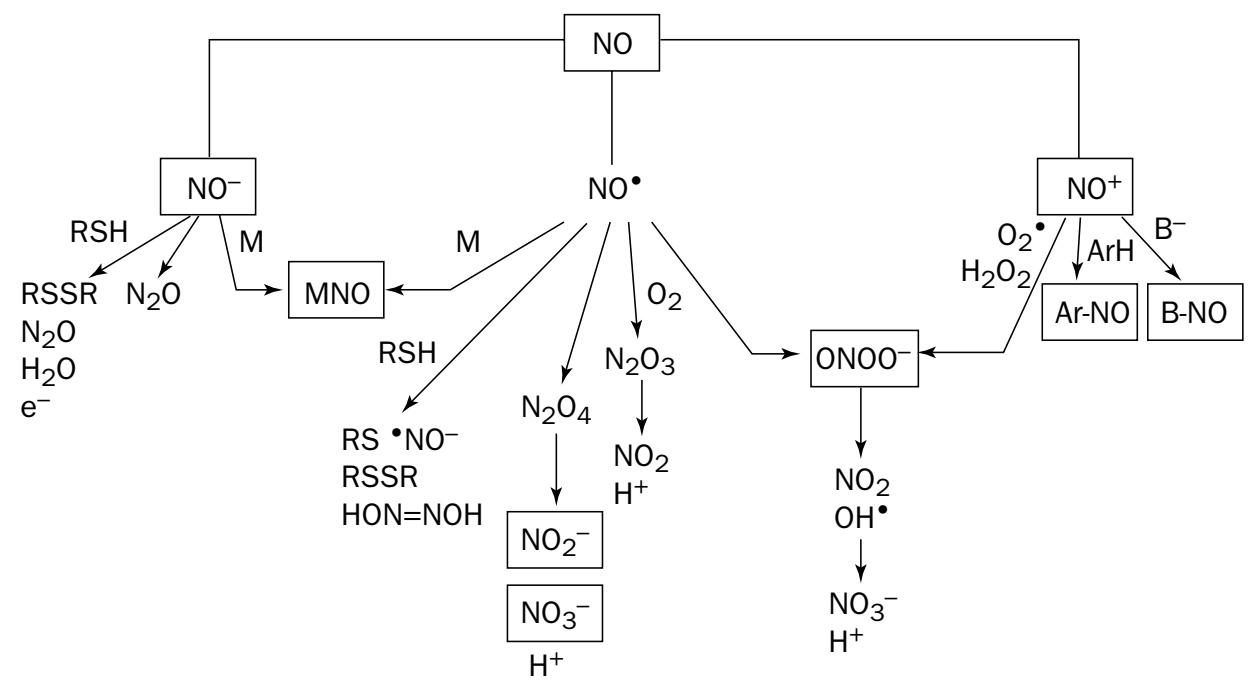

Figure 3.15 - Représentation des réactions possibles de NO sous forme d'anion, de radical et de cation

NO anion peut réagir avec des thiols pour donner des composés qui, finalement, conduisent à la production de disulfites. Ceux-ci vont produire de l'oxyde nitreux et de l'eau. NO, sous la forme anionique ou radicalaire, peut réagir avec des métaux (M) pour donner des métallo-nitro-complexes (M-NO). La dimérisation spontanée de $\mathrm{NO}^{-}$induit la formation de $\mathrm{NO}_{2}{ }^{-}$, et la réaction de l'acide correspondant sur un groupe thiol déclenche la formation de disulfite et d'acide hyponitreux. Les mêmes produits sont formés lors de la réaction de NO radicalaire sur les thiols. En outre, $\mathrm{NO}^{\bullet}$ peut se lier à l'oxygène pour donner des nitrites et des nitrates, et avec l'oxygène radicalaire pour produire l'anion peroxynitrite générateur de $\mathrm{OH}^{-}$. Le cation $\mathrm{NO}^{+}$peut être oxydé par $\mathrm{H}_{2} \mathrm{O}_{2}$ pour produire, lui aussi, l'anion peroxynitrite. De plus, $\mathrm{NO}^{+}$peut donner des réactions de nitrosation avec des composés aromatiques $(\mathrm{ArH})$ ou des bases $\left(\mathrm{B}^{-}\right)$comme les amines.

Un des aspects les plus importants de la chimie de NO est sa capacité à réagir avec des métaux et, en particulier, les métalloprotéines (voir fig. 3.15). Ainsi, NO réagit avec les hémoprotéines (hémoglobine, guanylate cyclase, NO synthases, prostaglandine $\mathrm{H}$ synthase), les protéines impliquées dans le métabolisme du fer (ferritine, ferroxydases, transferrine, le récepteur à la transferrine, l'iron responsive factor), les oxydoréductases du métabolisme de $\mathrm{O}_{2}$ et $\mathrm{O}_{2}{ }^{\cdot-}$ (la céruloplasmine, les superoxydes dismutases à $\mathrm{Cu}-\mathrm{Zn}$, à fer, à Mn).

La formation de liaisons de coordination entre $\mathrm{NO}$ et le centre métallique de ces protéines conduit à des modifications importantes de leurs propriétés. Ainsi, dans certains cas, ces modifications provoquent le passage de l'état inactif à l'état actif (guanylate cyclase soluble), dans d'autres elles conduisent à des altérations qui pourraient être à l'origine d'une partie des propriétés cytotoxiques du NO. 


\subsection{BIOSYNTHÈSE ET DONNEURS DE NO}

\subsubsection{Biosynthèse de NO}

$\mathrm{Si}$, chez les microbes, NO peut être produit par la réduction des nitrites ou l'oxydation de l'ammoniaque, la synthèse de NO chez les Mammifères résulte, quant à elle, de processus différents : la L-arginine est oxydée par des NO synthases (NOS), constitutives (cNOS) ou inductibles (iNOS), en NO et L-citrulline (fig. 3.16 et 3.17).

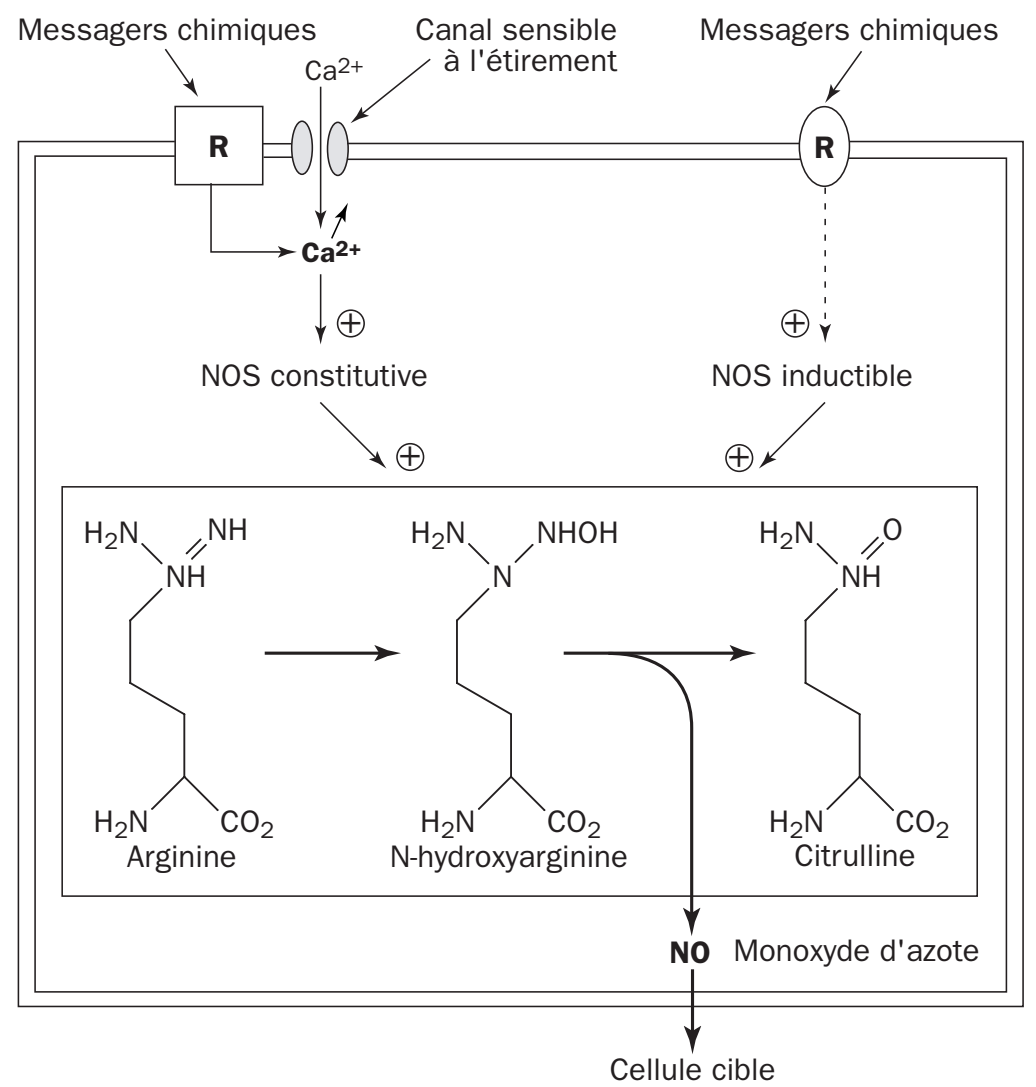

Figure 3.16 - Représentation schématique des mécanismes impliqués dans la synthèse de NO

Ca-Calm : calcium-calmoduline; NOS : NO synthase inductible ou constitutive.

Ces deux types de NOS sont des enzymes dimériques composées de deux sous-unités identiques de poids moléculaire compris entre 130 et $150 \mathrm{kDa}$. Ces deux formes ont des activités spécifiques proches, comprises entre 0,8 et $1,3.10^{-6} \mathrm{~mol} / \mathrm{min} / \mathrm{mg}$ de protéine $\left(37^{\circ} \mathrm{C}\right)$, et elles présentent beaucoup d'homologies avec la cytochrome $\mathrm{P}-450$ réductase. Trois isoformes de ces enzymes ont été identifiées (fig. 3.18). 


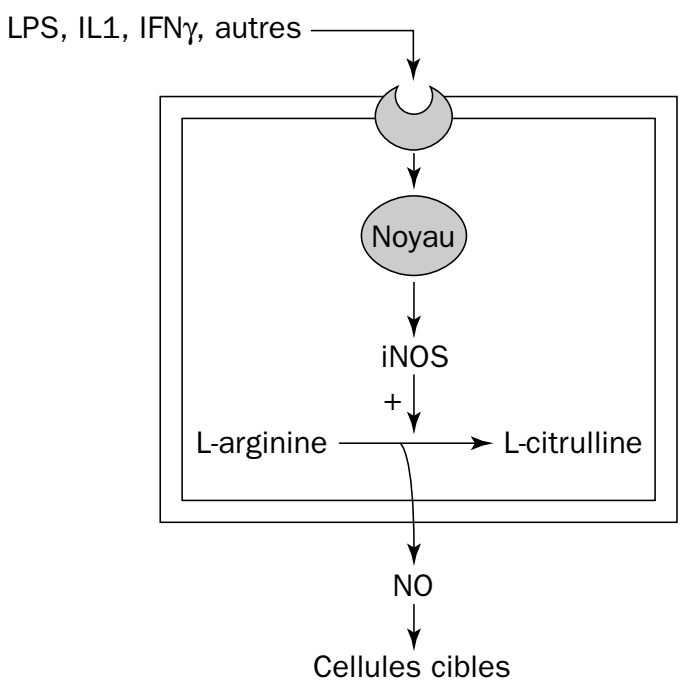

Figure 3.17 - Production de NO via l'activation de la synthèse d'une NO synthase inductible

IFN $\gamma$ : interféron $\gamma$; IL1: interleukine 1; LPS : lipopolysaccharide ; NADPH : adénine dinucléotide phosphate.

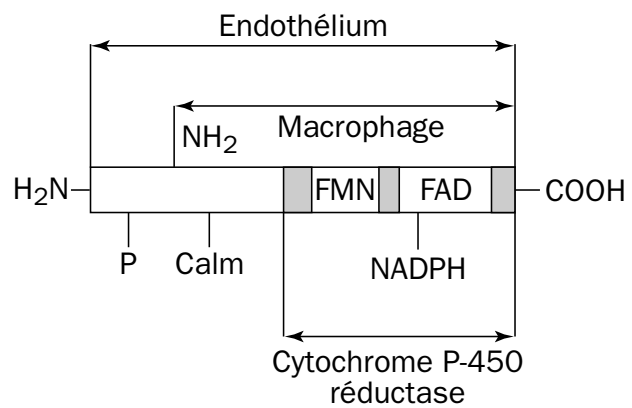

Figure 3.18 - Représentation schématique de la structure des NO synthases de l'endothélium et du macrophage, ainsi que celle de la cytochrome P-450 réductase Ces enzymes présentent des sites communs de fixation pour l'adénine dinucléotide phosphate (NADPH), la flavine adénine dinucléotide (FAD), la flavine mononucléotide $(F M N)$, ainsi que des sites probables de fixation pour la calmoduline (Calm), et de phosphorylation $(P)$.

Les NO synthases constitutives de l'endothélium (eNOS) et du système nerveux (nNOS ou bNOS) sont respectivement appelées NOSIII (ou NOS3) et NOSI (ou NOS1), et la NOS inductible qui est présente dans de nombreux types cellulaires (hépatocytes, macrophages, chondrocytes...) est appelée NOSII (ou NOS2). Ces isoformes diffèrent pour leur sensibilité au calcium et à la calmoduline, leur cinétique et leurs mécanismes de régulation qui peuvent nécessiter comme co-facteurs du NADPH de la tétrahydrobioptéridine, du FAD et/ ou de la FMN (tab. 3.3). Ainsi, les deux NOS constitutives ont leur activité régulée par le calcium. En revanche, la NOS inductible est considérée comme largement indépendante du calcium. 


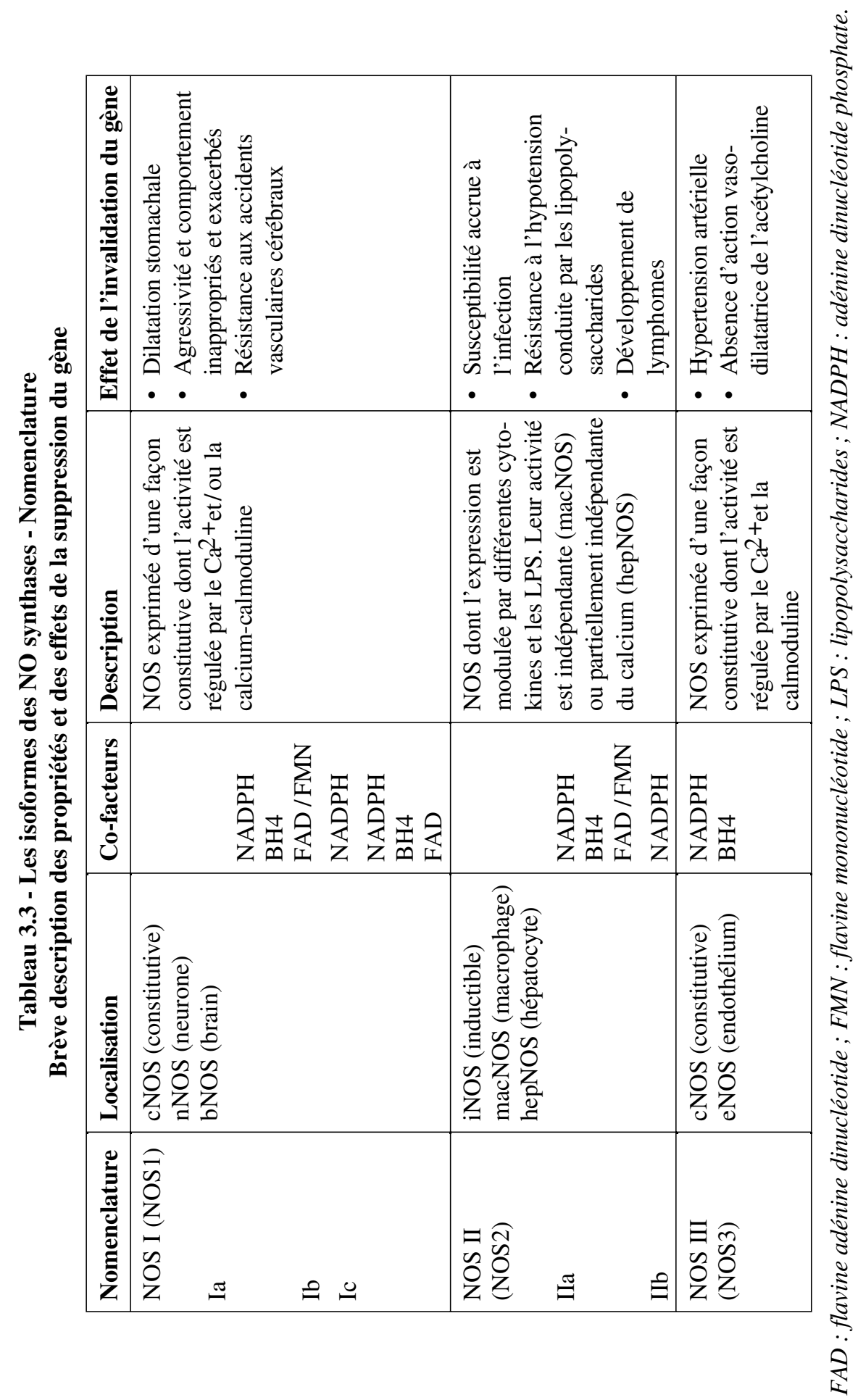


Dans les cellules possédant une NOS constitutive, lors de l'activation de récepteurs membranaires (ou lors de la mise en jeu de canaux ioniques sensibles à l'étirement) conduisant à une augmentation de la teneur en calcium libre cellulaire, les cNOS produisent, pendant une période courte (quelques secondes, quelques minutes) une petite quantité de NO (de l'ordre de la picomole). En revanche les iNOS produisent, lorsqu'elles sont stimulées, une quantité beaucoup plus grande $(\mathrm{nmol} / \mathrm{min} / \mathrm{mg}$ ) de NO et ce, pendant un temps beaucoup plus long (plusieurs heures).

Parmi les cytokines susceptibles d'induire l'activation de la iNOS, il a été montré que l'interféron $\gamma$ agit en synergie avec les lipopolysaccharides (LPS) pour stimuler la transcription des ARNm de l'iNOS, mais aussi pour le stabiliser. En revanche, le transforming growth factor $\beta$ (TGF $\beta$ ) possède une action opposée. De plus, il a aussi été démontré que NO exerce une rétroaction négative sur sa synthèse via une action probable sur le gène qui régit cette synthèse. Le tableau 3.4 donne les niveaux connus de la régulation de la synthèse des iNOS ; la complexité de ces régulations (un grand nombre est probablement inconnu) suggère le double rôle que peut jouer NO : agent de défense, mais aussi agent cytotoxique pour la cellule productrice.

Tableau 3.4 - Régulation de l'activité de la iNOS

\begin{tabular}{|c|c|}
\hline Niveau de la régulation & Agents \\
\hline Augmentation de la synthèse de l'ARNm & $\begin{array}{l}\text { Agents actifs sur la synthèse de AMPc } \\
\mathrm{UV}, \mathrm{O}_{3}\end{array}$ \\
\hline $\begin{array}{l}\text { Transcription } \\
\text { Stimulation } \\
\text { Suppression } \\
\text { Facteur de transcription }\end{array}$ & $\begin{array}{l}\text { IFN } \gamma ; \text { LPS } \\
\text { LPS ; TGF } \beta \text {-glucocorticoïdes } \\
\text { NF-KB }\end{array}$ \\
\hline $\begin{array}{l}\text { Stabilité de l'ARNm } \\
\text { Augmentée } \\
\text { Diminuée }\end{array}$ & $\begin{array}{l}\text { IFN } \gamma \\
\text { TGF } \beta\end{array}$ \\
\hline $\begin{array}{l}\text { Translation de l'ARNm } \\
\text { Supprimée }\end{array}$ & TGF $\beta$-dexaméthasone \\
\hline $\begin{array}{l}\text { Régulation post-translationnelle ou autre } \\
\text { Suppression de la stabilité } \\
\text { Rétrocontrôle négatif } \\
\text { Limitation de la quantité de substrat } \\
\text { Limitation de la quantité de co-facteur } \\
\text { Phosphorylation }\end{array}$ & $\begin{array}{l}\text { TGF } \beta \\
\text { NO } \\
\text { L-arginine } \\
\text { BH4-Calm activée ou non par } \mathrm{Ca}^{2+} \\
\text { Statut énergétique cellulaire }\left(\mathrm{O}_{2} ?\right)\end{array}$ \\
\hline
\end{tabular}

AMPc : adénosine monophosphate cyclique ; BH4 : tétrahydrobioptéridine ; Calm : calmoduline ; IFN $\gamma$ : interféron $\gamma$; LPS : lipopolysaccharides ; TGF $\beta$ : transforming growth factor $\beta$; UV : rayonnement ultraviolet. 
L'augmentation de la teneur en calcium cytoplasmique résultant de l'activation de récepteurs membranaires - ou de l'ouverture de canaux ioniques sensibles à l'étirement - provoque une activation de la NO synthase qui, en deux étapes successives, conduit à la production de $\mathrm{NO}$ et de citrulline (voir fig. 3.16). Un certain nombre d'analogues de la L-arginine tels que la $\mathrm{N}^{\mathrm{G}}$-monométhyl-L-arginine (L-NMMA), analogue non-métabolisable de la L-arginine, sont des inhibiteurs de la synthèse de NO, alors que l'adénine dinucléotide phosphate (NADPH), la flavine adénine dinucléotide (FAD), la flavine mononucléotide (FMN) et la tétrahydrobioptéridine (BH4) sont des activateurs.

Différents messagers chimiques tels que les lipopolysaccharides (LPS), l'interféron $\gamma$ (IFN $\gamma$ ) et l'interleukine 1 (IL1) peuvent conduire à la synthèse d'une NO synthase. La présence d'une NO synthase inductible a été mise en évidence dans un grand nombre de types cellulaires : les macrophages, les cellules neutrophiles, les cellules endothéliales et les cellules musculaires vasculaires.

\subsubsection{Les donneurs de NO, le métabolisme de NO, cible potentielle d'actions thérapeutiques}

L'implication de NO dans un grand nombre de situations physiologiques et pathologiques conduit à penser qu'il existe un intérêt à intervenir sur son métabolisme (fig. 3.19).

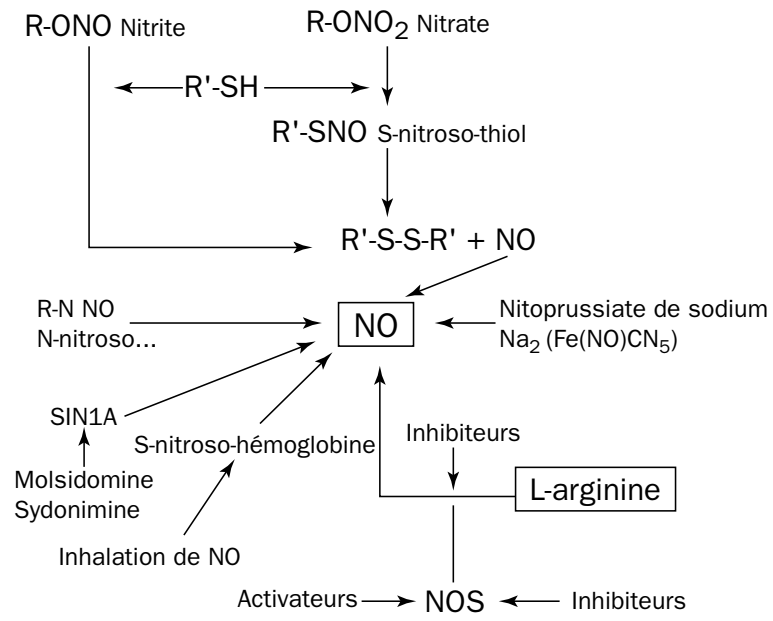

Figure 3.19 - Représentation schématique des interventions possibles sur le métabolisme de NO

La L-arginine est le seul précurseur physiologique connu de NO. Il existe un grand nombre d'analogues synthétiques non-métabolisables de la L-arginine qui sont des inhibiteurs de cette synthèse ; c'est, parmi d'autres, le cas de la L-NAME $\left(\mathrm{NG}^{\mathrm{G}}\right.$-nitroL-arginine méthyl ester), de la L-NMA ( $\mathrm{N}^{\mathrm{G}}$-méthyl-L-arginine) ou de la L-NAA

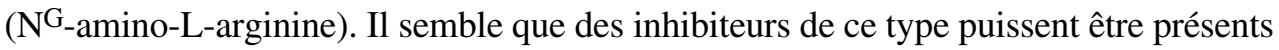


d'une manière endogène (en particulier au niveau du tissu rénal). Il existe des inhibiteurs tels que les isothiourées, différentes substances portant le groupe amidine des NOS et des activateurs $\left(\mathrm{Ca}^{2+}\right.$, tous les inducteurs de la synthèse des iNOS). Différentes substances utilisées ou non en thérapeutique sont des donneurs potentiels de NO (nitrates, nitrites, S-nitroso-thiols, nitroprussiate de sodium, SIN1A). Toutefois, il faut avoir à l'esprit que, lors de l'utilisation de ces substances, la production de NO peut être accompagnée de la production d'une grande variété de substances biologiquement actives dont certaines sont toxiques. Il est aussi possible que l'inhalation de NO exerce non seulement un effet bénéfique par son action au niveau des bronches, mais pourrait agir, via la formation de S-nitrosohémoglobine, comme une technique potentielle de vaso-dilatation active à long terme (voir fig. 3.19).

Ainsi, lors du choc septique ou en présence de certaines altérations du fonctionnement du système nerveux central, il pourrait être intéressant de limiter la production de NO soit en inhibant l'activité des NO synthases, soit en utilisant des analogues nonmétabolisables de la L-arginine. Au contraire, lors de situations d'ischémie, d'hypertension chronique ou d'impuissance masculine, la stimulation des NO synthases ou l'utilisation de donneurs de NO peuvent avoir un effet bénéfique. Enfin, l'inhalation de NO, qui produit une vaso-dilatation transitoire des artérioles pulmonaires, pourrait aussi agir sur la dilatation bronchique et sur la pression artérielle (via la formation de S-nitroso-hémoglobine) et serait un moyen de lutte contre différents types d'affections respiratoires.

\subsection{NO ET LA PHYSIOLOGIE CARDIO-VASCULAIRE}

\subsubsection{NO et les vaisseaux}

Les veines et les artères sont essentiellement constituées de deux types cellulaires : les cellules endothéliales et les cellules musculaires lisses. Les cellules endothéliales constituent une monocouche - l'endothélium - $\left(2 \mathrm{~kg}, 1000 \mathrm{~m}^{2}\right)$ qui forme une interface entre le sang et les cellules musculaires lisses. Ces dernières assurent la tonicité vasculaire. L'endothélium, qui peut être considéré comme une glande endocrine diffuse (voir chap. 9) joue un rôle important dans la régulation, à court et à long terme, du tonus vasculaire, ainsi que dans la modulation de processus physiologiques tels que l'inflammation, l'agrégation plaquettaire, la fibrinolyse, l'angiogenèse, le métabolisme de certains messagers circulants (angiotensine, bradykinine, catécholamines). L'endothélium synthétise et libère une grande variété de substances actives paracrines et/ou autocrines. Parmi celles-ci, des dérivés de l'acide arachidonique, des facteurs de croissance, le facteur VIII de Willebrandt, des molécules anti-adhésives et anti-agrégatives, l'endothéline et au moins deux facteurs de nature inconnue. L'un de ces facteurs (facteur hyperpolarisant) induit une hyperpolarisation des cellules musculaires lisses et, par là, une vaso-dilatation, l'autre provoque une vaso-constriction. 
Comme nous l'avons vu plus haut, l'endothélium synthétise également le NO. C'est l'utilisation de différentes techniques de mesure (résonance paramagnétique électronique, électrode sensible à NO) de donneurs de NO, d'inhibiteurs de la production de NO et d'animaux déficitaires en NOS constitutive endothéliale qui a permis d'admettre que l'EDRF est bien NO. L'endothélium vasculaire contient une eNOS constitutive qui joue un rôle physiologique primordial, mais aussi une NOS inductible dont les rôles sont mal connus ou soupçonnés (la situation est symétrique pour les cellules musculaires lisses vasculaires, dont la iNOS semble jouer un rôle prépondérant dans le fonctionnement de base et dont le rôle de la NOS constitutive est mal défini).

Au niveau de l'endothélium vasculaire, le monoxyde d'azote est libéré soit sous forme de $\mathrm{NO}^{\circ}$, soit pris en charge par une molécule contenant un groupe $\mathrm{SH}$. L'acétylcholine, la 5-hydroxytryptamine, la thrombine, l'acide arachidonique et d'autres messagers chimiques, ainsi que tous les facteurs chimiques ou physiques (forces de cisaillement, pression sanguine) qui induisent une augmentation du calcium libre cytoplasmique, sont des facteurs qui stimulent cette production via l'activation de la NOS constitutive (fig. 3.20).

Le monoxyde d'azote libéré active une guanylate cyclase soluble présente au niveau des cellules musculaires lisses vasculaires, des plaquettes et de l'endothélium luimême. Il a été émis l'hypothèse que c'est la liaison de NO avec le fer hémique de la guanylate cyclase et la libération simultanée d'une histidine fixée axialement qui provoquent l'activation enzymatique. L'importante production de guanosine monophosphate cyclique (GMPc) qui résulte de cette activation provoque, au niveau de la cellule musculaire lisse vasculaire, une activation d'une ou plusieurs protéine kinases G dépendantes du GMPc (PKG). S'il est clair que cette activation des protéine kinases $\mathrm{G}$ entraîne une diminution de la teneur intracellulaire en calcium libre responsable de la vaso-relaxation, les mécanismes mis en jeu sont encore mal connus. Il est cependant probable que ce sont la phosphorylation d'une protéine régulatrice de la calcium-ATPase du réticulum (et peut-être de celle du sarcolemme), ainsi que celle des canaux calciques activables par l'inositol $(1,4,5)$ triphosphate (IP3) qui sont responsables de cette vaso-relaxation (fig. 3.20).

Il faut aussi garder à l'esprit que les protéine kinases $\mathrm{G}$ exercent d'autres actions (fig. 3.21) qui pourraient elles aussi contribuer à la vaso-relaxation. En particulier, les PKG phosphorylent des canaux potassiques, ce qui augmente leur sensibilité au calcium, l'hyperpolarisation résultante réduit l'entrée de calcium par les canaux calciques sensibles au voltage. Il a été, en outre, montré que NO pouvait directement stimuler ce type de canal potassique, mais aussi les canaux potassiques sensibles à l'ATP, contribuant ainsi à l'hyperpolarisation induite par l'activation des PKG. La vaso-dilatation ainsi provoquée rétroagit négativement sur les facteurs physicochimiques (diminution de la $\mathrm{pO}_{2}$, forces de cisaillement, pression sanguine) qui ont pu engendrer la production de NO. Cette action vaso-dilatatrice et son implication 
dans la régulation physiologique de la pression artérielle sont confirmées par l'observation d'une hypertension (35\% d'augmentation) et la perte de l'action vasodilatatrice de l'acétylcholine induites chez la souris par délétion du gène de la eNOS.

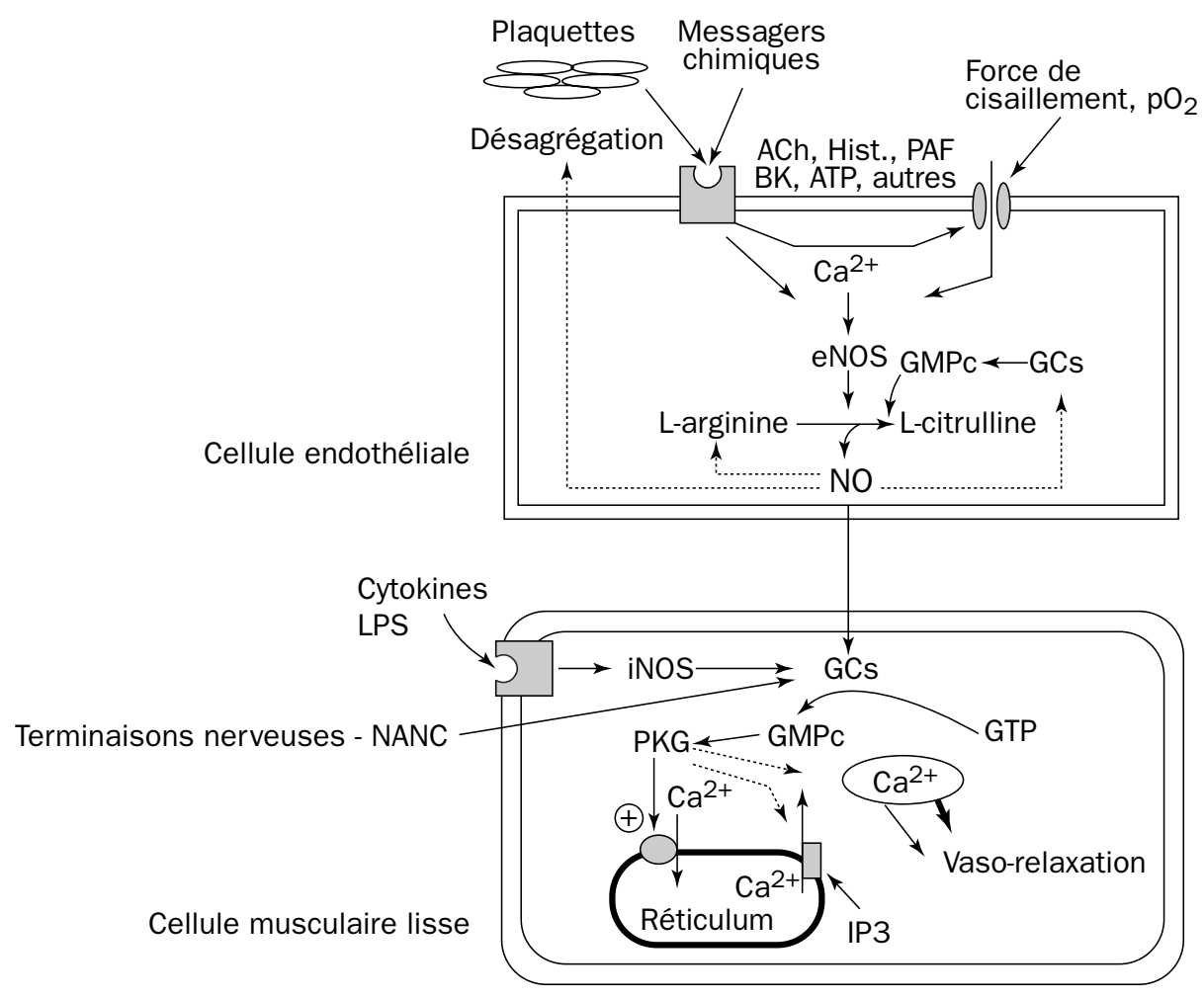

Figure 3.20 - Action vaso-dilatatrice de NO

La NO synthase constitutive de l'endothélium (eNOS) est activée par tous les mécanismes qui conduisent à une augmentation de la teneur cytoplasmique en calcium. A ce niveau, le NO rétroagit négativement sur sa production, soit directement, soit via l'activation d'une guanylate cyclase soluble (GCs). Le NO produit diffuse jusqu'aux plaquettes où il réduit l'agrégation, et jusqu'au niveau des cellules musculaires lisses où il stimule fortement la production de GMPC. Cette production provoque l'activation d'une ou plusieurs protéine kinases G sensibles au GMPc (PKG). L'activation des PKG provoque, au niveau du réticulum sarcoplasmique, une phosphorylation inhibitrice des canaux calciques activables par l'inositol $(1,4,5)$ triphosphate (IP3) et une phosphorylation activatrice de la calciumATPase, et, au niveau de la membrane plasmique, une phosphorylation des canaux potassiques sensibles au calcium. II a aussi été montré que NO peut directement stimuler ce type de canal, de même que les canaux $\mathrm{K}^{+}$sensibles à l'ATP. L'hyperpolarisation qui en résulte diminue l'entrée de calcium par les canaux calciques membranaires sensibles au voltage. L'ensemble de ces mécanismes conduit, au niveau de la cellule musculaire lisse, à une diminution de la teneur cytoplasmique en calcium et, par là, à une vaso-dilatation.

Au niveau des cellules musculaires lisses, le NO peut provenir non seulement de l'activité des cellules endothéliales, mais aussi des différents types d'innervation vasculaire, où NO peut être libéré par des neurones "nitrinergiques" ou co-libérés (voir § 3.4.1). En outre, les cellules musculaires lisses possèdent une NOS inductible (iNOS), activable par différentes cytokines et le lipopolysaccharide (LPS). 
Augmentation de la conductance des canaux $\mathrm{K}^{+}$sensibles au calcium, ce qui entraîne une hyperpolarisation et la réduction de l'entrée de calcium par les canaux membranaires sensibles au voltage.

Diminution de la sensibilité au calcium des protéines contractiles.

(ou PKG)

Augmentation de l'activité des calcium-ATPases de la

membrane plasmique et du réticulum sarcoplasmique.

Diminution de l'activité des canaux calciques

(phosphorylation de protéines cytosquelettiques

régulatrices des canaux).

Figure 3.21 - Représentation schématique des propriétés des protéine kinases GMPcK (ou PKG), activables par le GMPc (d'après Lincolm et Cornwell, 1993)

A côté du rôle que joue NO dans la régulation du tonus vasculaire, il a été montré (utilisation d'inhibiteurs de synthèse) que NO est impliqué dans l'état de choc septique ou hémorragique. Le platelet activating factor (PAF) participe, lui aussi, à l'état de choc. Il pourrait agir directement mais aussi via l'induction de la synthèse de NO. L'état de choc est caractérisé, entre autres symptômes, par une vaso-dilatation périphérique importante responsable d'une hypotension dramatique, une augmentation majeure de la perméabilité vasculaire et une insensibilité aux vaso-constricteurs, l'ensemble de ces altérations pouvant conduire à la mort. C'est, semble-t-il, l'activation de la iNOS des cellules musculaires lisses (mais aussi de la iNOS des cellules endothéliales), ainsi que l'altération de la eNOS, qui participent à l'état de choc. Cette défaillance circulatoire majeure est, de plus, accompagnée d'une diminution de la contractilité cardiaque (voir paragraphe suivant), mécanisme contribuant à amplifier l'hypotension qui devient alors irréversible.

Par ailleurs, il a été mis en évidence que NO est un facteur anti-angiogénique. L'angiogenèse est un processus qui met en jeu plusieurs étapes (migration, prolifération, différenciation des cellules endothéliales et musculaires lisses) ; il est impliqué dans des mécanismes fondamentaux tels que le développement des hypertrophies cardiaque et musculaire, ainsi que dans celui des tumeurs solides. Cette action anti-angiogénique du NO est à rapprocher de ses effets antiprolifératif et cytotoxique (voir $\$ 3.5$ ).

NO produit par l'endothélium apparaît donc, dans les conditions physiologiques, comme un facteur majeur de la régulation de la pression sanguine. Ce mécanisme de régulation est altéré dans certaines pathologies comme l'athérosclérose et certains types d'inflammation. Au niveau vasculaire, NO participe en outre (avec la prostacycline) à l'inhibition de l'agrégation plaquettaire, ainsi qu'à l'inhibition de l'adhésivité des leucocytes à la paroi vasculaire. L'action conjuguée du PAF, de différentes cytokines et l'expression, au niveau des cellules endothéliales, de facteurs 
chémotactiques et d'adhésion conduisent à l'activation des leucocytes. Les leucocytes activés libèrent des enzymes protéolytiques, $\mathrm{O}^{\bullet-}$, ainsi que divers radicaux libres. La genèse de ces espèces radicalaires participe à la défense de l'organisme contre "le non-soi" mais pourrait être aussi, en partie, responsable des altérations tissulaires observées au niveau de différents organes lors d'épisodes d'isché$\mathrm{mie} /$ reperfusion.

\section{Conclusions et perspectives}

Ainsi, compte tenu des rôles fondamentaux joués au niveau vasculaire par NO, la possibilité d'agir sur sa synthèse ou son lieu de production (d'une façon aiguë ou chronique) est un objectif d'une importance majeure. L'utilisation de donneurs de NO (considérés comme libérant $\mathrm{NO}$ au niveau des cellules musculaires lisses, mais aussi endothéliales) est réalisée depuis plus d'un siècle. Néanmoins, une intervention plus fine est souhaitable. Aussi des interventions permettant d'agir spécifiquement sur un type de NO synthase, alliées à l'inhalation de NO (voir § 3.6) et/ ou à des techniques de thérapie génique (les cellules endothéliales sont un matériel de choix pour ce type d'intervention), sont-elles en cours d'élaboration.

\subsubsection{NO et le muscle cardiaque}

La structure fractale du réseau vasculaire coronaire et la présence de l'endocarde font que NO produit par ces endothéliums peut facilement agir au niveau de la cellule myocardique (fig. 3.22). En outre, cette cellule, qui possède une NOS inductible et une NOS constitutive, est capable de synthétiser de grandes quantités de NO, et de le dégrader avec une vitesse cent fois plus grande que celle mesurée dans les vaisseaux.

Le NO diffusant à partir des cellules de l'endocarde, des cellules des vaisseaux coronaires et celui synthétisé au niveau de la cellule myocardique elle-même réduisent l'activité contractile du muscle cardiaque. Cette action inotrope négative de NO a pour cause, d'une part, une moindre production d'énergie et, d'autre part, une inhibition du courant calcique de type L. Le monoxyde d'azote inhibe directement la production d'énergie par son action sur différentes enzymes mitochondriales, en particulier, en entrant en compétition avec l'oxygène au niveau de la cytochrome oxydase. En revanche, NO inhibe le courant calcique de type L via la production de GMPc par un mécanisme analogue à celui décrit au niveau de la cellule musculaire lisse vasculaire.

L'endotoxémie, ou l'exposition aux cytokines inflammatoires, induit au niveau de tous les types cellulaires une production importante de NO via l'activation de NOS inductibles indépendantes du calcium. Cette forte production de NO conduit à une importante réduction de l'activité contractile du myocarde qui peut, dans certains cas, conduire à la défaillance cardiaque. Ainsi, il est probable qu'une surproduction de NO pourrait être impliquée dans différentes situations pathophysiologiques comme les myocardites d'origine variée et le rejet de greffes. 


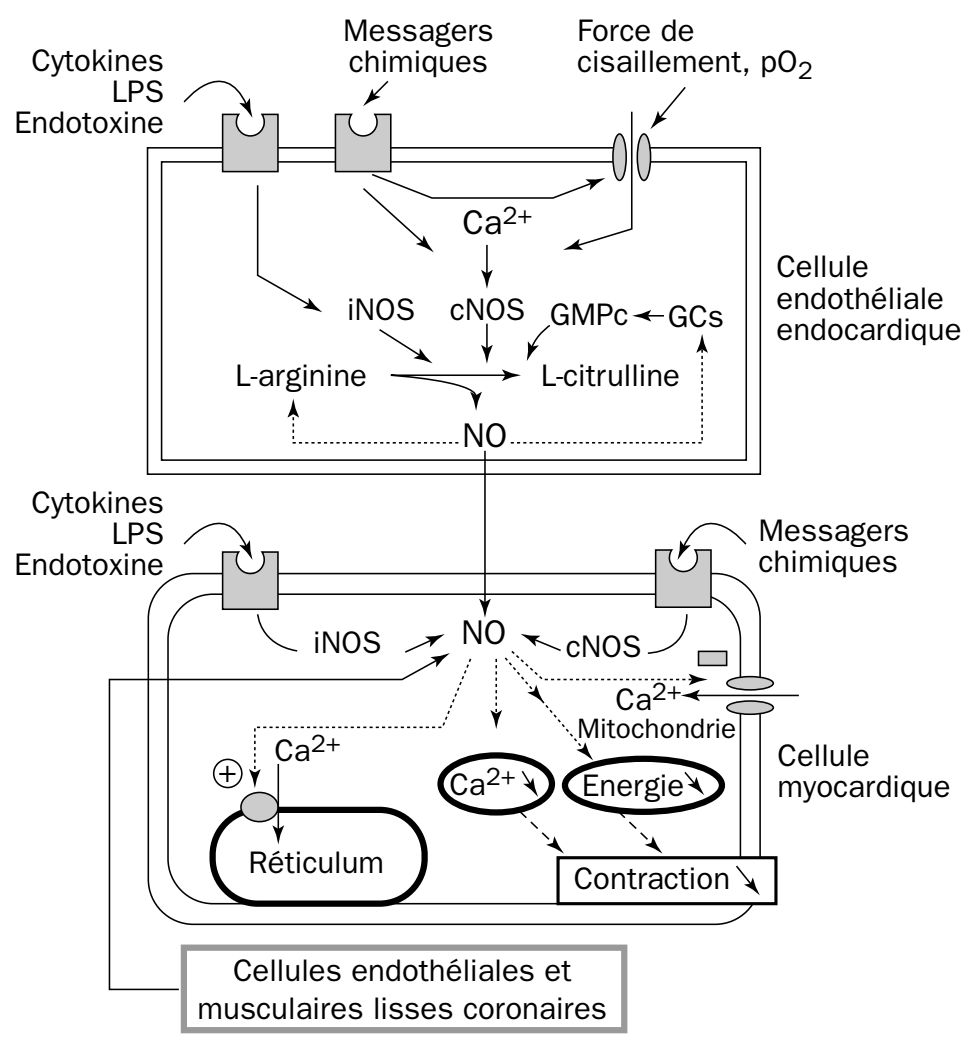

Figure 3.22 - NO et le cœur

Le NO diffusant ou produit par la cellule myocardique elle-même génère une diminution de la production d'énergie, la synthèse de GMPc et une réduction de l'activité contractile du myocarde. Cette diminution de l'activité contractile du myocarde rétroagit négativement sur les facteurs physico-chimiques qui ont pu conduire à la synthèse de NO (la diminution de $\mathrm{pO}_{2}$ agit probablement par réduction de la production d'ATP, ce qui provoque une augmentation du $\mathrm{Ca}^{2+}$ cytoplasmique, ainsi que par une action directe sur la eNOS). Lorsque la réduction de l'activité contractile du myocarde est trop importante, elle peut conduire à la défaillance cardiaque.

\section{Conclusion et perspectives}

NO joue donc un rôle fondamental au niveau de la physiologie cardio-vasculaire. Toutefois, un grand nombre de questions restent à élucider. En particulier, les mécanismes intimes du fonctionnement des différents types de NOS, de même que la connaissance de leurs localisations et de leurs régulations devront être approfondis. Une autre question reste posée, celle d'une synergie possible entre NO et les autres facteurs actifs sur le tonus vasculaire ou myocardique (prostaglandines, acide arachidonique, hormones, autres facteurs libérés par l'endothélium). Ainsi, la compréhension de l'implication de NO dans la physiologie et la pathophysiologie cardiaques ne fait que débuter et la réponse à ces questions devrait nous permettre de mieux utiliser la production de NO à des fins thérapeutiques. 


\subsection{NO ET LE SYSTÈME NERVEUX}

Depuis la mise en évidence du rôle de NO comme agent dérivé de l'endothélium capable d'induire une vaso-dilatation, un grand nombre de données ont permis de démontrer que NO était impliqué, à différents niveaux, dans le fonctionnement du système nerveux.

Ces découvertes ont bouleversé la notion de communication synaptique. En effet, jusqu'alors, la communication au niveau des synapses chimiques était conçue comme résultant de la libération par les cellules nerveuses pré-synaptiques d'une substance nommée neuromédiateur qui, se fixant sur des récepteurs métabotropiques (dont l'activation conduit à la synthèse de seconds messagers) ou canal ionique situés sur la membrane post-synaptique, induirait des modifications du métabolisme et/ou des perméabilités ioniques membranaires. Ainsi, dans le cas des cellules excitables, la fixation du neuromédiateur est responsable de variations locales de potentiel : les potentiels post-synaptiques inhibiteur (PPSI) ou excitateur (PPSE). Le PPSE, lorsqu'il atteint un niveau de dépolarisation suffisant, génère l'ouverture des canaux sodiques sensibles au voltage et donne naissance à un potentiel d'action propagé.

\subsubsection{NO et le système nerveux central}

C'est en 1988 que J. Garthwaite a montré que la stimulation de neurones en culture par un acide aminé excitateur, le glutamate, induisait la libération d'une substance labile capable de provoquer la relaxation de cellules musculaires lisses. Puis, il a été mis en évidence que cette stimulation générait une forte synthèse de GMPc. Enfin, la présence au niveau des neurones d'une NOS constitutive (nNOS ou bNOS) a été démontrée (depuis elle a été purifiée, son $\mathrm{ADN}$ a été cloné et séquencé). L'ensemble de ces données suggérait que NO pouvait jouer un rôle au niveau du système nerveux.

Les études électrophysiologiques réalisées sur des neurones en culture ou des coupes de cerveau, alliées à l'utilisation de donneurs et/ou d'inhibiteurs de la synthèse de NO, ainsi qu'à celle du 8-Br-cGMP (analogue de GMPc capable de traverser la membrane cellulaire), ont permis de montrer que NO pouvait stimuler ou inhiber l'activité de certains neurones. NO peut agir soit directement, soit via le GMPc - ou encore par l'intermédiaire des PKG activées - sur l'activité de certains canaux ioniques, en particulier les canaux potassiques sensibles au calcium ou ceux sensibles à l'ATP. Par ailleurs, il a été mis en évidence que NO peut moduler la libération d'hormones par le complexe hypothalamo-hypophysaire. Toutefois, le rôle physiologique exact joué par NO dans ces processus (comme dans beaucoup d'autres) reste largement inconnu.

Les premiers travaux portant sur le système nerveux et NO, s'ils ont été largement contestés, voire remis en question, ont eu le mérite d'ouvrir la voie à toute une série de recherches portant sur le rôle de NO dans la plasticité du système nerveux central. 
La plasticité du système nerveux résulte de la capacité de connexions synaptiques à devenir sélectives d'une façon durable - potentialisation à long terme (LTP) - ou, au contraire, à être bloquées (ou devenir labiles ?), en réponse à un stimulus externe - dépression à long terme (LTD) - . Ce phénomène qui est présent dans de nombreuses structures nerveuses (hippocampe, cortex, cervelet) a suscité beaucoup d'intérêt car il pourrait être impliqué dans les phénomènes d'apprentissage et de mémorisation. Le phénomène le plus étudié de plasticité du système nerveux central est la potentialisation à long terme qui a été bien observée aux niveaux des synapses glutaminergiques excitatrices de l'hippocampe CA1. Il peut être mesuré comme une augmentation différée ( $1 \mathrm{~h}$ à $3 \mathrm{~h}$ ) de l'amplitude et de la vitesse d'établissement du PPSE après un train de stimulations. L'utilisation des inhibiteurs des NOS et des donneurs de NO a confirmé la participation (partielle ?) de NO dans le phénomène de LTP. Le mécanisme hypothétique proposé est schématisé dans la figure 3.23.

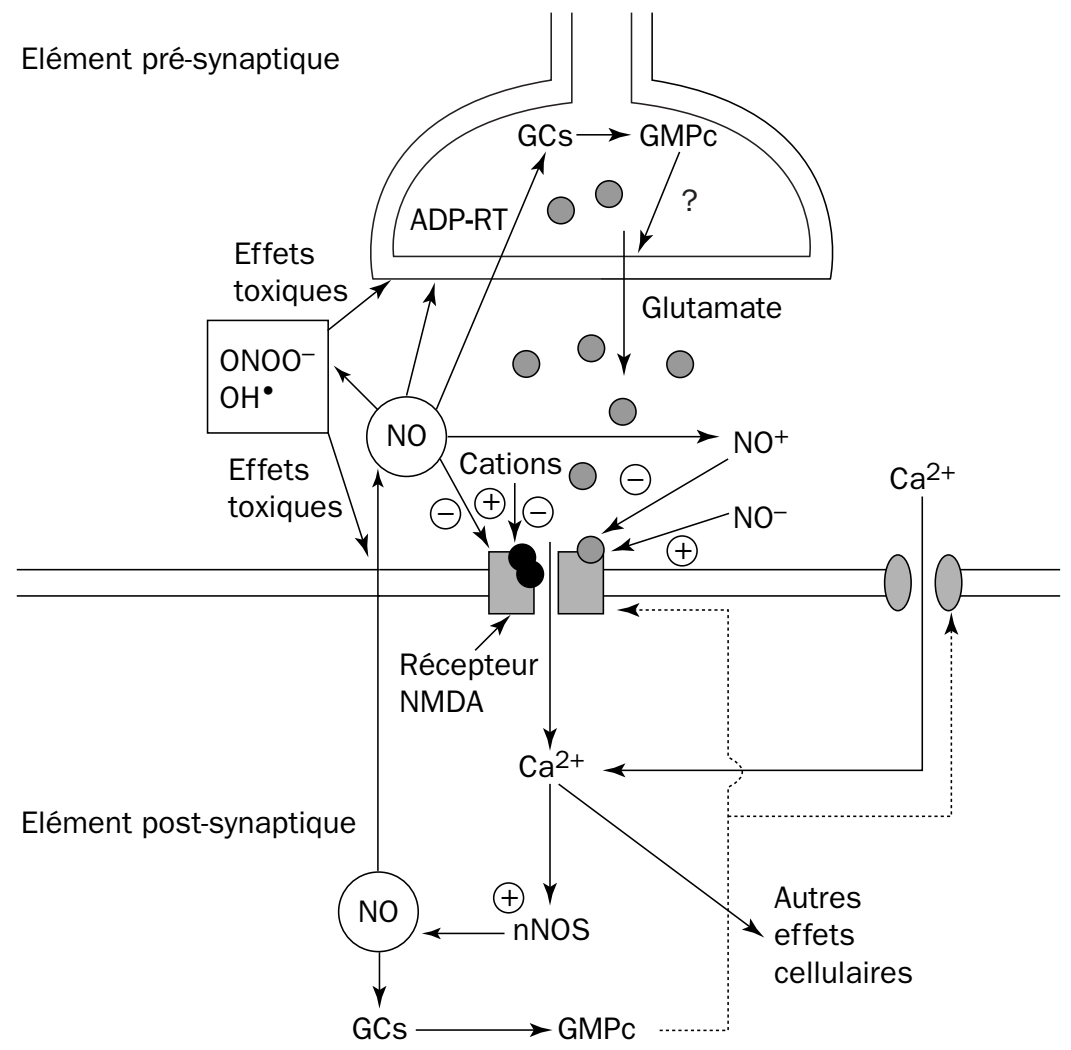

Figure 3.23 - Représentation schématique du rôle hypothétique de NO au niveau de la transmission synaptique glutaminergique

ADP-RT : ADP-ribosyltransférase ; GCs : guanylate cyclase soluble ; NMDA : N-méthyl-Daspartate ; nNOS : NOS neuronale.

Une libération importante de glutamate est nécessaire pour la stimulation des récepteurs NMDA (N-méthyl-D-aspartate). L'entrée de calcium consécutive à cette 
stimulation stimule à son tour la NOS neuronale. Le NO libéré pourrait alors rétroagir pour modifier, à long terme, la capacité de production et/ou de libération de neuromédiateur. Ce mécanisme impliquerait pour partie la synthèse de GMPc et/ou une action de NO sur une ADP-ribosyltransférase mais une action directe de NO n'est pas à exclure. D'autre part le NO produit au niveau de l'élément post-synaptique intervient pour moduler le fonctionnement des récepteurs NMDA et des récepteurs AMPA ( $\alpha$-amino-3-hydroxy-5-methyl-4-isoazolepronic acid) de cet élément postsynaptique. Cette modulation pourrait s'exercer par un effet allostérique des formes ioniques $\left(\mathrm{NO}^{-}, \mathrm{NO}^{+}\right)$de $\mathrm{NO}$ et/ou par une action, variable en fonction du voltage, sur l'inhibition exercée, à ce niveau, par les cations bivalents.

Les mêmes mécanismes (variations dans l'intensité et/ou mise en jeu préférentielle d'un mécanisme particulier) peuvent être évoqués pour expliquer la dépression synaptique à long terme (LTD) observée au niveau du cervelet. Dans ce cas, cette plasticité synaptique pourrait sous-tendre les apprentissages moteurs cérébelleux. Cependant, il est à noter que d'autres mécanismes ont été proposés en particulier la mise en jeu des récepteurs métabotropiques (Glu 1 et Glu 5) au glutamate semble participer à ces processus de LTP et LTD sans implication de NO.

Par ailleurs, l'administration à des rats d'inhibiteurs des NOS induit une perte des capacités de mémorisation spatiale, ainsi qu'une altération du comportement. Des études récentes ont montré que des souris mâles transgéniques déficitaires en nNOS présentent des comportements agressif et sexuel inappropriés et exacerbés. Le NO joue aussi, lors du développement embryonnaire, un rôle déterminant dans la mise en place des connexions synaptiques et exerce des effets protecteurs ou délétères lors de l'ischémie et la reperfusion de l'encéphale. Les neurones contenant une quantité importante de NOS sont les plus résistants aux altérations provoquées par des fortes doses de glutamate ou par l'ischémie, et ne dégénèrent pas lors de pathologie du système nerveux telles que la maladie de Huntington ou d'Alzheimer. Toutefois, l'interprétation de ces résultats reste délicate car on trouve, dans ces neurones, parallèlement à la présence de NOS, une quantité importante d'enzymes qui peuvent réduire la teneur et la production de radicaux libres, donc exercer un effet protecteur.

Les neurones ne sont pas les seules cellules du système nerveux central à posséder des NOS. En effet, des NOS inductibles ont été détectées dans les astrocytes et les cellules de la microglie. Le rôle physiologique de ces iNOS indépendantes du calcium est peu connu. Il semble que les astrocytes qui présentent beaucoup de similitudes avec les macrophages pourraient jouer un rôle dans le mécanisme de défense du système nerveux.

\subsubsection{Neurotoxicité de NO}

A côté des effets bénéfiques de faibles quantités de NO, une surproduction de $\mathrm{NO}$ a des effets délétères. Ces effets toxiques ont été aussi bien observés sur des modèles expérimentaux in vitro qu' in vivo. Ainsi, in vivo, les inhibiteurs des NOS et des 
antagonistes des récepteurs NMDA protègent-ils contre les destructions neuronales générées par des épisodes d'ischémie/reperfusion. D'autre part, in vivo, une forte induction, par différents types de virus, des iNOS neuronales provoque une importante destruction des neurones. NO pourrait être impliqué dans différentes pathologies neurodénégératives. Cette opinion est essentiellement fondée sur l'observation in vitro d'une forte induction des NOS par les protéines $\beta$-amyloïdes 25-35 caractéristiques de la maladie d'Alzheimer.

\section{Conclusions et perspectives}

Ainsi, au niveau de l'encéphale, les deux faces de NO bénéfique/toxique apparaissent-elles clairement. Lorsque NO est produit en faible quantité, il exerce un effet positif sur le transfert synaptique de l'information et probablement sur l'apprentissage, voire sur la protection neuronale. En revanche, lorsqu'il est produit en forte quantité, il devient un "cytotueur" agissant sans discrimination. Une meilleure connaissance du rôle de NO et de ses sites de production devrait nous aider à comprendre le fonctionnement physiologique et cognitif du cerveau, mais devrait aussi faire émerger de nouveaux types de psychotropes utilisables comme agents thérapeutiques et/ou neuroprotecteurs.

\subsubsection{NO et le système nerveux périphérique}

L'existence d'une neurotransmission non-adrénergique et non-cholinergique (NANC) a été, pendant de nombreuses années, un sujet de controverse. Cependant, de même que les multiples rôles physiologiques de NO sont bien établis, l'existence, au niveau du système nerveux périphérique, d'une transmission de type NANC mettant en jeu NO est maintenant largement admise. La démonstration de ce type de transmission synaptique, où NO est le médiateur de l'information ${ }^{1}$, est essentiellement fondée sur la détermination immuno-histochimique de la présence de nNOS dans certains neurones périphériques et sur l'utilisation de donneurs de NO et d'inhibiteurs de NO synthases, ainsi que sur la constatation que les souris transgéniques déficitaires en nNOS présentent une dilatation stomachale importante. Ce type de transmission NAC mettant en jeu NO a été observée au niveau des tractus gastro-intestinal et urogénital, ainsi qu' au niveau de certains vaisseaux. Toutefois, on ne peut pas exclure l'existence d'autres médiateurs que NO dans la transmission synaptique de type NANC (CO ?), neuromédiateurs qui pourraient agir en synergie avec les neurones libérant NO, de même qu'avec les neuromédiateurs classiques (fig. 3.24). Au niveau des différents types de muscles lisses innervés par des neurones à NO (ou neurones nitrinergiques), les mécanismes générés par NO conduisant à une relaxation ne sont pas différents de ceux décrits au niveau de la cellule musculaire vasculaire pour le NO produit par les cellules endothéliales (voir fig. 3.20).

1 Le rôle de NO comme neuromédiateur remet en cause la notion classique de neuromédiateur activant un récepteur membranaire post-synaptique. 


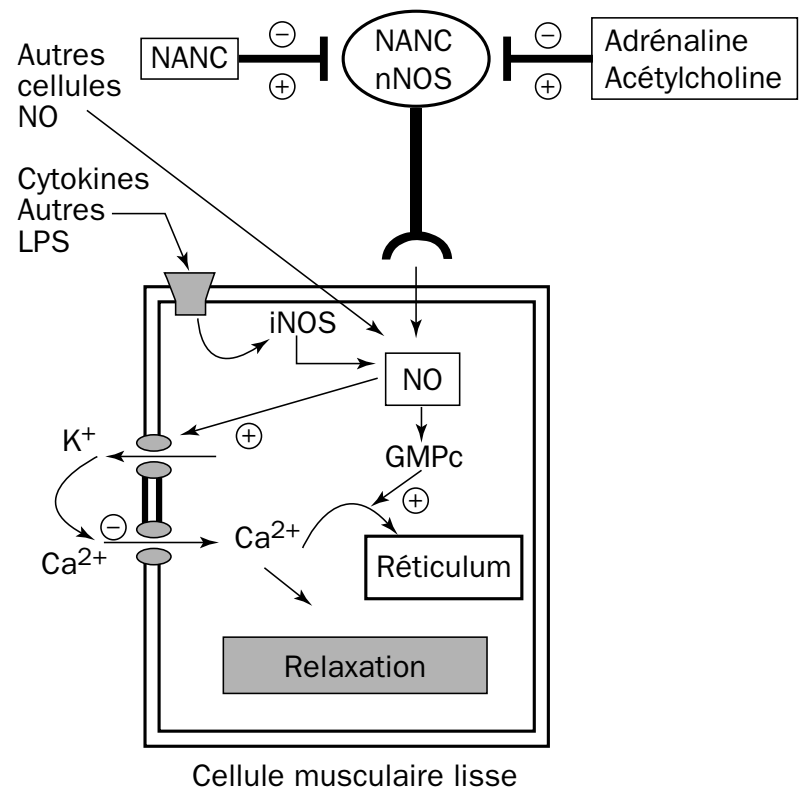

Figure 3.24 - Représentation schématique d'une neurotransmission NANC mettant en jeu NO (transmission nitrinergique)

Les neurones NANC (non-adrénergiques et non-cholinergiques), qui contiennent une nNOS (neurones nitrinergiques), libèrent NO qui diffuse et agit sur une guanylate cyclase soluble pour induire la production de GMPc qui active une ou plusieurs PKG. L'ensemble des actions directes ou non de NO et du GMPc conduit à une réduction de la teneur en calcium libre cytoplasmique, responsable de la relaxation de la cellule musculaire lisse (pour plus de détails, voir la figure 3.20). Il est possible que des neurones de type NANC ne produisant pas NO, de même que des neurones à neuromédiateurs "classiques" (par exemple les neurones à acétylcholine), puissent moduler l'activité des neurones NANC produisant NO. Par ailleurs, NO peut être produit par d'autres cellules possédant des NOS, ainsi que par la cellule musculaire lisse elle-même, qui possède une NOS inductible.

D'un point de vue physiologique, on considère que ces types de neurones à NO sont impliqués dans la régulation du tonus musculaire lisse, en particulier des sphincters. Ces neurones participent aussi au fonctionnement physiologique de l'estomac (régulation de l'irrigation sanguine et production d' $\mathrm{HCl}$ ), ainsi qu'à celui du corps caverneux pénien. L'absence d'une production suffisante de NO pourrait être à l'origine des spasmes pyloriques observés chez l'enfant et de certains types d'impuissance. Dans ce dernier cas, on peut utiliser des donneurs locaux de NO (pommade) ou des inhibiteurs spécifiques (Viagra ${ }^{\circledR}$ ) de l'enzyme de dégradation du GMPc en GMP.

\subsection{NO - AUTRES EFFETS CYTOTOXIQUES}

Nous avons évoqué dans un paragraphe précédent l'action neurotoxique de NO lorsque celui-ci est produit en grande quantité. Ce n'est pas toujours le cas, dans certaines situations une forte production de NO peut être bénéfique. L'utilisation de donneurs de NO, d'inhibiteurs des NOS et d'animaux modifiés génétiquement ne 
possédant pas de NOS inductible a permis de montrer, essentiellement au niveau des macrophages, le rôle bénéfique d'une forte production de NO.

\subsubsection{NO et les macrophages}

Les macrophages contiennent une NOS inductible. La transcription du gène de cette iNOS est contrôlée par une grande variété de messagers chimiques appelés cytokines, ainsi que par le lipopolysaccharide qui est un des constituants de la paroi des bactéries gram-négatives. Les inducteurs les plus importants sont l'interféron $\gamma$, le tumor necrosing factor (TNF), les interleukines 1 et 2 . Le TNF (et peut-être d'autres cytokines) semble agir en synergie avec l'interféron $\gamma$. Le transforming growth factor $\beta$ (TGF $\beta$ ), les interleukines 4 et 10 sont des inhibiteurs de la production de NO par les macrophages. Il faut cependant noter que les mécanismes intimes des régulations exercées par ces cytokines sont mal connus, de même que les effets d'une rétroaction de NO sur les facteurs contrôlant sa production et sur les macrophages eux-mêmes (voir fig. 3.25). Le NO produit par les macrophages activés diffuse dans les tissus voisins où il peut agir directement sur les métallo-enzymes ou via la production de peroxynitrite et de radicaux $\left[\mathrm{OH}^{*}\right]$ (voir $\S 3.1$ ). Parmi les enzymes dont le fonctionnement est modifié et qui pourraient être impliquées dans les effets cytotoxiques de NO, figurent des enzymes du métabolisme énergétique de l'ADN. Ainsi, NO produit par les macrophages agirait sur l'aconitase mitochondriale, une enzyme clé du cycle de Krebs, enzyme qui pourrait être connue, au niveau cytoplasmique, sous un autre nom "l'iron regulatory factor" (un modulateur post-transcriptionnel de gènes impliqués dans le métabolisme du fer), ainsi que sur d'autres enzymes mitochondriales, la glycéraldéhyde-3-phosphate déshydrogénase (enzyme de la glycolyse) et la ribonucléotide réductase (enzyme qui convertit les ribonucléotides en désoxyribonucléotides utilisés dans la synthèse de l'ADN). De plus, NO déplète la teneur intracellulaire en glutathion, augmentant ainsi la susceptibilité au stress oxydatif. Il est probable que, suivant le type cellulaire, l'intensité du métabolisme énergétique et son type (glycolytique/lipolytique), l'action de NO sera plus ou moins intense et pourra conduire à une gamme d'effets allant de l'inactivation à la destruction cellulaire, en passant par des effets mutagènes. Finalement, de l'ensemble des données obtenues in vitro et in vivo, on peut considérer que $\mathrm{NO}$ peut avoir une action antiproliférative et qu'il peut être un nouveau médiateur de la réponse immunitaire non-spécifique (fig. 3.25). Cette opinion est fondée sur un certain nombre d'expériences réalisées in vivo et in vitro, qui ont permis de mettre en évidence les capacités antihelminthe, antibactérienne (Listeria, Fularemia, Salmonella, Mycobacterium), antivirale (Herpes, Vaccinia, Ectromelia), antifongique (Candida albicans, Cryptococcus), antiparasitaire (Leishmania, Plasmodium, Toxoplasma, Trypanasoma, Shistosoma). Néanmoins, là encore, les deux facettes de NO se manifestent. En effet, à côté de ses effets bénéfiques, il est probable qu'une production incontrôlée de NO pourrait être à l'origine de phénomènes d'auto-immunité (les macrophages activés sont cytotoxiques pour les cellules $\beta$ du pancréas) et d'immunosuppression par destruction des lymphocytes $\mathrm{T}$. 


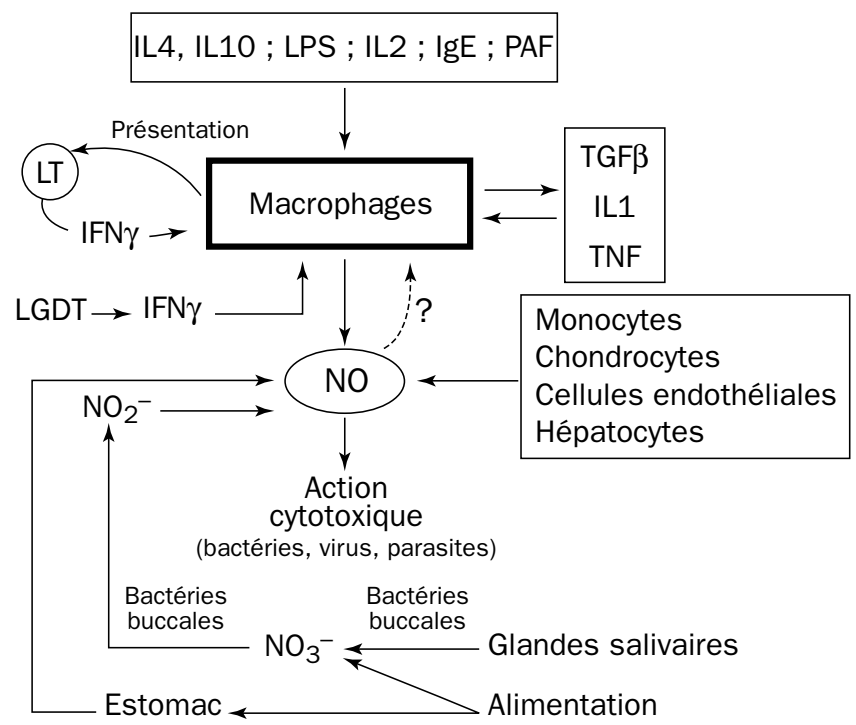

Figure 3.25 - Représentation schématique des différents types cellulaires impliqués dans une production cytotoxique de NO

IgE : immunoglobuline $E$; IFN $\gamma$ : interféron $\gamma ; \operatorname{IL1}, 2,4,10$ : interleukines 1, 2, 4, 10 ; $L T$ : lymphocyte $T$; PAF : platelet activating factor ; TGF $\beta$ : transforming growth factor $\beta$; TNF : tumor necrosing factor.

\subsubsection{Autres types cellulaires et cytotoxicité de NO}

Comme le montre la figure 3.25, d'autres types cellulaires peuvent produire du NO impliqué dans les mécanismes de défense de l'organisme. C'est le cas des monocytes activés par les immunoglobulines $\mathrm{E}$, des cellules endothéliales qui, in vitro, ont révélé un pouvoir antitumoral et des hépatocytes qui, in vitro, ont montré leur capacité de produire NO après activation par des cytokines.

En outre, il a été récemment montré que les nitrates contenus dans la salive (les glandes salivaires sont impliquées dans le métabolisme des nitrates ; leur teneur en nitrates est cent fois plus grande que celle du plasma) sont dégradés en nitrite par des bactéries de la surface de la langue. Ces nitrites, lorsqu'ils sont acidifiés par d'autres bactéries buccales, ou après ingestion dans l'estomac (il en serait de même des nitrites et nitrates ingérés), pourraient générer du NO. Ce NO serait alors susceptible d'exercer une action antiproliférative pour les bactéries et champignons ingérés comme certaines bactéries buccales ou Helicobacter pylori (facteur associé dans près de $90 \%$ des cas à l'ulcère gastrique). Ainsi, ce mode de production de NO serait un nouveau type de symbiose entre les bactéries et les Mammifères, symbiose dévolue à transformer les nitrates salivaires en nitrites et finalement en NO jouant un rôle protecteur.

Enfin, il a été rapporté une production excessive de NO dans les cas de colite ulcéreuse, de psoriasis, d'arthrite, de rejet du greffon, de certains types d'inflammation, de lupus érythémateux et de choc (voir § 3.3). Dans ces pathologies, les sources potentielles de NO peuvent être multiples, les cellules endothéliales, les 
cellules musculaires lisses vasculaires, les macrophages, les hépatocytes, les chondrocytes étant les principaux types cellulaires impliqués.

\section{Conclusions et perspectives}

La production de NO au niveau des macrophages, ainsi que son implication dans la réponse immunitaire non-spécifique, sont clairement démontrées et ouvrent la voie à de nouvelles recherches. Les inhibiteurs des NOS synthases deviendront probablement des agents importants dans le traitement des hypotensions induites par le choc septique, ou chez les cancéreux traités à l'aide de différents types de cytokines (interleukines 1 et 2 ; TNF). Il faut cependant noter qu'actuellement, des réserves sont formulées quant à leur utilisation (à cause des effets secondaires cardiaques et rénaux de ces inhibiteurs). Si les premiers travaux concernant un rôle de NO dans la régulation de l'expression génique et la mise en évidence des capacités mutagéniques de NO sont confirmés, c'est une nouvelle page qui s'ouvre dans notre connaissance de NO.

\subsection{NO ET LE SYSTÈME RESPIRATOIRE}

L'utilisation d'inhibiteurs de la synthèse de NO, la mise en évidence de NOS synthase au niveau de l'épithélium pulmonaire, les mesures de NO dans l'air expiré (en particulier la détection d'une production pulmonaire de NO et d'une surproduction dans certaines pathologies comme l'asthme) conduisent à penser que NO pourrait être un médiateur physiologique responsable d'une dilatation des bronches et des vaisseaux pulmonaires.

Chez l'homme et l'animal, l'inhalation de faibles doses de $\mathrm{NO}(<80 \mathrm{ppm})$ augmente les capacités respiratoires, la teneur en oxygène du sang et réverse la vaso-constriction observée lors d'hypoxie ou d'hypertension pulmonaire. Ces effets ne sont pas accompagnés d'hypotension systémique (NO est rapidement inactivé par l'hémoglobine). Dans toutes ces situations, NO semble agir par induction d'une dilatation des artérioles pulmonaires au niveau de segments pulmonaires dilatés donc mieux ventilés.

\section{Conclusions et perspectives}

Bien que l'inhalation de NO ait été présentée comme le traitement magique de certaines pathologies pulmonaires telles que l'hypertension pulmonaire (et par certains probablement comme une forme sans danger de dopage), elle doit être considérée, actuellement, comme une forme expérimentale de thérapie. Thérapie qui ne devrait être utilisée qu'avec précautions et dans le cadre de protocoles d'utilisation établis entre plusieurs équipes. En effet, l'inhalation de NO n'est certainement pas inoffensive. Les dangers potentiels peuvent résulter de l'interaction de $\mathrm{NO}$ avec $\mathrm{O}_{2}$ et $\mathrm{O}_{2}{ }^{-}$(voir $§ 3.1$ ) et de la probable potentialité mutagénique des dérivés oxygénés de l'azote (suspectés d'être générateurs des cancers pulmonaires provoqués par la fumée de cigarettes). 


\subsection{NO ET LE MUSCLE SQUELETTIQUE}

La mise en évidence, au niveau du muscle squelettique, d'une NO synthase de type neural ne date que de 1994. Cette forme de NOS, sensible au calcium, qui est plus abondante au niveau des fibres rapides (type II) est localisée au niveau du sarcolemme. Le rôle physiologique de NO produit à ce niveau est largement méconnu. Il est possible que le GMPc synthétisé sous l'action de NO, en particulier durant la contraction par activation de la NOS due à l'augmentation de calcium, puisse exercer une action inhibitrice sur la contraction. En revanche, les dérivés provenant de réactions de S-nitrosylation pourraient induire une libération de calcium par le réticulum et ainsi favoriser la contraction. Des travaux récents montrant une liaison de la NOS du sarcolemme avec le complexe protéique associé à la distrophine, de même que la diminution, chez les souris $m d x$ ou chez des patients atteints de myopathie de Duchesne, de la teneur sarcolemmique en NOS, suggèrent qu'une réduction de la production de NO serait, en partie, impliquée dans ce type de pathologie.

\section{Conclusions et perspectives}

L'implication de NO dans la physiologie musculaire n'avait, jusqu'alors, été montrée qu' au niveau de la synapse neuromusculaire. Une nouvelle ère de recherches s'ouvre avec ces premiers résultats. Ces recherches devraient permettre d'établir rapidement des corrélations entre certaines formes de myopathies congénitales présentant des lésions des tissus nerveux et musculaire.

\subsection{NO ET DIABÈTE}

Une cNOS ainsi qu'une iNOS ont été mises en évidence au niveau des cellules $\beta$ du pancréas. Une série de travaux convergents réalisés in vitro et in vivo - en particulier l'observation et la stimulation de la libération d'insuline par la L-arginine et son inhibition par des analogues non-métabolisables de celle-ci - conduisent à penser que $\mathrm{NO}$, dans les conditions physiologiques, pourrait participer à la régulation de la libération d'insuline. NO pourrait agir, entre autres modalités, via son action sur le métabolisme calcique. Il a été montré qu'une surproduction de NO par les cellules $\beta$ ou par les macrophages pourrait contribuer à l'induction du diabète de type I.

\section{Conclusions et perspectives}

Parallèlement à une meilleure compréhension du rôle de NO dans l'activité des cellules $\beta$ du pancréas, l'objectif actuel est de trouver un inhibiteur spécifique des NOS de ces cellules. Cet inhibiteur pourrait être un agent susceptible de limiter, sinon d'inhiber, la progression du nombre de malades atteints de diabète de type I. 


\subsection{NO - FUTURES DIRECTIONS}

NO, dont le rôle physiologique dans les processus de vaso-dilatation n'était que suspecté dans les années 80, est devenu, en 1992, la "Molécule de l'année" et voit sans cesse révélée son implication dans de nouveaux processus physiologiques.

Nos connaissances exactes des rôles et modes d'action de ce gaz restent néanmoins partielles. Ainsi, il est impossible de manipuler finement l'activité d'une NOS spécifique dans un type cellulaire donné. Gageons que l'intérêt thérapeutique (et financier) stimulant la recherche, ceci sera réalisé dans quelques années.

\section{LE FACTEUR ACTIVATEUR DES PLAQUETTES (PAF)}

Le facteur activateur des plaquettes (platelet activating factor ou PAF) est un phosphoglycéride. Il doit son nom au groupe de Benveniste qui, en 1972, avait étudié un médiateur produit par les basophiles, capable de stimuler le relargage d'amines vasoactives par les plaquettes. Ce n'est qu'en 1980 que la structure chimique du PAF a été clairement élucidée. Depuis, de nombreux travaux ont permis de montrer que cette molécule, impliquée dans de nombreux processus physiologiques et pathophysiologiques, est produite par une grande variété de types cellulaires où elle joue le rôle de médiateur inter- et/ou intracellulaire.

\subsection{STRUCTURE CHIMIQUE}

Le PAF est un phospholipide (1-O-alkyl-2-acétyl-sn-glycéro-3-phosphorylcholine) (fig. 3.26). Pour être actif, le PAF doit posséder un résidu O-alkyl éther de 14 à 18 atomes en position $s n-1$, un radical acyle court en position $s n-2$, la position $s n-3$ devant être occupée par un groupement polaire O-phosphorylcholine.

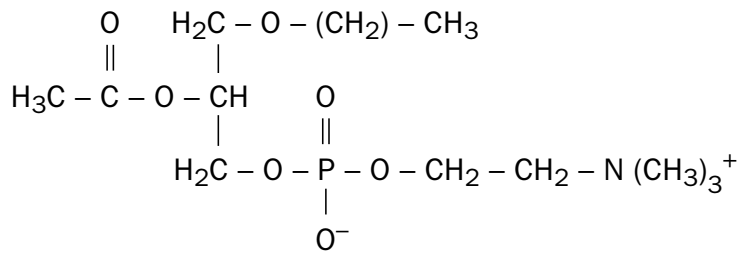

\section{Figure 3.26 - Structure chimique du PAF (platelet activating factor)}

Le PAF est un glycérophospholipide de formule 1-0-alkyl-2-acétyl-sn-glycéro-3-phosphorylcholine, où $n$ peut être égal à 15 ou 17.

Les analogues du PAF, obtenus (ou présents in vivo) par des variations de la longueur et de la saturation de la chaîne $s n-1$, peuvent être extrêmement actifs. Un grand nombre d'antagonistes spécifiques du PAF présentent des analogies structurales importantes avec le PAF. 


\subsection{MÉTABOLISME}

Deux voies métaboliques conduisent à la synthèse du PAF (fig. 3.27). L'une, la synthèse vicariante, utilise une molécule préexistante proche structuralement du PAF, molécule qui est remodelée, l'autre, la synthèse de novo, met en jeu le simple transfert d'une phosphorylcholine.

La biosynthèse de PAF a été mise en évidence au niveau des cellules endothéliales après stimulation par la bradykinine, la thrombine, l'angiotensine II (ensemble de messagers qui provoquent une augmentation du calcium libre intracellulaire). De même, le A 23187 (un calcium ionophore) induit la synthèse de PAF par les polynucléaires neutrophiles, éosinophiles, basophiles, les monocytes, les lymphocytes, les macrophages, les plaquettes, les cellules de Küpffer, les cellules rénales.

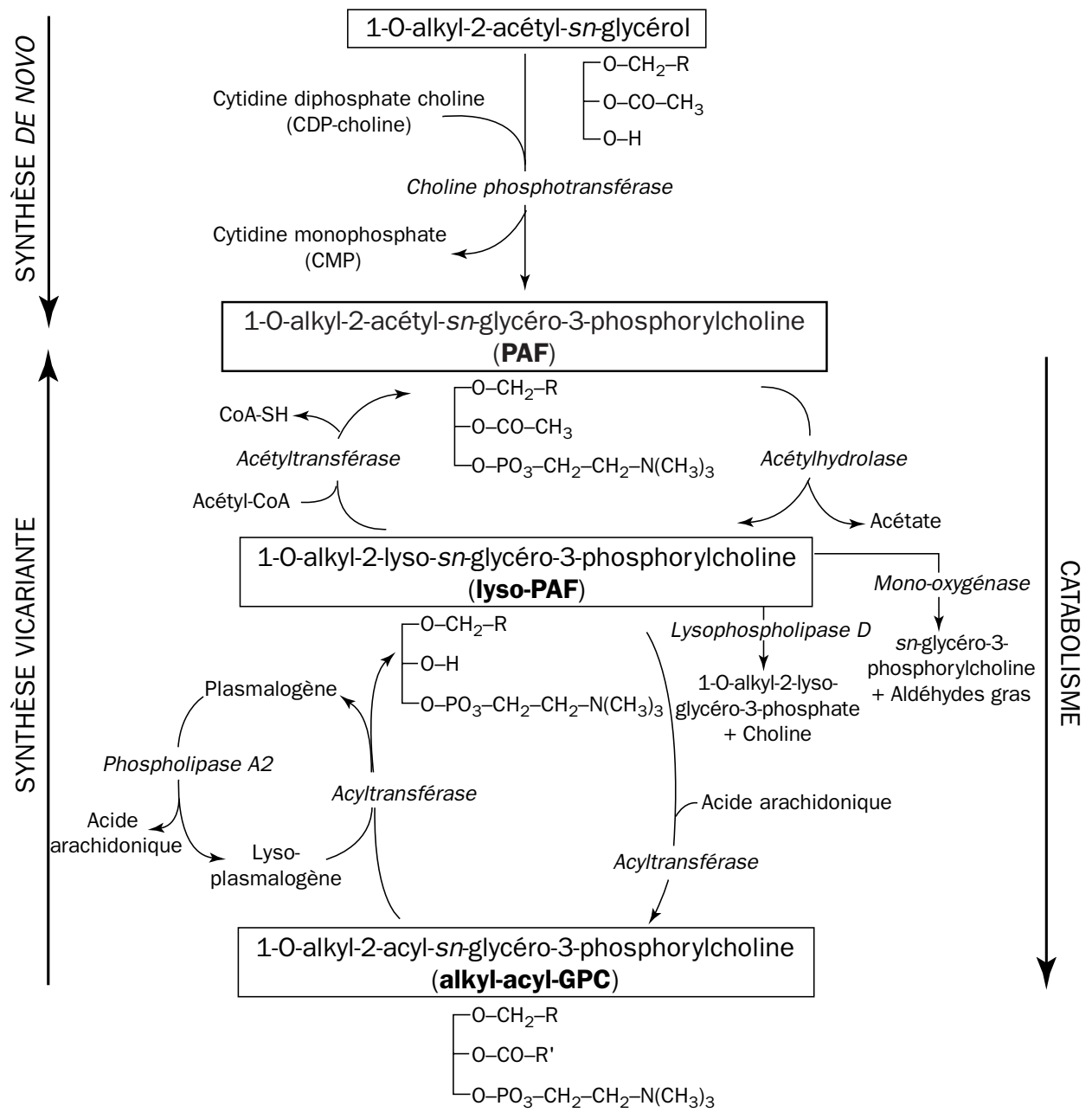

Figure 3.27 - Métabolisme du PAF

Biosynthèses et catabolisme du PAF (1-0-alkyl-2-acétyl-sn-glycéro-3-phosphorylcholine). 


\subsubsection{La synthèse vicariante}

Bien que cette synthèse ait été la première décrite, elle ne semble intervenir que dans des processus physiopathologiques (réponses allergique ou inflammatoire).

Elle implique un phospholipide, le 1-O-alkyl-2-acyl-sn-glycéro-3-phosphorylcholine qui, sous l'action d'une phospholipase A2 (activable par le calcium), conduit à la formation de 1-O-alkyl-2-lyso-sn-glycéro-3-phosphorylcholine ou lyso-PAF et d'acide arachidonique ${ }^{2}$. Ensuite, l'action d'une acyltransférase stimulée par le calcium, ainsi que par les kinases A et C, permet le transfert d'un acyl sur le lysoPAF pour donner le PAF.

\subsubsection{Synthèse de novo}

Dans cette synthèse, le transfert, sous l'action d'une choline phosphotransférase insensible au calcium, d'une phosphorylcholine à un 1-O-alkyl-2-acétyl-sn-glycérol, conduit directement à la synthèse de PAF. Il est probable que cette voie de synthèse permette une production basale de PAF qui pourrait jouer un rôle physiologique.

\subsubsection{Catabolisme}

Deux boucles successives de dégradation permettent de remonter les étapes de la synthèse vicariante. Dans la première, le PAF est catabolisé en lyso-PAF par une acétylhydrolase. Le lyso-PAF (composé toxique) peut suivre deux voies de dégradation. L'une - correspondant à la seconde boucle de la synthèse vicariante - conduit, sous l'action d'une acyltransférase inhibée par le calcium, à la réincorporation de l'acide arachidonique pour donner le 1-O-alkyl-2-acyl-sn-glycérol-3-phosphorylcholine. L'autre met en jeu une mono-oxygénase qui transforme le lyso-PAF en $s n$-glycéro-3phosphorylcholine. La première boucle d'activation/inactivation (PAF/lyso-PAF) est une plaque tournante de la biodisponibilité de ce médiateur. Cependant, il semble bien que, dans certaines conditions et dans certains types cellulaires, seule une faible partie du PAF synthétisé soit sécrétée. Ceci suggère que le PAF pourrait être à la fois un médiateur des communications inter- et intracellulaires.

\subsection{LES RÉCEPTEURS DU PAF ET LEUR ACTIVATION}

\subsubsection{Les récepteurs}

L'utilisation du [H3]-PAF a permis de montrer l'existence de récepteurs hautement spécifiques du PAF sur les membranes d'un grand nombre de types cellulaires, aussi bien chez les rongeurs que chez l'homme. Ces récepteurs, dont la densité est faible (quelques centaines par cellule) ont été observés dans les cellules nerveuses, endothéliales, musculaires lisses, les cellules de la lignée hématoḯtiques, ainsi qu'au niveau

2 L'acide arachidonique, ainsi que ses produits de dégradation sont eux-mêmes des messagers fortement actifs (voir chap. $2, \S 2.2 .7$ ). 
des tissus hépatique, rénal et pulmonaire. Ils possèdent sept domaines transmembranaires et sont couplés à des protéines G. Les récepteurs pour le PAF montrent une grande hétérogénéité d'un type cellulaire à l'autre, tant dans l'affinité vis-à-vis du PAF $\left(K_{D}\right.$ de $10^{-11}$ à $\left.10^{-5} \mathrm{M}\right)$ que dans la coexistence sur le même type cellulaire de plusieurs types de récepteurs d'affinités différentes. Il semble aussi exister des différences dans l'intensité de l'action des antagonistes du PAF et des différences dans les effets de l'activation de ces récepteurs par le PAF. Le PAF régule directement l'expression de ses récepteurs (down-regulation). Les protéine kinases $\mathrm{A}$ et $\mathrm{C}$ (lorsque cette dernière est fortement stimulée) inhibent les récepteurs pour le PAF. En revanche, la protéine kinase $C$ faiblement activée les stimule. Par ailleurs, les ions modulent la liaison PAF/R-PAF, ainsi, $\mathrm{Na}^{+}$et $\mathrm{Zn}^{2+}$ l'inhibent alors que $\mathrm{Mg}^{2+}$, $\mathrm{Ca}^{2+}, \mathrm{Mn}^{2+}$ la favorisent.

De plus, l'existence de récepteurs du PAF sur les membranes intracellulaires a été montrée dans quelques types cellulaires, corroborant ainsi l'hypothèse d'un rôle de messager intracellulaire pour le PAF.

\subsubsection{Activation des récepteurs du PAF}

L'activation des récepteurs du PAF conduit, via la mise en jeu de protéines $\mathrm{G}$, à une stimulation directe des canaux calciques, à la production de DAG et d'IP3, ainsi qu'à celle d'acide arachidonique (fig. 3.28). La production de ce dernier messager et de ses dérivés peut conduire à des actions paracrines et autocrines (voir chap. $2, \S 2.2 .7$ ).

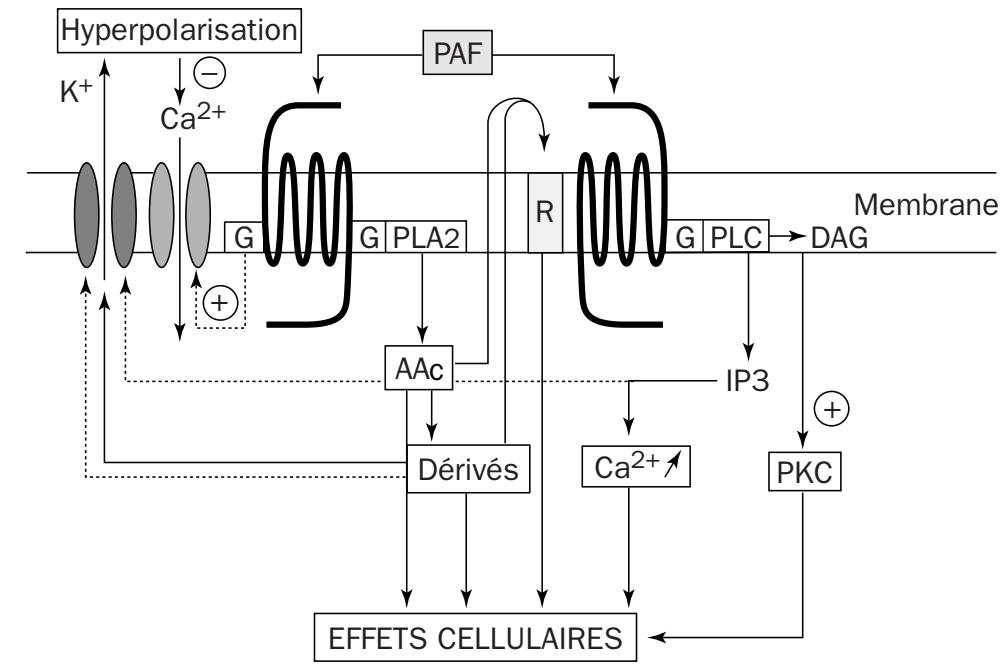

Effets immédiats : modifications des activités enzymatiques et caractéristiques des canaux ioniques Effets tardifs : modulation de l'expression génétique

Figure 3.28 - Effets de l'activation des récepteurs du PAF

$A A c$ : acide arachidonique ; DAG : diacylglycérol ; $G$ : protéine $G$; IP3 : inositol $(1,4,5)$ triphosphate ; PAF : platelet activating factor ; PKC : protéine kinase C ; PLA2 : phospholipase $A 2$; $P L C$ : phospholipase $C$; $R$ : récepteurs de l'AAC ou récepteurs de ses dérivés. 


\subsection{RôLES PHYSIOLOGIQUES}

Le PAF produit lors de situations physiologiques ou physiopathologiques est actif pour des concentrations comprises entre $10^{-12} \mathrm{M}$ et $10^{-9} \mathrm{M}$. La grande variété de ses récepteurs, ainsi que celle des seconds messagers qui découlent de leur stimulation, conduit à de multiples effets cellulaires, dont certains sont pathologiques. Le tableau 3.5 (non-exhaustif) récapitule les principaux effets biologiques du PAF.

\subsection{CONCLUSIONS ET PERSPECTIVES}

Le PAF agit via la mise en jeu de récepteurs spécifiques variés dont l'activation conduit à la synthèse de multiples seconds (troisième, quatrième) messagers. Cette grande diversité explique la diversité en qualité et en intensité des réponses biologiques initiées par le PAF. L'utilisation des techniques de la biologie moléculaire et de l'immunologie devrait permettre de mieux comprendre l'origine de l'hétérogénéité des récepteurs et, par là, devrait conduire à la synthèse d'antagonistes et/ou d'agonistes spécifiques d'un type d'action donnée. Enfin, le rôle du PAF dans les mécanismes d'adhésion (et de migration) cellulaire reste à explorer.

\section{L'ENDOTHÉLINE}

L'endothéline est essentiellement produite par l'endothélium vasculaire (fig. 3.29).

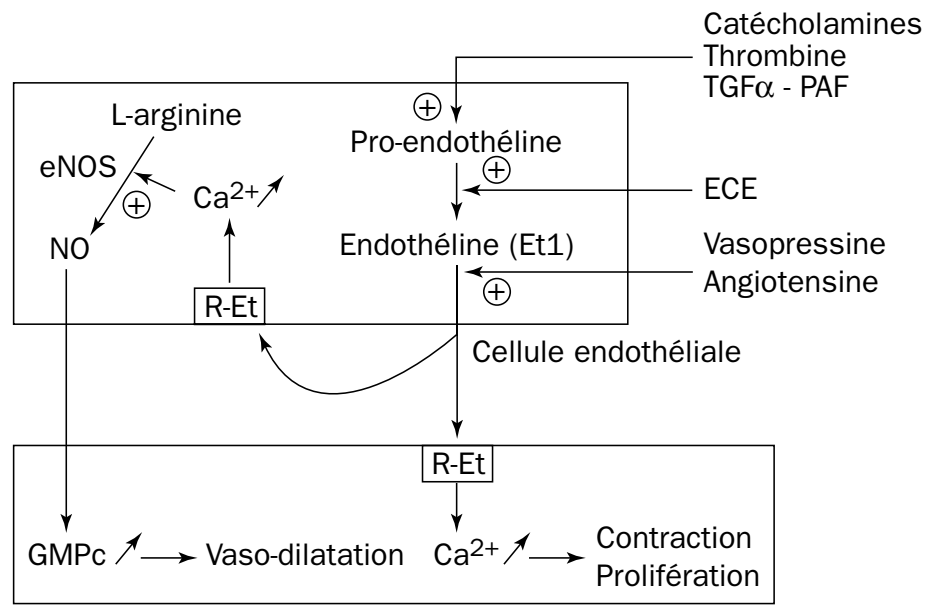

Cellule musculaire lisse

Figure 3.29 - Représentation schématique de la synthèse et de la libération d'endothéline (Et1) par l'endothélium vasculaire

ECEt: enzyme de conversion de l'endothéline; eNOS: NO synthase constitutive de l'endothélium ; PAF : platelet activating factor ; $R$-Et : récepteur à l'endothéline ; TGF $\alpha$ : transforming growth factor $\alpha$. 
Tableau 3.5 - Principaux effets biologiques du PAF

\section{Plaquettes}

- Adhésion - agrégation - formation de thrombus

- Relargage par les plaquettes d'amines vaso-actives

\section{Système cardio-vasculaire}

- Vaso-dilatation

- Hypotension - modification des résistances vasculaires périphériques

- Extravasion plasmatique

- Choc : hypotension gravissime, modification des perméabilités

- Athérogenèse

- Réduction du débit coronaire et de la force de contraction du myocarde

- Arythmie

\section{Système immunitaire}

- Chimiotactisme des polynucléaires éosinophiles et neutrophiles

- Stimulation des polynucléaires neutrophiles, éosinophiles, basophiles et des macrophages

- Production de radicaux libres

- Inflammation

- Rejet de greffes

- Manifestations allergiques - eczéma

- Anaphylaxie

- Chocs endotoxiniques

\section{Système rénal}

- Hémodynamique rénale

- Filtration glomérulaire - transport des électrolytes

- Altérations rénales

- Modulation de la production de rénine

\section{Système respiratoire}

- Broncho-constriction

- Asthme

\section{Système gastro-intestinal}

- Hypertension portale

- Stimulation de la sécrétion pancréatique

- Pancréatites

- Formation d'ulcères gastro-intestinaux

- Glycogénolyse hépatique

\section{Système reproducteur}

- Ovulation - fertilisation - nidation - grossesse - parturition

\section{Système nerveux}

- Neuromodulateur

- Potentialisation à long terme (LTP) ?

- Edème cérébral 
La masse de celui-ci $(2 \mathrm{~kg})$ et sa surface $\left(1000 \mathrm{~m}^{2}\right)$, ainsi que la grande variété de substances qu'il produit, en font une véritable glande diffuse. L'endothéline est un petit peptide de 21 AA. Il existe trois isoformes de l'endothéline appelées Et1, Et2, Et3. Seule Et1 est produite par l'endothélium et Et3 semble être impliquée dans les mécanismes de neurotransmission centrale. Ces trois isoformes codées par trois gènes différents sont produites sous forme de pré-pro-endothéline, clivée en proendothéline, puis finalement sous l'action d'une enzyme de conversion (ECEt) en endothéline. L'enzyme de conversion de l'endothéline (ECEt) a été localisée au niveau de différents organes (rein, poumons, microcirculation, système nerveux...).

Il existe deux types de récepteurs à l'endothéline (R-EtA et R-EtB). L'activation de ces récepteurs conduit à la synthèse d'inositol $(1,4,5)$ triphosphate et de diacylglycérol, et donc à la libération de calcium par le réticulum ainsi qu'à l'activation de la protéine kinase C. Les récepteurs à l'endothéline sont présents sur un grand nombre de types cellulaires (cellules endothéliales et musculaires lisses vasculaires ; cardiomyocytes, neurones).

\section{EFFETS CARDIO-VASCULAIRES DE L'ENDOTHÉLINE}

La production majeure d'endothéline est réalisée par l'endothélium, ce qui explique ses effets au niveau du système cardio-vasculaire. L'effet majeur immédiat de l'endothéline est une vaso-constriction et donc une augmentation de la pression artérielle. Cette vaso-constriction résulte de la libération de calcium au niveau des cellules musculaires lisses (fig. 3.30). Cependant, l'activation de ses récepteurs portés par les cellules endothéliales induit une vaso-dilatation temporaire. Cette vaso-dilatation est due à la stimulation de la NO synthase constitutive endothéliale, enzyme activée par le calcium. L'action de l'endothéline sur le muscle cardiaque, ainsi que sur le système nerveux central, contribue aussi à une augmentation de la pression artérielle.

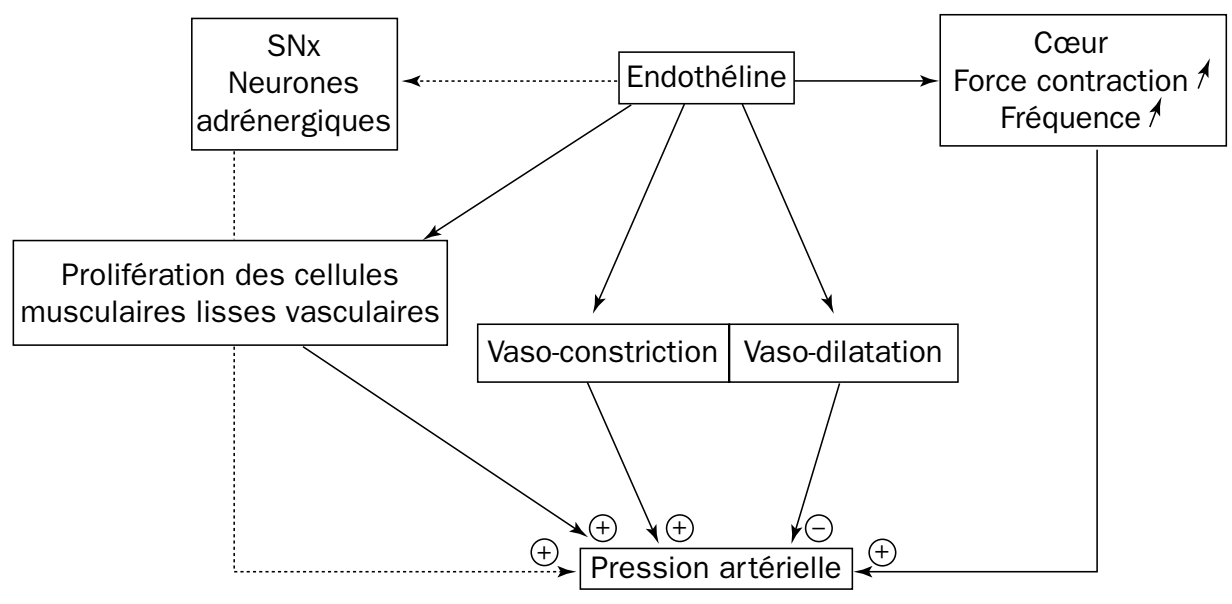

Figure 3.30 - Représentation schématique des effets de l'endothéline sur la pression artérielle 
L'utilisation d'inhibiteur des récepteurs à l'endothéline ainsi que la production d'animaux transgéniques ont permis de montrer qu'il existe une production basale d'endothéline. Cette observation, alliée à d'autres données expérimentales, laisse penser qu'un dérèglement de la production d'endothéline et/ou de la synthèse de ses récepteurs pourrait être responsable de certains types d'hypertension artérielle. Aussi, les travaux actuels s'orientent-ils vers la production d'inhibiteurs des récepteurs à l'endothéline et l'élaboration d'un vaccin anti-endothéline.

\section{L'ECDYSONE}

\subsection{ISOLEMENT DE L'ECDYSONE}

L'hormone de mue ou ecdysone (fig. 3.31) a été isolée pour la première fois par Butenandt et Karlson, en 1954. En traitant $500 \mathrm{~kg}$ de chrysalides de ver à soie (Bombyx mori), ils ont obtenu $25 \mathrm{mg}$ d'hormone cristallisée. Par la suite, ils obtinrent $100 \mathrm{mg}$ d'ecdysone à partir de $3000 \mathrm{~kg}$ de chrysalides.

Si l'on injecte du cholestérol tritié à un asticot de Calliphora, on retrouve de l'ecdysone radioactive dans son sang ou son hémolymphe (les insectes étant incapables de synthétiser un stérol, l'ecdysone a son origine dans le cholestérol alimentaire).

Immédiatement après sa synthèse, l' $\alpha$-ecdysone est déversée dans l'hémolymphe. Elle est convertie dans le corps gras en $\beta$-ecdysone qui est beaucoup plus active et qui circule dans l'hémolymphe liée à une protéine, comme les hormones stéroïdes chez les Vertébrés.
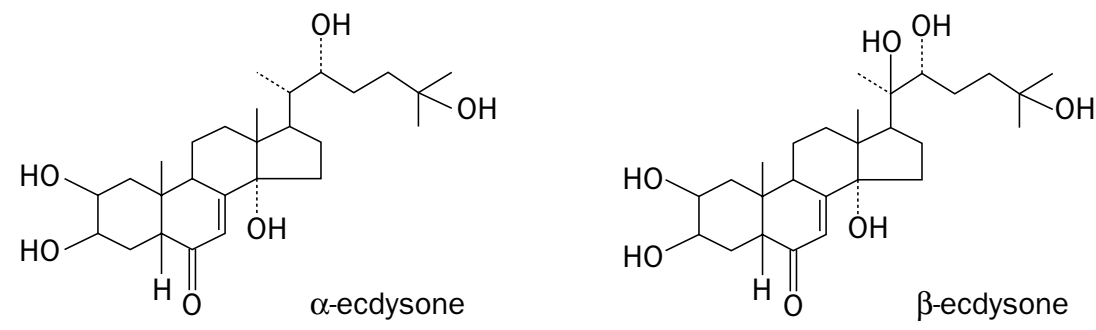

Figure 3.31 - Structure de l'ecdysone

\subsection{LE PUPARIUM DES DIPTÈRES}

La nymphe des Diptères est une pupe, entourée par un puparium constitué par la dernière cuticule larvaire brunie et durcie.

La formation de ce puparium est un phénomène de sclérotisation (brunissement et durcissement), il est sous la dépendance de l'ecdysone. Or, la cuticule des Insectes renferme essentiellement des protéines riches en tyrosine, et associées à de la chitine (qui est un polymère de $\mathrm{N}$-acétylglucosamine). 
Fraenkel ligature une larve de mouche Calliphora erythrocephala en arrière de l'anneau de Weissmann. La région antérieure seule forme un puparium, si on pose la ligature avant la "période critique" ( $16 \mathrm{~h}$ avant la formation du puparium). L'unité Calliphora a été définie comme la quantité d'ecdysone nécessaire pour déclencher la formation du puparium dans le tronçon postérieur d'une larve ainsi ligaturée. Elle correspond à $0,0075 \mu \mathrm{g}$ d'hormone cristallisée, soit 7,5 ng d'ecdysone.

\subsection{CHROMOSOMES GÉANTS ET PUFFS (fig. 3.32)}

Les Diptères possèdent quatre paires de chromosomes homologues $(2 \mathrm{n}=4)$ :

I : ce sont les chromosomes sexuels XY ou XX (si XY, Y est très court par rapport à $\mathrm{X}$ ),

II : $107 \mu \mathrm{m}$ de long,

III : $106 \mu \mathrm{m}$ de long,

IV : le plus petit a $0,1 \mu \mathrm{m}$ de long.

Ces chromosomes sont réunis par un chromocentre chez Drosophila (fig. 3.32.a) et seulement soudés deux à deux chez Chironomus.

Des dilatations riches en ARN, appelée puffs ou anneaux de Balbiani, apparaissent au niveau des bandes (correspondant à un ou plusieurs locus de gènes), à des moments et à des endroits variés. Quelques locus forment des puffs seulement à certains stades de la métamorphose; les gènes correspondants prennent part à des activités métaboliques en rapport avec ces stades (fig. 3.32.b).

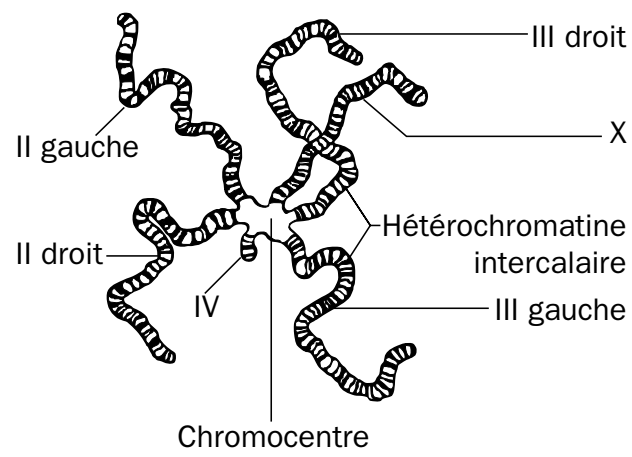

a - Chromosome de

Drosophila melanogaster

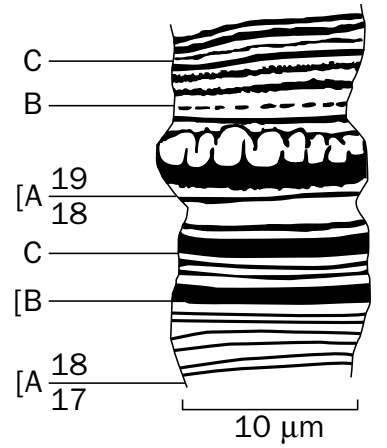

b - Loci 18 et 19 du chromosome I de Chironomus tentans

Figure 3.32 - Chromosomes géants de Diptères (d'après Beermann, 1952)

\subsection{MISE EN ÉVIDENCE DU RÔLE DE L'ECDYSONE}

- En 1960, Clever et Karlson injectent de l'ecdysone au dernier stade larvaire de Chironomus. Ceci déclenche la métamorphose. Or :

- 15 à 30 min après l'injection, apparaît un puff au niveau du chromosome I au locus $18 \mathrm{C}$; 
- 30 min à $1 \mathrm{~h}$ après, un autre puff au niveau du chromosome IV, au locus $2 \mathrm{~B}$. Par la suite apparaissent d'autres puffs, mais ils ne sont pas caractéristiques car ils s'observent aussi à l'intermue. Puis, plus tard, se forment des puffs caractéristiques de la période prénymphale qui prélude à la métamorphose, en même temps qu'augmente le métabolisme protidique.

Il existe au moins deux gènes dont la mise en activité est spécifique de la métamorphose, et qui ont été activés par l'hormone spécifique.

Le seuil de réaction de ces gènes a pu être établi à l'aide de quantités très faibles d'ecdysone :

- pour le locus $18 \mathrm{C}$ de I : avec $10^{-7} \mathrm{mg}$ d'extrait larvaire ;

- pour le locus $2 \mathrm{~B}$ de IV : avec $10^{-6} \mathrm{mg}$ d'extrait larvaire.

L'adjonction à l'eau de l'aquarium d'actinomycine D (qui bloque l'ARN polymérase et agit donc sur la transcription) fait disparaître ces puffs.

Chez des prénymphes qui entrent en diapause avant d'avoir accompli leur mue nymphale (sans doute par insuffisance d'ecdysone dans l'hémolymphe de 1'Insecte), ces puffs n'apparaissent pas.

- En 1952, Karlson et Sekeris prouvent, à l'aide de substances marquées, que l'ecdysone intervient en deux points de cette chaîne en provoquant la synthèse de deux enzymes : la DOPA-décarboxylase et une phénoloxydase.

On peut évidemment se demander si l'action de l'ecdysone sur les chromosomes est une action directe ou indirecte. Or :

- l'apparition des puffs est le premier des effets observables de l'ecdysone : les changements de téguments n'apparaissent que 20 à $30 \mathrm{~h}$ après l'injection ;

- des doses d'ecdysone infimes font apparaître les puffs mais ne déclenchent pas la nymphose.

Karlson est alors conduit à penser, tenant compte des données sur la structure de l'ADN et du schéma de Monod et Jacob, que l'ecdysone agit sur le chromosome en déspiralant l'hélice à un locus donné (dérépression du gène). Ceci se traduit par la synthèse de l'ARN messager qui se concrétise, sur ces chromosomes géants, par l'apparition d'un puff. Ce puff correspond à ce qu'on appelle maintenant un complexe de transcription (déroulement en boucles du nucléofilament d'ADN + histones, sites de synthèse des fibrilles d'ARN en cours d'élongation).

Depuis les travaux de Karlson, les mécanismes d'action des hormones stéroïdes sont mieux connus et rentrent dans le cadre des messagers à récepteurs nucléaires (voir chap. $2, \S 4)$.

Le gène du récepteur de l'ecdysone (R-Ec) a été cloné. Le complexe lié à l'ADN comporte deux protéines, l'une R-Ec est le produit du gène, l'autre est une protéine "ultraspiracle", USP (messager unique d'un gène usp), homologue des récepteurs R$\mathrm{XR}$, constituant un hétérodimère (voir chap. 2, § 4). Chacune des protéines de l'hétérodimère comporte un site de liaison avec l'ecdysone et un site de liaison avec l'ADN. Les ecdystéroïdes régulent ainsi, de façon séquentielle, plusieurs classes de 
gènes (fig. 3.33) (Leid et coll., 1992 ; Deutsch, 1993 ; Thomas et coll., 1993 ; Yao et coll., 1993). L'action des ecdystéroïdes sur différents ARNm a été étudiée par Hiruma et coll. (1997).

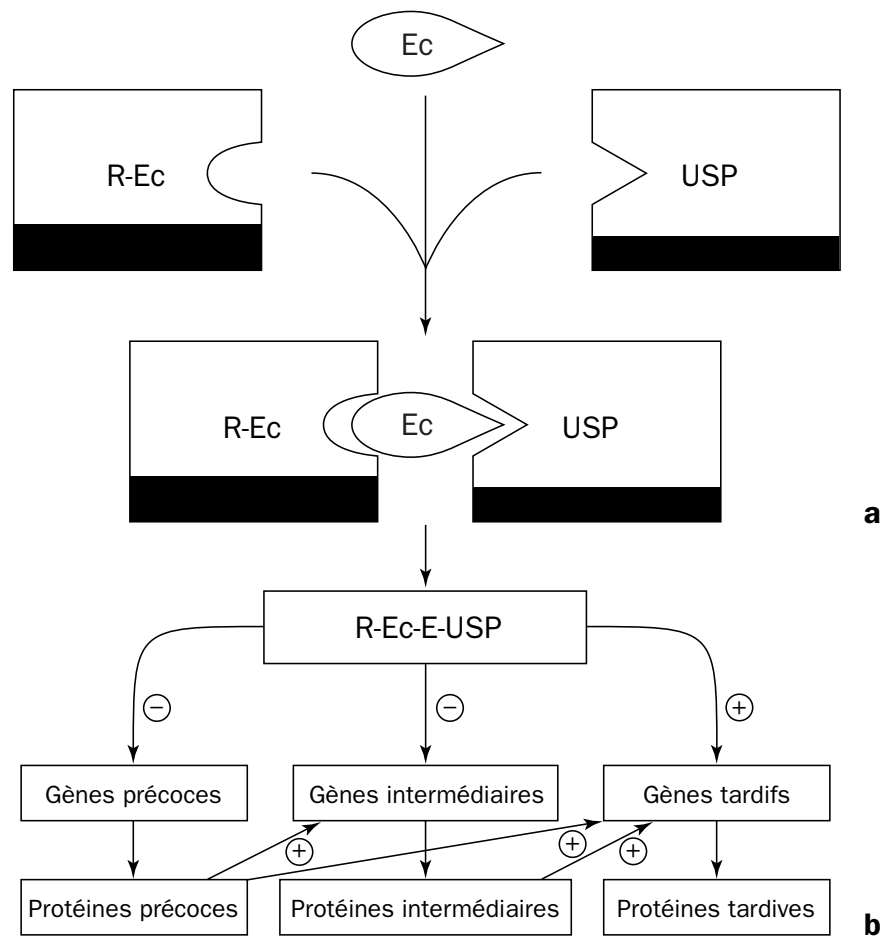

Figure 3.33 - Représentation schématique de l'action des ecdystéroïdes sur leurs cellules cibles

Ec : ecdysone ; R-Ec : récepteur de l'ecdysone ; R-Ec-E-USP : hétérodimère constitué par le récepteur de l'ecdysone et la protéine ultraspiracle, liés à l'ecdysone; USP: protéine ultraspiracle.

a - La formation d'un hétérodimère (R-Ec-E-USP) entre le récepteur à l'ecdysone (R-EC) et le produit du gène ultraspiracle (USP) conduit à un complexe actif dont une partie (noire) correspond au domaine de fixation à l'ADN.

$\boldsymbol{b}$ - La régulation de la transcription des gènes se déroule selon un modèle dérivé de celui proposé par Ashburner en 1974, certains gènes seraient activés et d'autres réprimés. Les produits de l'activation des gènes précoces déréprimeraient des gènes intermédiaires dont les produits agiraient pour déréprimer les gènes tardifs. 


\section{RÉFÉRENCES BIBLIOGRAPHIQUES DE LA PREMIÈRE PARTIE}

\section{MÉTHODES UTILISÉES EN ENDOCRINOLOGIE}

AHARONOWITZ Y. \& COHEN G., Les micro-organismes et l'industrie pharmaceutique, Pour la Science, $\mathrm{n}^{\circ}$ spécial novembre, 93-105, 1981a.

AHARONOWITZ Y. \& COHEN G., The microbiological production of pharmaceuticals, Sci. Am., 245, 140-152, 1981 b.

AVRAMEAS S., Immunoenzyme techniques: enzymes as markers for the localization of antigens and antibodies, Int. Rev. Cytol., Bourne \& Danielli eds, 27, 349-407, Academic Press, New York \& London, 1970.

ENGVALL E. \& PERLMANN P., Enzyme-linked immunosortent assay (ELISA), Quantitative assay of immunoglobulin G, Immunochemistry, 8, 871-874, 1971.

LEMARCHANDEL V. \& MONTAGUTELLI X., La recombinaison homologue, Médecine/Sciences, 6, 18-29, 1990.

RANE S.G., DUBUS P., METTUS R.V., GALBREATH E.J., BODEN G., REDDY E.P. \& BARBACID M., Loss of Cdk4 expression causes insulindeficient diabetes and Cdk4 activation results in $\beta$-islet cell hyperplasia, Nature genetics, 22, 44-52, 1999.

TOUITOU Y., FEVRE M., LAGOGUEY M., CARAYON A., BOGDAN A., REIBERG A., BECK H., CESSELIN F. \& TOUITOU C., Age and mental health-related circadian rhythm of plasma levels of melatonin, prolactin, luteinizing hormone and follicle-stimulating hormone in man, J. Endocrinol., 91, 467-475, 1981.

VIVILLE S., Recombinaison homologue : nouveaux vecteurs, nouvelles perspectives, Médecine/Sciences, 11, 735-746, 1995.

YALOW R.S. \& BERSON S.A., Immunoassay of endogenous plasma insulin in man, J. Clin. Invest., 39, 1157-1175, 1960. 


\section{LES MESSAGERS CHIMIQUES}

\section{MÉCANISMES DE TRADUCTION DE LEUR INFORMATION}

ASHBURNER M., CHIHARA C., MELTZER P. \& RICHARDS G., Temporal control of puffing activity in polytene chromosomes, Cold Spring Harb. Sym. Quant. Biol., 38, 655-662, 1974.

BAULIEU E.E. \& KELLY P.A., Hormones, Hermann, Paris, 1990.

BEATO M., Gene regulation by steroid hormones, Cell, 56, 335-344, 1989.

CHAN L. \& O’MALLEY B.W., Steroid hormone action : recent advances, Ann. Intern. Med., 89, 694-701, 1978.

CSABA G. (ed.), Development of hormone receptors, Birkhaüser Verlag, 1987.

EVANS R.M., The steroid and thyroid hormone receptor superfamily, Science, 240, 889-895, 1988.

FEUILLOLEY M. \& coll., Quels sont les rôles du cytosquelette dans les processus de sécrétion des hormones stéroïdes ?, Médecine/Sciences, 5, 674-677, 1989.

GORSKI J., The nature and development of steroid hormone receptors, in "Development of hormone receptors", Csaba G. ed., 67-77, 1987.

GROYER A. \& coll., Antiglucocorticosteroid effects suggest why steroid hormone is required for receptors to bind DNA in vivo but not in vitro, Nature, 328, 624626, 1987.

HANOUNE J. \& SALTIEL H., Mécanisme d'action des hormones, Enc. Méd. Chir., 1510-4.10.06, 1984.

HOULE B. \& BRADLEY W.E.C., Cancer du poumon, rétinoïdes et RAR $\beta$, Médecine/Sciences, 9, 528-533, 1993.

LAVAU C., JANSEN J., WEIS K., LAMOND A. \& DEJEAN A., Leucémie aiguë promyélocytaire et acide rétinoïde : le paradoxe, Médecine/Sciences, 10, 817-824, 1994.

LEID M., KASTNER P. \& CHAMBON P., Multiplicity generated diversity in the retinoic acid signalling pathways, Trends Biochem. Sci., 17, 427-433, 1992.

O'MALLEY A., Steroid hormone action in eucaryotic cells, J. Clin. Invest., 74, 307312, 1984.

VAISSE C., Leptine : après le récepteur, la voie de transduction, Médecine/Sciences, 13, 99-101, 1997. 


\section{DES MESSAGERS CHIMIQUES PARTICULIERS}

\section{Facteurs de croissance}

COHEN S., Isolation of a mouse submaxillary gland protein accelerating incisor eruption and eyelid opening in the new-born animal, J. Biol. Chem., 237, 15551559, 1962.

DER GEER P. (Van) \& HUNTER T., Receptor protein-tyrosine kinases and their signal transduction pathways, Ann. Rev. Cell. Biol., 10, 251-337, 1994.

PAWSON T., Protein modules and signaling network, Nature, 373, 573-580, 1995.

SEGER R. \& KREBS G. (de), The MAPK signaling cascade, Faseb J., 728, 726-735, 1995.

WOLOWIEC D. \& FRENCH M., Kinases dépendantes des cyclines : rôles biologiques et implications dans la pathologie humaine, Médecine/Sciences, 12, 165-173, 1996.

\section{Kinines}

BASCONDS J.L. \& GIROLAMI J.P., La bradykinine. Médecine/Sciences, 5, 582-592, 1996.

BHOOLA K.D., FIGUEROO C.D. \& WORTHY K., Bioregulations of kinins : kallikreins, kininogens, and kinases, Pharmacol. Rev., 44, 1-80, 1992.

CARBINI L., GUILLERMO SICLI A. \& CARRETERO O.A., The molecular biology of the kallikrein-kinin system : III. The human kallikrein gene family and kallikrein substrate, J. Hypertension, 11, 893-898, 1993.

LINZ W., WIEMER G. \& SCHÖLKENS B.A., Role of kinins in the pathophysiology of myocardial ischemia. In vitro and in vivo studies, Diabetes, 45, 551-558, 1996.

\section{NO}

ÄNGGOR E., Nitric oxide : mediator, murderer, and medicine, Lancet, 343 : 8907, 1199-1206, 1994.

BREDT D.S. \& SNYDER S.H., Nitric oxide : a physiological messenger molecule, Annu. Rev. Biochem., 63, 175-195, 1994.

FURCHGOTT R.F. \& ZAWADZKI J.V., The obligatory role of endothelial cells in the relaxation of arterial smooth muscle by acetylcholine, Nature, 288, 373-376, 1980.

GARTHWAITE J. \& coll., Nitric oxide signaling in the control nervous system, Annu. Rev. Physiol., 57, 683-736, 1988. 
GRIFFITH O.W. \& STUEHR D.J., Nitric oxide synthases : properties and catabolytic mechanism, Annu. Rev. Physiol., 57, 707-736, 1995.

GROSS S.S. \& WOLIN M.S., Nitric oxide : pathophysiological mechanisms, Annu. Rev. Physiol., 57, 737-769, 1995.

KERWIN J.F., HELLER J.R. \& M., The arginine-nitric oxide pathway : a target for new drugs, Med. Res. Rev., 14, 23-74, 1994.

KOSTKA P., Free radicals (Nitric oxide), Anal. Chem., 57, 411R-416R, 1995.

LINCOLN T.M. \& CORNWELL T.L., Intracellular cyclic GMP receptor proteins, 7, 328-338, Faseb J., 1993.

MEHTA J.L., Endothelium, coronary vasodilatation and organic nitrates, Am. Heart J., 129, 382-391, 1995.

MONCADA S., HIGGS E.A. \& PALMER R.M., Characterization and biological significance of endothelium-derived relaxing factor, Biochem. Soc. Trans., 16, 484-486, 1988.

RAND M.J. \& LI C.G., Nitric oxyde as a transmitter in peripheral nerves : nature of transmitter and mechanism of transmission, Annu. Rev. Physiol., 57, 659-682, 1995.

UMANS J.G. \& LEVI R., Nitric oxide in the regulation of blood flow and arterial pressure, Annu. Rev. Physiol., 57, 771-790, 1995.

ZHANG J. \& SNYDER S.H., Nitric oxide in the nervous system, Annu. Rev. Pharmacol. Toxicol., 35, 213-233, 1995.

\section{PAF}

BRAQUET P., Ginkgolides chemistry, biology, pharmacology and clinical perspectives, J.R. Prous Science ed., 1988.

CHAO W. \& OLSON M.S., Platelet-activating factor : receptors and signal transduction, Biochem. J., 292, 617-629, 1993.

DISERBO M., Action du Platelet-Activating Factor (PAF) sur les cellules de la lignée N1E-115 : effets sur la concentration du calcium libre cytosolique et sur les flux ioniques transmembranaires, Thèse de l'Université de Grenoble I, 1995.

VENABLE M.E., ZIMMERMAN G.A., Mc INTYRE T.M. \& PRESCOTT S.M., Platelet-activating factor : a phospholipid autocoid with diverse actions, J. Lipid Res., 34, 691-702, 1993.

\section{Endothélines}

DOUGLAS S.A. \& OHLSTEIN E.H., Signal transduction mechanisms mediating the vascular actions of endothelin, J. Vasc. Res., 34, 152-164, 1997. 
KRÄMER B.K., ITTNER K.P., BEYER M.E., HOFFMEISTER H.M. \& RIEGGER G.A., Circulatory and myocardial effects of endothelin, J. Mol. Med., 75, 886-980, 1997.

NEWBY D.E. \& WEBB D.J., Advances in clinical pharmacology and therapeutics : endothelin, Brit. J. Hosp. Med., 56, 360-364, 1996.

ORLÉANS-JUSTE P. (d'), GRATTON J.P., LEDUC R., BKAILY G. \& CLAING A., L'endothéline : pharmacologie cardiovasculaire et considérations physiopathologiques, Médecine/Sciences, 12, 563-564, 1996.

ORTEGA MATEO A. \& ARTIÑANO A.A., Highlights on endothelins : a review, Pharmacol. Res., 36, 339-351, 1997.

ROSENDORFF C., Endothelin, vascular hypertrophy, and hypertension, Cardiovasc. Drug Ther., 10, 795-802, 1997.

SCHIFFRIN E., L'endothéline est-elle impliquée dans l'hypertension?, Médecine/Sciences, 12, 599-608, 1996.

TURNER A.J. \& MURPHY L.J., Molecular pharmacology of endothelin converting enzymes, Biochem. Pharmacol., 51, 91-102, 1996.

WARREN J.B. (ed.), The endothelium, J. Wiley \& Sons, 1990.

WEBB D.J., Endothelin : from molecule to man, Brit. J. Clin. Pharmaco., 44, 9-20, 1997.

\section{Ecdysone}

DEUTSCH J., Ultraspiracle et récepteur de l'ecdysone ou les relations dans la famille des récepteurs hormonaux nucléaires de la drosophile au mammifères, Médecine/Sciences, 9, 701-705, 1993.

HIRUMA K., BÔCKING D., LAFONT R. \& RIDDIFORD L.M., Action of different ecdysteroids on the regulation of mRNAs for the ecdysone receptor, MHR3, dopa decarboxylase, and a larval cuticle protein in the larval epidermis of the tobacco hornworm, Manduca sexta, Gen. Comp. Endocr., 107, 84-97, 1997.

LEID M., KASTNER P. \& CHAMBON P., Multiplicity generated diversity in the retinoic acid signalling pathways, Trends Biochem. Sci., 17, 427-433, 1992.

THOMAS H.E., STUNNENBERG H.G. \& STEWART A.F., Heterodimerization of the Drosophila ecdysone receptor with retinid $\mathrm{X}$ receptor and ultraspiracle, Nature, 362, 471-475, 1993.

YAO T.P., FORMAN B.M., JIANG Z., CHERBAS L., CHEN J.D., Mc KNEOWN M., CHERBAS E. \& EVANS R.M., Functional ecdysone receptor is the product of EcR and ultraspiracle genes, Nature, 366, 476-479, 1993. 



\section{DEUXIÈME PARTIE}

\section{ENDOCRINOLOGIE GÉNÉRALE}

Chapitre 4 Le complexe hypothalamo-hypophysaire

Chapitre 5 La glande thyroüde

Chapitre 6 Les glandes surrénales

Chapitre 7 Le pancréas endocrine

Chapitre 8 Les parathyroüdes et l'équilibre phosphocalcique

Chapitre 9 Les structures endocrines diffuses

Chapitre 10 L'épiphyse 
